\title{
Influence of Alumina Addition to Aluminum Fins for Compact Heat Exchangers Produced by Cold Spray Additive Manufacturing
}

\author{
By \\ Aslan Farjam
}

A thesis submitted to the Faculty of Graduate and Postdoctoral Studies

in partial fulfillment of the requirements for the degree of

MASTER OF APPLIED SCIENCE

in Mechanical Engineering

\author{
University of Ottawa \\ Ottawa, Ontario, Canada
}

November-15

CAslan Farjam, Ottawa, Canada, 2015 


\section{Abstract}

Aluminum and aluminum-alumina powder mixtures were used to produce pyramidal fin arrays on aluminum substrates using cold spray as an additive manufacturing process. Using aluminum-alumina mixtures instead of pure aluminum powder could be seen as a costeffective measure, preventing nozzle clogging. The fin geometries that were produced were observed using a 3D digital microscope to determine the flow passages width and fins geometric details. Heat transfer and pressure tests were carried out using different ranges of appropriate Reynolds numbers for the sought commercial application to compare each fin array and determine the effect of alumina content. It was found that the presence of alumina reduces the fins' performance when compared to pure aluminum but that they still outperform traditional fins. Numerical simulations were performed and were used to explain the obtained experimental results. The numerical model opens up new avenues in predicting different parameters such as pressure and substrate temperature. 


\section{Acknowledgments}

Primarily, I would like to take this opportunity to thank my supervisor, Professor Bertrand Jodoin for his supervision and guidance through all levels of this program. His encouragement and enthusiasm always helped me to reach new levels of knowledge and academic success and to overcome difficulties in research work. Furthermore, his structured and organized method of tracking the progress of my research and diverse weekly tasks taught me how to make the most of my time. Undoubtedly, my work would have not been completed without his valuable support and knowledge. Thank you for making this great experience possible for me.

I would like to thank Dr. Mohammed Yandouzi for his assistance. His training and his expertise in the laboratory setting and in the other available facilities not only increased my knowledge of procedures and equipment but also allowed me to obtain my results in a proper and standard way.

A special thanks to Yannick Cormier and Philippe Dupuis for all of their support. They always shared their experiences when needed and offered their knowledge to both facilitate the progress and enhance the quality of this study. Another huge thanks must be made out to Lucas West for being not only one of my best colleagues but also one of my best friends. I will never forget your unique and motivating personality and its tremendous impact on my academic achievements. Moreover, I would also like to thank all of my laboratory colleagues for helping and supporting me. Tyler Samson, Patrick Trahan, Antoine Bacciochini, Deliang Guo, Daniel MacDonald, Daniel Cormier, Samuel Leblanc-Robert and Aleksandra Nastic, thank you so much for your help and for making this such an enjoyable experience. 
I am very grateful for my parents and dear brother who have encouraged me at every stage of this experience. To my beloved family, thank you all.

I would also like to thank the MITACS acceleration program for financially supporting this study.

Last but not least, I would like to express my deepest gratitude to all of the personnel and friends who helped me over the course of my studies here at the University of Ottawa. Specifically, I would like to thank the machine shop personnel at the University of Ottawa, especially John. Thank you John for showing me how to make use of the machines required to make my samples and complete my projects. 


\section{Contents}

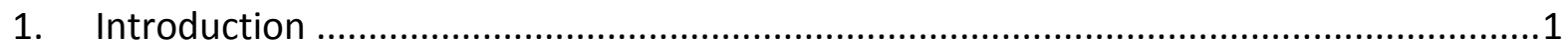

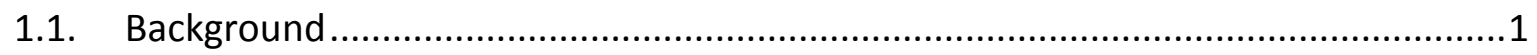

1.2. Motivation of Research and General Objectives..............................................4

1.3. Outline of the Thesis.................................................................................. 4

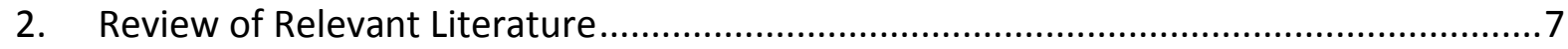

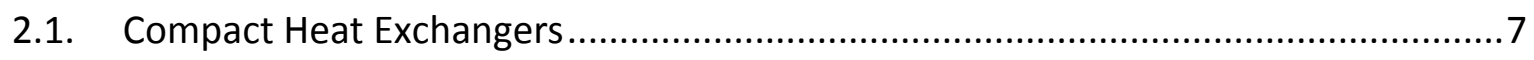

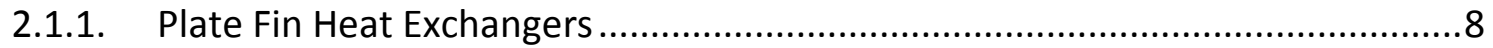

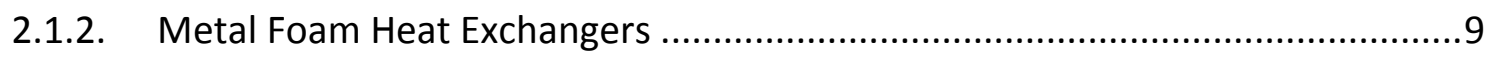

2.1.3. Wire Mesh Heat Exchangers ….................................................................11

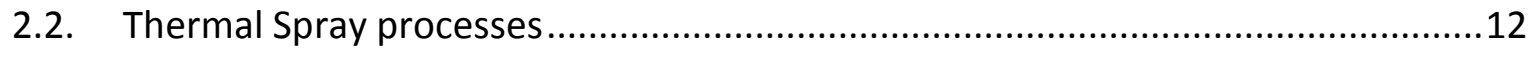

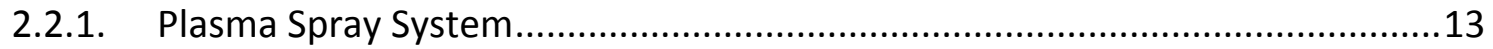

2.2.2. High Velocity Oxygen-Fuel Spray ...........................................................14

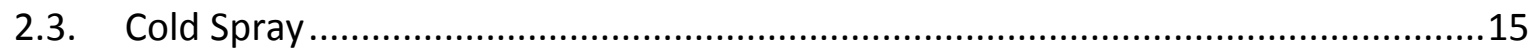

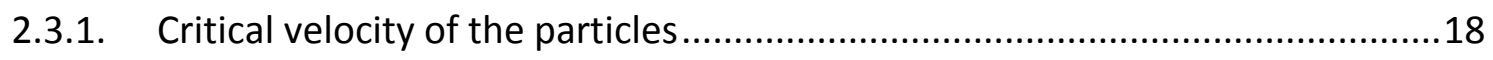

2.3.2. Particle deformation and bonding mechanism .......................................21

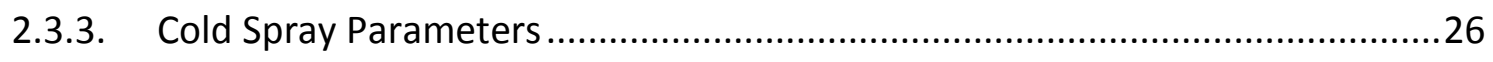

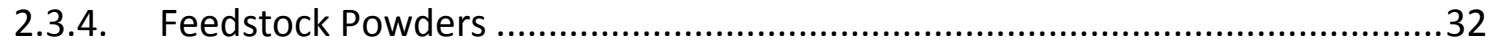

2.3.5. Cold spray and other thermal spray processes: Comparison .........................33

2.3.6. Advantages and Disadvantages of Cold Spray ..........................................34

2.3.7. Compact Heat Exchanger \& Cold Spray ..................................................... 36

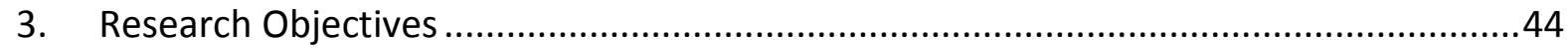

3.1. Experimental work Objectives.....................................................................44

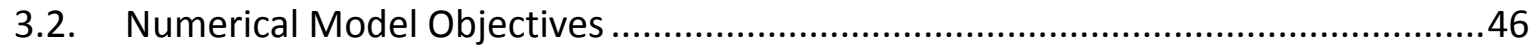

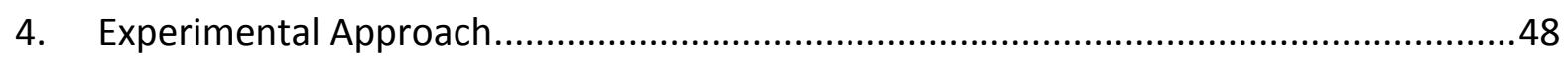

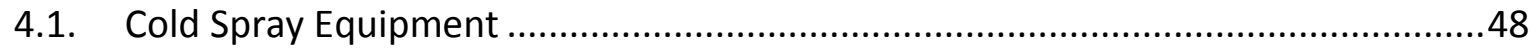

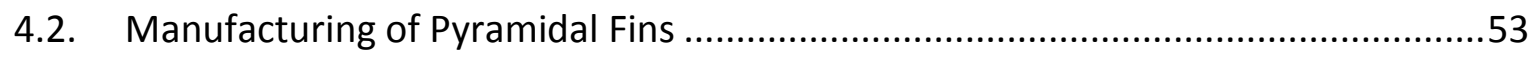

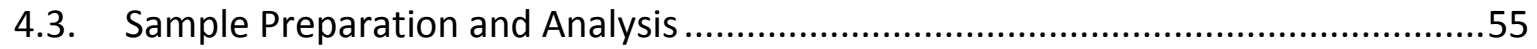




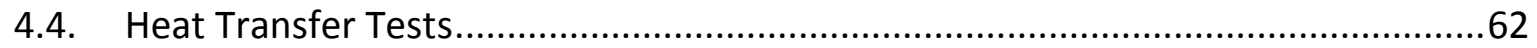

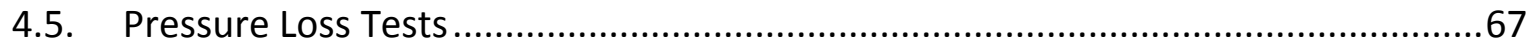

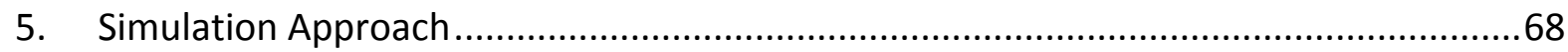

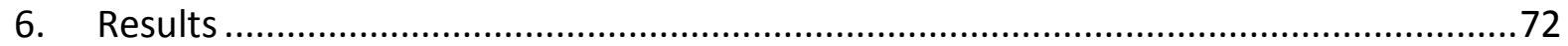

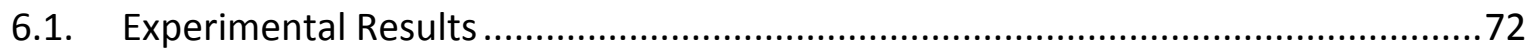

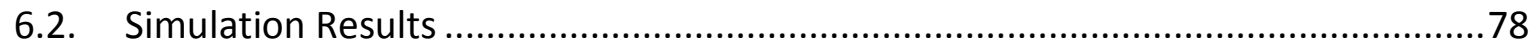

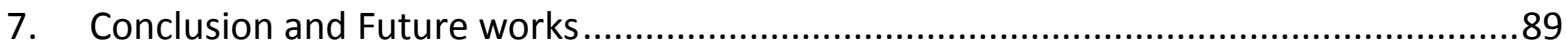

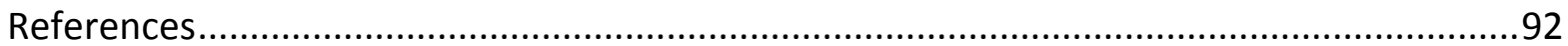

Appendix I: Grid Independency of the Solution.........................................................97

Appendix II: Convergence History .............................................................................. 98

Appendix III: Boundary Condition Used for Different Modelling Cases .............................101 


\section{List of Tables}

Table 5.1 Simulation boundary conditions .................................................................69

Table 6.1 Geometrical values of pyramidal fins measured with 3D microscope ...................72

Table 6.2 Experiment (Exp.) and model (Mod.) results comparison for $29 \%$ alumina sample at different Reynolds numbers (model validation) ..............................................................81 


\section{List of Figures}

Figure 1.1 (a) High pressure cold spray system (b) Low pressure cold spray system [4] .........3

Figure 2.1 Different designs of aluminum brazed PFHE: (a) Plain (b) herringbone.................9

Figure 2.2 Picture of metallic foam used in MFHE [16] .................................................10

Figure 2.3 Traditional configuration of WMHE ...........................................................

Figure 2.4 Schematic Figure of Thermal Plasma Spray System [26] ..................................13

Figure 2.5 Schematic Figure of High Velocity Oxygen-Fuel Spraying System [34] ...............15

Figure 2.6 Schematic configuration of cold spray system ...............................................17

Figure 2.7 Theoretical critical velocities of a $25 \mu \mathrm{m}$ particle for different materials [5]........19

Figure 2.8 Schematic trend of critical and impact velocities as a function of particle size [41]

Figure 2.9 Impact sequences of a $25 \mu \mathrm{m}$ Cu particle on a Cu substrate with initial temperature of $20^{\circ} \mathrm{C}$ and velocity of $500 \mathrm{~m} / \mathrm{s}$. (a) and (b) strain field (c) and (d) temperature field [42]

Figure 2.10 Average temperature changes as a function of time for $25 \mu \mathrm{m}$ Cu particle at different impact veocities [42].

Figure 2.11 Simulation of the formation of a jet at different time periods for a collision of a substrate material at (a) 4.4 ns (b) 13.2 ns (c) 22 ns (d) 30.8 ns [43] .................................24

Figure 2.12 Mechanical bonding of Cu particle on the Cu substrate [40] ............................25

Figure 2.13 Changes of deposition efficiency as a function of stand-off distance for aluminum, titanium and copper particles [49].

Figure 2.14 Schematic behaviour deposition efficiency as a function of stand-off distance

Figure 2.15 Comparison of different thermal spray methods [29]

Figure 2.16 (a) Folded mesh heat exchanger with the zoom brazed area (b) Schematic of WMHE produced with additive manufacturing .37

Figure 2.17 Wire mesh heat exchanger with fins produced by cold spray. .39

Figure 2.18 Cold spray apparatus set-up using wire mesh masks .40

Figure 2.19 Thermal conductance as a function of Re number [9] . .42

Figure 4.1 Low pressure cold spray system at the university of Ottawa laboratory .49

Figure 4.2 Nitrogen gas bottle packs. .51

Figure 4.3 Powder feeder (Model 1264 from Praxair Surface Technologies) .52

Figure 4.4 Steel nozzle assembly. .53 
Figure 4.5 Pyramidal fin arrays produced with cold spray .............................................55

Figure 4.6 Keyence VHX three dimension microscope .................................................56

Figure 4.7 (a) Schematic view of one pyramid fin (b) Actual 3D shape of pyramid fin taken by

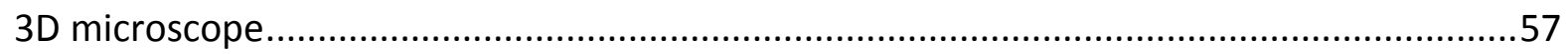

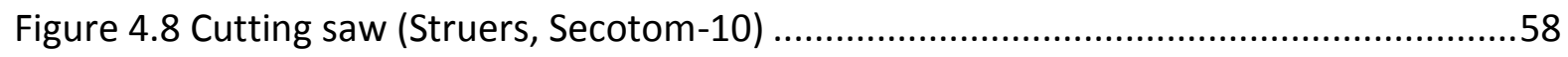

Figure 4.9 Thermosetting resin mounting machine (Struers LaboPress-3) .........................59

Figure 4.10 Polishing machine (Struers Tegrapol, TegraForce-5 and TegraDoser-5) ............60

Figure 4.11 Example of polished sample embedded in polymeric resin .............................61

Figure 4.12 Kingdak NMM-800TRF Optical Microscope ...................................................62

Figure 4.13 Schematic of the heat transfer fixture ..........................................................63

Figure 5.1 Arrangement of the model ...................................................................... 71

Figure 6.1Cross-sectional view of sprayed fin using optical microscope (a) Pure aluminum (b) $19 \%$ volume fraction of alumina particles (c) $29 \%$ volume fraction of alumina particles 73 Figure 6.2 Comparison of overall heat transfer coefficient associated with different alumina volume fractions. .75

Figure 6.3 Comparison of different sample's volume based heat transfer surface efficiency for different alumina volume fractions............................................................................... 77 Figure 6.4 Fin pressure loss as a function of Reynolds number .......................................78 Figure 6.5 Temperature $\left({ }^{\circ} \mathrm{C}\right)$ contours with mass flow rate of $8.0 \times 10-4 \mathrm{~kg} / \mathrm{s}$ for the pure aluminum, $19 \%$ volume fraction alumina and $29 \%$ volume fraction alumina pin fins. The fin temperature scale is on the left

Figure 6.6 Cross-section view of the flow channel for pin fin pyramids with mass flow rate of $8.0 \times 10-4 \mathrm{~kg} / \mathrm{s}$ for pure aluminum, $19 \%$ and $29 \%$ volume fraction alumina containing samples. The flow temperature $\left({ }^{\circ} \mathrm{C}\right)$ scale is on the left .................................................80

Figure 6.7 Schematic of pin fin array (a) Isometric view (b) Top view. .83 Figure 6.8 Outflow temperature $\left({ }^{\circ} \mathrm{C}\right)$ contours for $29 \%$ alumina sample at mass flow rate $(\mathrm{kg} / \mathrm{s})$ of (a) $4.0 \times 10-4$ (b) $8.0 \times 10-4$ (c) $1.4 \times 10-3$. The flow temperature variation is illustrated by the scale on left .84

Figure 6.9 (a) Configuration of pyramids sides and numbering of the sides for heat flux $(\mathrm{W} / \mathrm{m} 2$ ) percentage of (b) Fifth pyramid surfaces (c) Tenth pyramid surfaces.... .86 Figure 6.10 Comparison between the stream lines of (a) rectangular fins and (b) pyramidal pin fins. 


\section{Nomenclature}

$\Delta P_{\text {fin }} \quad$ Fin differential pressure $[\mathrm{Pa}]$

$\Delta T_{1} \quad$ Inlet temperature difference [K]

$\Delta T_{2} \quad$ Outlet temperature difference [K]

$\Delta T_{l m} \quad$ Log mean temperature difference [K]

$\eta \quad$ Fan efficiency

$\eta_{f} \quad$ Individual fin efficiency

$\eta_{o} \quad$ Overall fin efficiency

$\theta \quad$ Pyramid angle $\left[{ }^{\circ}\right]$

$\mu \quad$ Dynamic viscosity [Pa·s]

$\rho \quad$ Fluid density $\left[\mathrm{kg} / \mathrm{m}^{3}\right]$

$A_{f} \quad$ Fin heat transfer area $\left[\mathrm{m}^{2}\right]$

$A_{\text {flow }}$ Net flow area $\left[\mathrm{m}^{2}\right]$

$A_{P} \quad$ cross-sectional area of the particle $\left[\mathrm{m}^{2}\right]$

$A_{\text {tot }} \quad$ Total heat transfer area $\left[\mathrm{m}^{2}\right]$

$B \quad$ Base fin length [m]

Cp Fluid specific heat capacity $[\mathrm{kJ} /(\mathrm{kg} \cdot \mathrm{K})]$

$C_{D} \quad$ Drag coefficient $[\mathrm{N}]$

$d_{h} \quad$ Hydraulic diameter [m]

$e_{v} \quad$ Pumping power per unit volume $\left[\mathrm{kW} / \mathrm{m}^{3}\right]$

$F_{D} \quad$ Drag force $[\mathrm{N}]$

FD Fin density [fin $/ \mathrm{m}]$

$H \quad$ Fin height [m] 
$h \quad$ Convection heat transfer coefficient $\left[\mathrm{W} /\left(\mathrm{m}^{2} \cdot \mathrm{K}\right)\right]$

$h_{f} \quad$ Fluid-side local heat transfer coefficient $[\mathrm{W} /(\mathrm{m} 2 \cdot \mathrm{K})]$

$I_{1} \quad$ Bessel function of order one

$I_{2} \quad$ Bessel function of order two

$k_{m} \quad$ Fin material thermal conductivity $[\mathrm{W} /(\mathrm{m} \cdot \mathrm{K})]$

$\dot{m} \quad$ Mass flow rate $[\mathrm{kg} / \mathrm{s}]$

$m \quad$ Fin heat transfer parameter $\left[\mathrm{m}^{-1}\right]$

$M \quad$ Mass of the particle $[\mathrm{Kg}]$

$P_{\text {flow }} \quad$ Flow perimeter $[\mathrm{m}]$

$q \quad$ Heat flux $\left[\mathrm{W} / \mathrm{m}^{2}\right]$

$q_{\text {rad }} \quad$ Radiative heat flux $\left[\mathrm{W} / \mathrm{m}^{2}\right]$

$R e_{D h} \quad$ Reynolds number based on hydraulic diameter

$R_{e q} \quad$ Equivalent thermal resistance $[\mathrm{K} / \mathrm{W}]$

$S \quad$ Space between fin edges [m]

$T_{\text {in }} \quad$ Inlet fluid temperature $[\mathrm{K}]$

$T_{f} \quad$ Local fluid temperature [K]

$T_{\text {out }} \quad$ Outlet fluid temperature $[\mathrm{K}]$

$T_{w} \quad$ Wall surface temperature $[\mathrm{K}]$

UA Thermal conductance $[\mathrm{W} / \mathrm{K}]$

$U A_{V} \quad$ Thermal conductance per unit volume $\left[\mathrm{kW} /\left(\mathrm{m}^{3} \cdot \mathrm{K}\right)\right]$

$v \quad$ Gas velocity $[\mathrm{m} / \mathrm{s}]$

$V \quad$ Volume $\left[\mathrm{m}^{3}\right]$

$V_{P V} \quad$ Particle velocity $[\mathrm{m} / \mathrm{s}]$

$\dot{V}_{f} \quad$ Volumetric flow rate $\left[\mathrm{m}^{3} / \mathrm{s}\right]$ 
$x \quad$ axial position of the particle [m]

W Channel width $[\mathrm{m}]$ 


\section{Introduction}

\subsection{Background}

Compact Heat Exchangers (CHE) make up approximately 10\% of the total heat exchanger market, and have experienced a yearly growth in sales of $10 \%$ compared to $1 \%$ for other types as a result of the high industrial demand for this category of heat exchangers [1]. CHE have increased heat transfer surface area to volume ratios when compared to more traditional heat exchangers. This is achieved using fins on the mediator wall (or walls) that separates the two flow streams exchanging heat [2]. CHE are ubiquitous in electronics and aerospace applications, where size and weight are important factors. Enormous effort has gone into enhancing the performance of heat exchangers to increase their efficiency. Many factors must be taken into account when trying to optimize a heat exchanger for a specific application including: component geometries, heat transfer mechanisms and flow arrangements. [3]

Cold spray is a method of coating deposition using ballistic impingement of feedstock particles on the substrate to be coated [4]. It was discovered in the mid-1980s, at the Institute of Theoretical and Applied Mechanics of the Siberian Division of the Russian Academy of Science in Novosibirsk [5]. For the first time they deposited a broad range of metals, composites and alloys on different substrates into dense coating layers formed on the substrates surface [5]. This has led to the creation of the first research team whose purpose was to characterize the cold spray process. This consortium was composed of several large 
corporations such as Ford Motor Company, General Motors, General Electric and the Pratt \& Whitney Division of United Technologies [5]. Currently, many research projects on cold spray are underway and the method is being used in many applications such as automotive industry, turbine blades pump shafts and the aerospace industry [6]. Cold spray is typically divided into two categories: High Pressure Cold Spray (HPCS) and Low Pressure Cold Spray (LPCS). These systems are differentiated from each other by the feedstock powder injection location and the operating pressure of the powder feeder. Figure 1.1 (a) and (b) show schematics of high pressure and low pressure cold spray systems. In LPCS, the feedstock powder is injected in the divergent part of the nozzle where the gas has already started to expand. Since the low pressure system does not need a high-pressurized powder feeder it is more convenient to be used as a portable system [4].

Taking advantage of cold spray, it can be used as an additive manufacturing process to improve the performance of CHE. This can be achieved by the addition of fins to the outer walls where the heat of the CHE's core will be conducted to the outer layers. These fins can be manufactured with the aid of cold spray [7-9]. For the various applications of CHEs, different types of feedstock powder materials can be deposited. Pure aluminum, due to its relatively low density and high thermal conductivity, is commonly used in industrial CHE applications. However, the combination of pure aluminum and alumina particles can result in a denser coating compared to the pure aluminum coating [10]. Another complementary benefit of adding alumina particles to the pure aluminum feedstock is the prevention of nozzle clogging when compared to pure aluminum spraying. In the current research, alumina contents have been chosen as a mixing component with pure aluminum powder due to an 
improvement in the properties of the coating, as well as its contribution in facilitating the spraying process (nozzle clogging prevention).

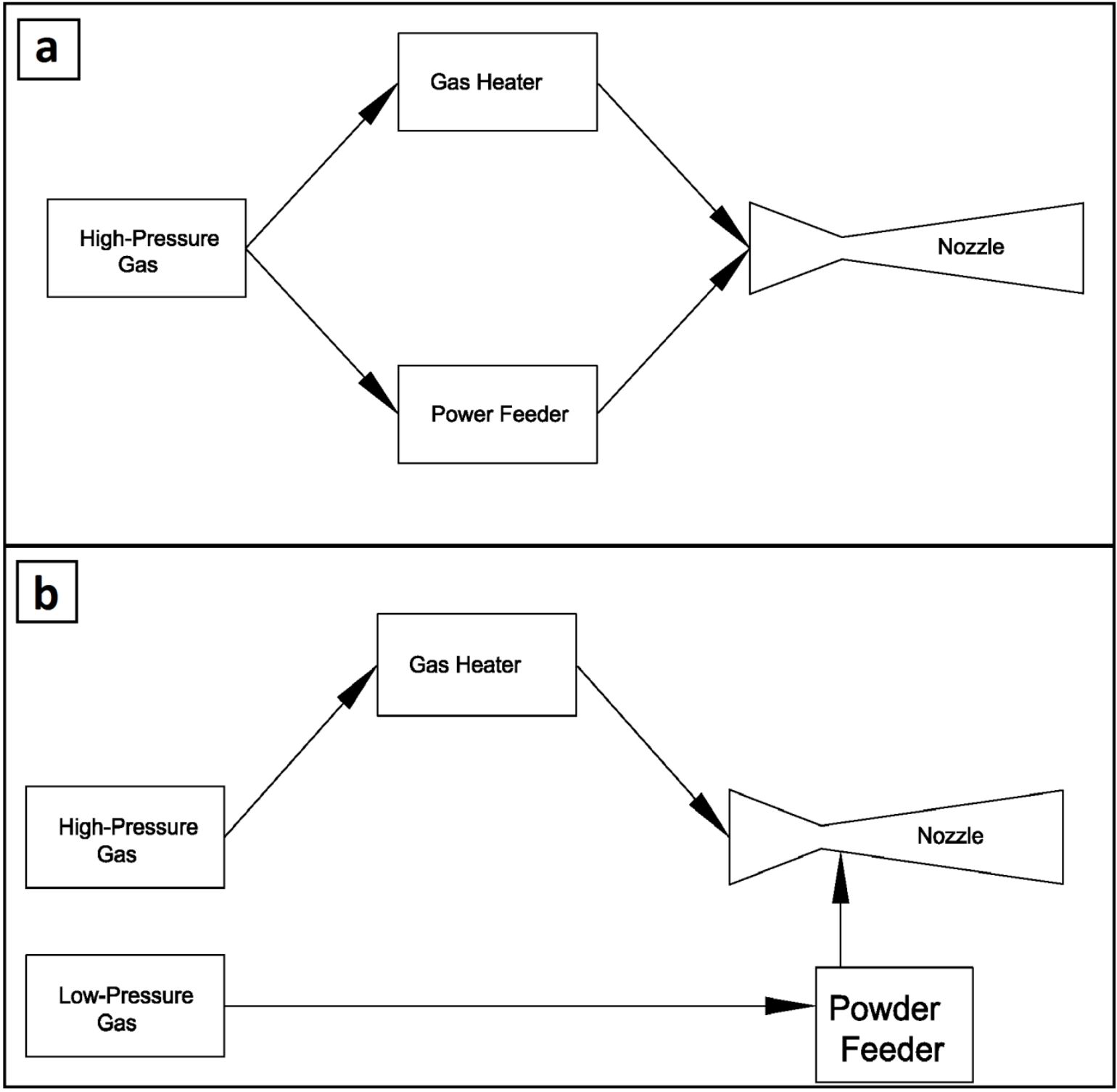

Figure 1.1 (a) High pressure cold spray system (b) Low pressure cold spray system [4] 


\subsection{Motivation of Research and General Objectives}

The current research was motivated by the need to evaluate the overall thermal performance of pin fin arrays produced by cold spray additive manufacturing when using aluminaaluminum as the feedstock powder vs. when using only pure aluminum. To this end, the following steps were undertaken:

- Creation of pin fin arrays with different percentages of alumina and pure aluminum powder mixtures by cold spray additive manufacturing.

- Geometric measurements of the created pin fins.

- Observation of the cross-section of the pin fins to determine the actual volume percentage of the alumina contents in the pin fins.

- Performing heat transfer and pressure loss tests on the samples to evaluate the performance characteristics of each produced sample.

- Validating a numerical model based on the performed experiments.

- Using the numerical model to better investigate the behaviour of both flow and the fins in more detail.

\subsection{Outline of the Thesis}

The content of this thesis is divided into six chapters. In chapter 1, an introduction of CHE and the cold spray process has been described. Brief explanation for some of the applications and the importance of using CHE as a useful industrial component are also 
brought to attention. Also a short history of early stages of Cold Gas Dynamic Spray (CGDS or simply cold spray) is given in this chapter.

Chapter 2 is a review of the relevant works and research that has been carried out in the areas of CHEs and cold spray. Studies have been performed on various types of CHEs common to the industry, all of which provide detailed reviews on their configurations, characterisation and fabrication methods. This is followed by an introduction and discussion of the mechanisms pertaining to thermal spray systems. Later in chapter 2 is a review of the different cold spray systems, including the apparatus, the operation process and spray parameters. Furthermore, the characterisation of the various feedstock powders used in this research is performed. A comparison is also performed between the different methods of the thermal spray system and the cold spray system. Lastly, a brief summary on the application of cold spray in manufacturing for the purpose of improving efficiency of CHEs is provided.

Chapter 3 explores the objectives of the research work in terms of the experiment and numerical model parts. Specifically, the outcome of producing CHEs using selected materials as well as the verification of a numerical model in order to better interpret the experimental results are discussed in this chapter.

Chapter 4 describes all of the preparation procedures and methods, such as sample preparation that were performed. Furthermore, different types of experiments that were done on the sample in order to obtain the results are provided. These experiments mainly include heat transfer and pressure loss tests. Also, the calculation process and governing equations for determination of desired parameters is discussed. Finally, the numerical model used to 
simulate the experiments with detailed applied boundary conditions and selected calculation method is reviewed.

Chapter 5 explains the numerical model used to simulate the experiments and selected calculation method. The applied grid for the numerical solution as well as grid independency verification is explained in this chapter. The type and location of the applied boundary conditions are reviewed in detail. The focus of this chapter is to discuss and define the structure of the modeled domain and computational method.

Chapter 6 reports all of the results from both the simulations and the experiments. A comparison between the performance of different samples, and between the numerical model and the experimental results is performed in this chapter. The validation of the simulation model and the liability of the results from the numerical model are also discussed in this section.

Chapter 7 presents the summarize of the performed works for this thesis. This is followed by the conclusions and findings from the research works. Finally the potential for future works and research opportunities are discussed. 


\section{Review of Relevant Literature}

The following chapter reviews the relevant works and studies associated to the current research. These works review the various types of heat exchangers, their structure and their mechanisms (reviews on their configurations, characterisation and fabrication methods). Following this is an overview of cold spray, including its characterization and specification. Lastly, a description is provided on the application of the process in manufacturing and its incorporation into the development of CHEs, supported by previous research relevant to the subject.

\subsection{Compact Heat Exchangers}

The thermal performance of heat exchangers depends on the capability of the designated surface or surfaces in the exchanger to carry on the thermal duty of the required specification [11]. However, increasing the effective surface area of the heat exchanger will cause an increase of the heat transfer efficiency. Some of the main reasons for using CHE are : smaller size, lower cost and lighter weight [12]. CHEs are mainly categorized based on the geometry and the mechanism of their associated mediums. Currently, CHEs are widely used in different industrial applications such as heating, ventilation and air-conditioning (HVAC), aeronautics and astronautics, automotive, electric and electronics. Various models of CHEs have been developed based on the requirements of each application. Plate Fin Heat Exchangers (PFHE), Metal Foam Heat Exchangers (MFHE) and Wire Mesh Heat 
Exchangers (WMHE) are some of the most common types of CHEs in the industry. A detailed discussion of their mechanisms and configurations is provided in the following sections.

\subsubsection{Plate Fin Heat Exchangers}

PFHE is a common configuration used in industry which uses a secondary surface of fin arrays to divide streams that results in improvement of heat transfer. Brazed aluminum PFHEs are heat exchangers originally developed for the aircraft industry in the 1940's [13]. In the brazed aluminum PHFE, there is a specific area with high fin density and a hydraulic diameter in range of 1-2 $\mathrm{mm}$. This area is capable of running multi-stream configurations that increases the overall efficiency of these CHEs [13]. Figure 2.1 illustrates several common aluminum brazed PFHE designs. 


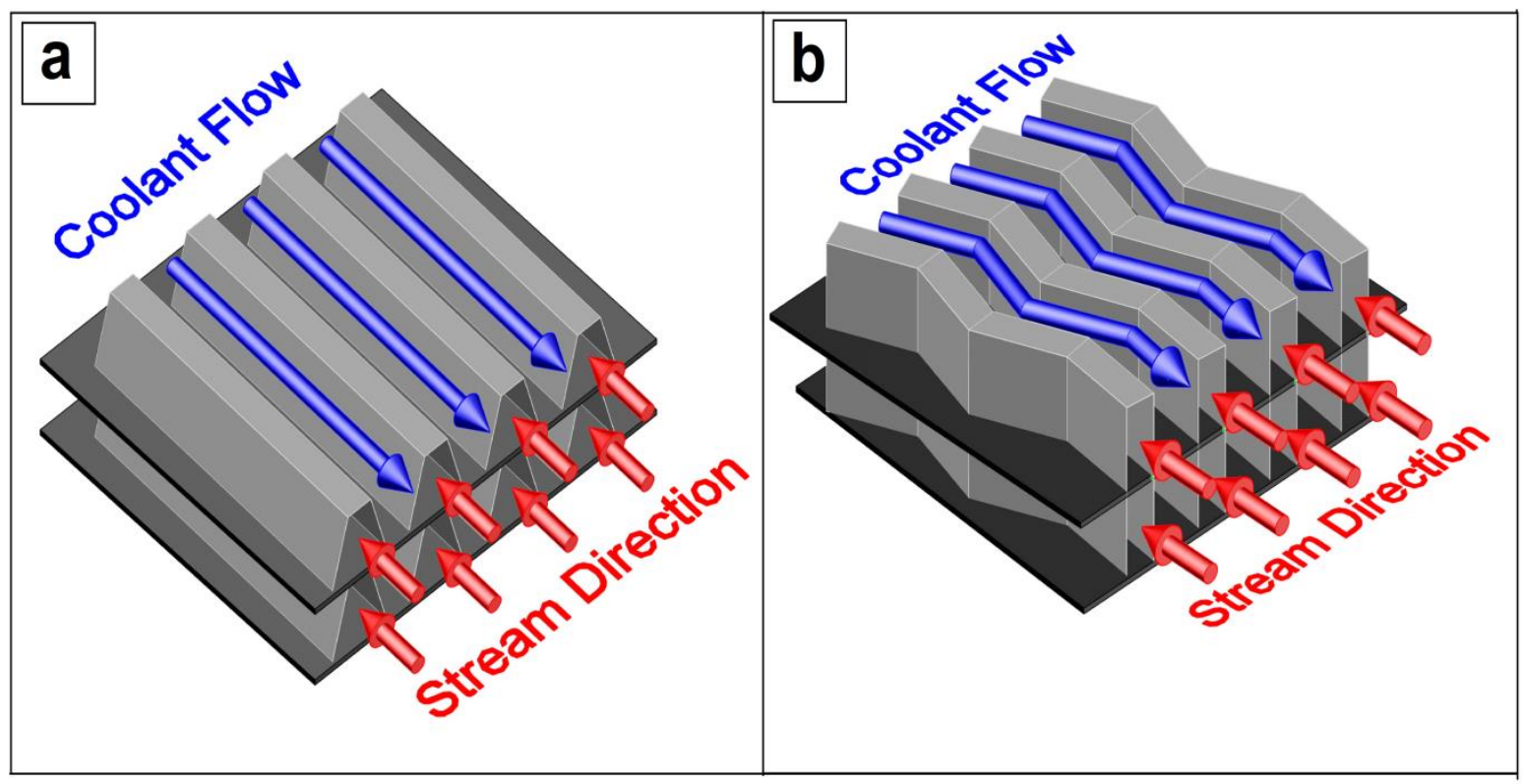

Figure 2.1 Different designs of aluminum brazed PFHE: (a) Plain (b) herringbone

Another CHE from this category is welded plate heat exchanger where, instead of brazing plates together they are welded. The advantage of this type is that the body of the medium is more resistant to more extreme operation conditions (such as higher pressure). At the same time the manufacturing cost is relatively high and the modification of the welded joints is limited. In addition, the choice of material for manufacturing this CHE is a concern since not all the applicable materials can be welded together.

\subsubsection{Metal Foam Heat Exchangers}

Metal Foam Heat Exchangers (MFHE) are compact heat exchangers which are characterized by metallic foam through which fluid flows. The porous media in these heat exchangers 
produces a high pressure loss. Although the pressure loss can be varied by changing the level of porosity and the pore diameter, it is still higher relative to other CHEs. High bending stiffness, strength, thermal conductivity and low weight result in high thermal performance and acceptable mechanical properties for the MFHE [14]-[17]. Many investigations have been performed to improve the efficiency and production process of the MFHEs. Taheri et al. [18] provided a theoretical model for determination of effective thermal conductivity of high porosity metal foams used in MFHE, where the general proposed model can be applied to any complex interconnected foam geometry. Azarmi et al. [19] introduced a novel production technique for manufacturing the foam core sandwiches in MFHE using the air plasma technique. It was shown that air plasma spraying can be a useful method to fabricate foam core sandwiches for MFHE, as there is no need for protective environments or vacuum conditions. Coatings can also be formed on curved substrates if both foam and substrate are made from ductile materials [19].

Figure 2.2 illustrates metallic coating deposited on metallic foam used in MFHE. In another study, four point bending tests were performed on the metallic foam core sandwich structures to examine the effects of porosity variation and heat treatment on the mechanical properties of the metallic sandwiches [20]. Results showed that increase in porosity of the foam leads to a decrease in flexural rigidity of sandwich cores [20].

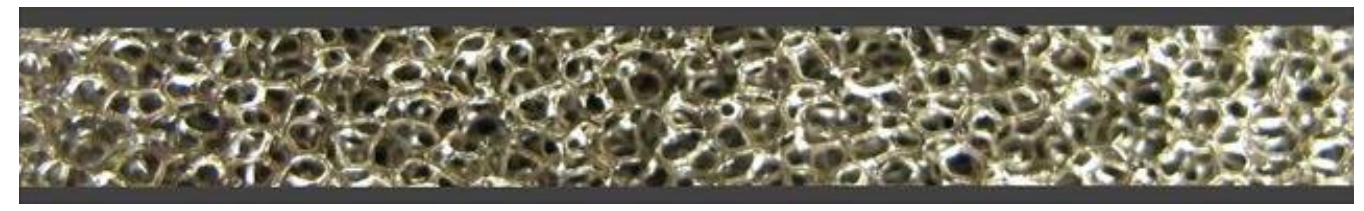

Figure 2.2 Picture of metallic foam used in MFHE [16] 


\subsubsection{Wire Mesh Heat Exchangers}

Wire Mesh Heat Exchangers (WMHE) are open cell heat exchangers with low weight and density. Early manufacturing of WMHE was based on folding metallic wire meshes that were connected to parting plates [21-22]. In this process, the plates were made into flow phase separators by brazing them to the tip of the folded mesh. This process had issues such as the small contact area between the metallic mesh and brazed plate, limitations of the number of times that the wire mesh could be folded, high energy consumption during brazing, and large costs to produce a heat exchanger [23]. Figure 2.3 illustrates schematically a WMHE.

When comparing WMHE with MFHE, WMHE has more mechanical load-bearing capability than MFHE [24]. This is due to the micro-truss structure of WMHE which improves the mechanical strength of the medium, where the cell separating wall in MFHE is subject to bending under mechanical loading [24].

Tian et al. [25] examined different sandwich core configurations with the same boundary conditions in terms of thermal input to specify the most efficient configuration out of the tested configurations. It was found that at the same Reynolds number, porosity and surface area density are the most important key factors affecting the amount of heat transfer for the tested cases. Also, copper wire meshes were compared with copper foam with the same weight to study the overall thermal efficiency of the mediums [25]. For the same boundary condition, it was shown that the copper wire meshes have three times better overall thermal efficiency than copper foam of the same weight [25]. 


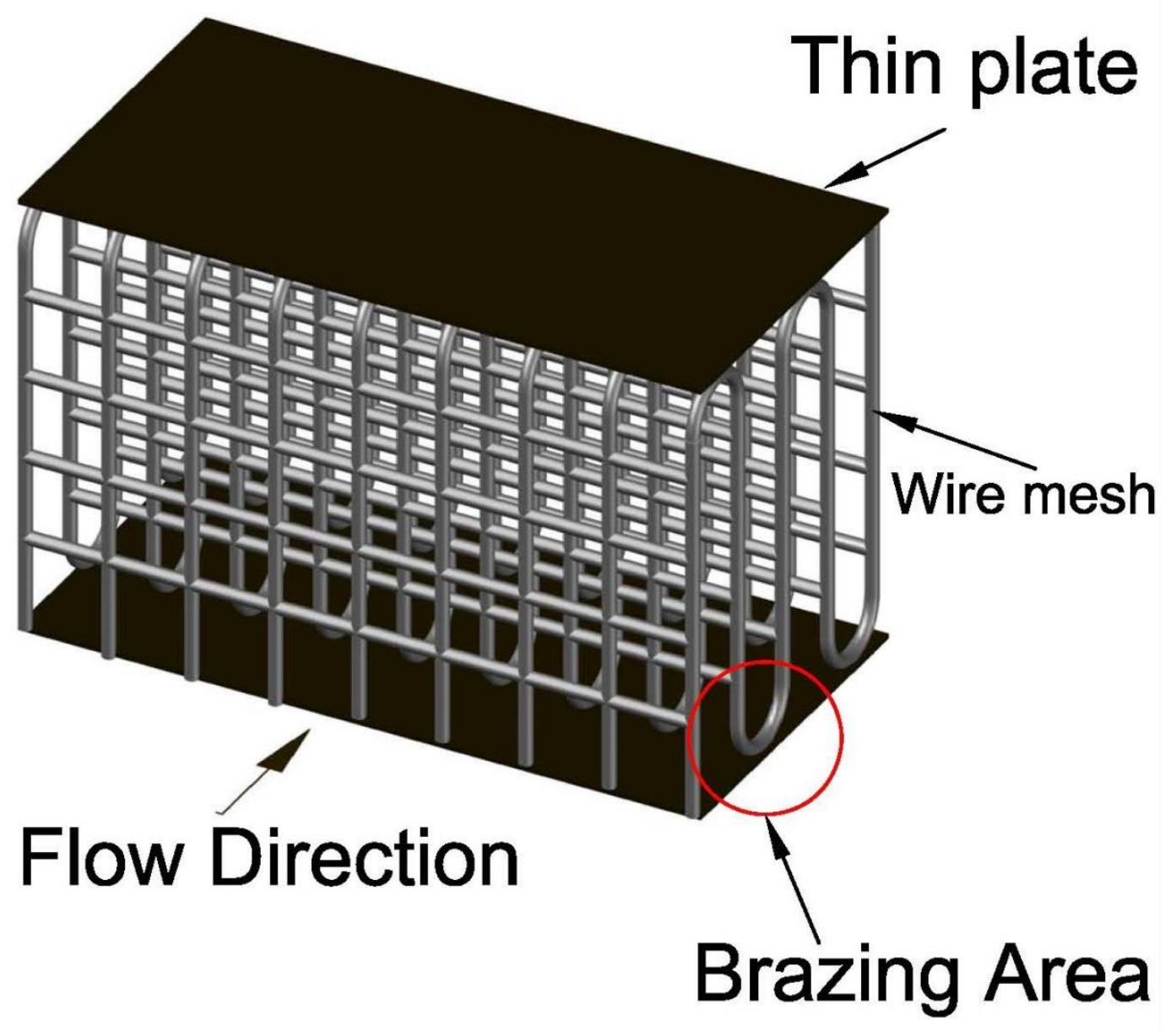

Figure 2.3 Traditional configuration of WMHE

\subsection{Thermal Spray processes}

Thermal spray processes are methods used to apply a metallic or non-metallic coating on substrates [6]. The mechanisms are based on heating up the coating material (powder, wire or rod) up to the molten or semi-molten state and accelerate the particles by a propellant gas until they hit the substrate [6]. Upon impact with the substrate, the particles solidify and form a coating and subsequent particles build up the coating thickness [6]. These processes can be 
categorized in different major groups, in particular Plasma Spraying and High Velocity Oxygen-Fuel (HVOF) spraying.

\subsubsection{Plasma Spray System}

The plasma spraying process operates based on the injection of solid particles in the path of the gas stream exiting from the plasma gun. The schematic of a plasma gun is shown in Figure 2.4.

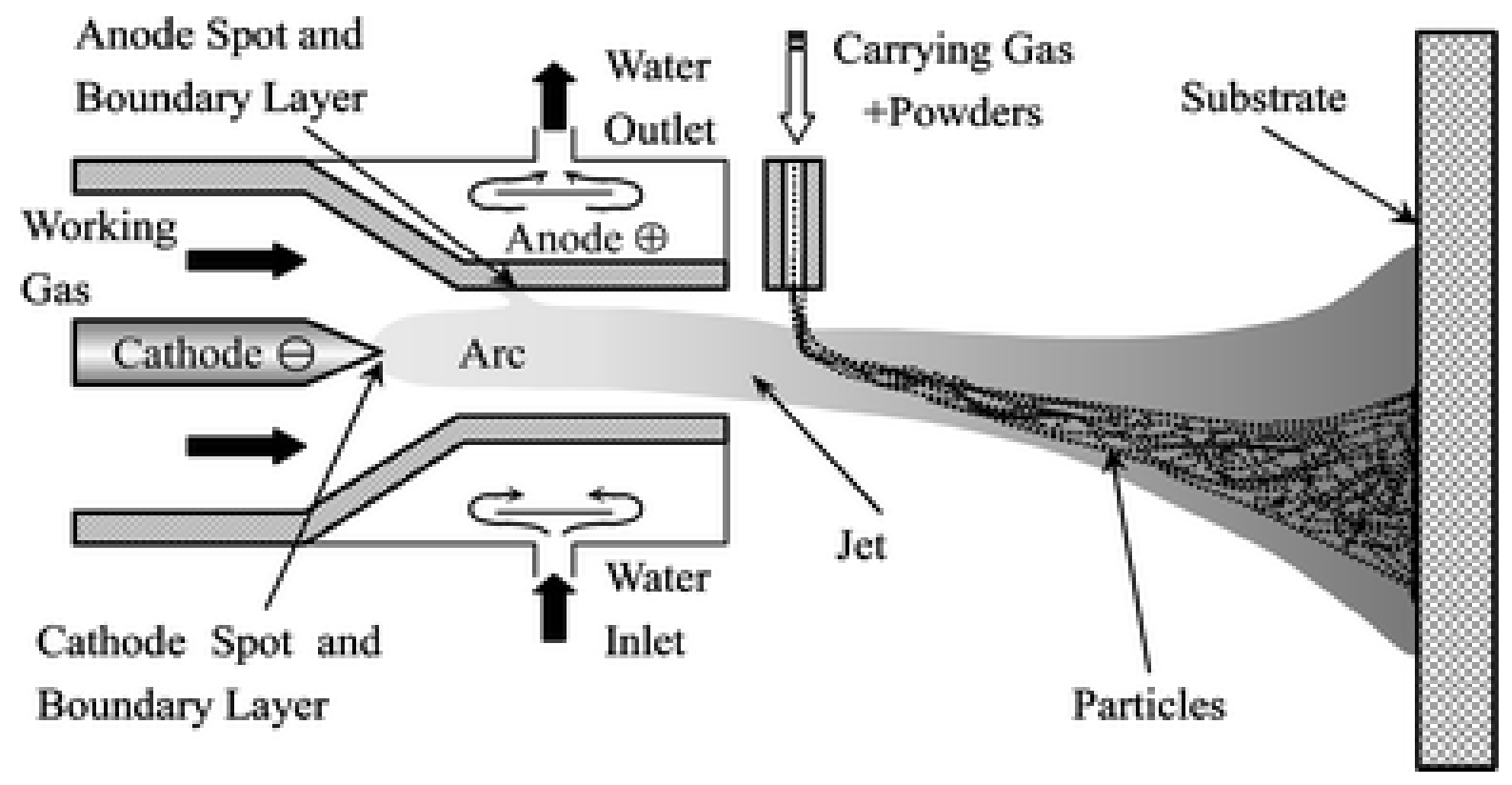

Figure 2.4 Schematic Figure of Thermal Plasma Spray System [26]

This figure shows the working gas path through the narrow passage between the cathode and the anode, where the electric arc produces the plasma plume [26-27]. The injected particles 
are accelerated and heated up to their melting temperature by the plasma gas, typically argon, until the particles hit the substrate and form the coating [26-27]. The high temperature produced by the plasma torch allows for the possibility of using a broad range of coating materials as long as the material does not decompose or sublimate as the melting point is achieved [28]. However, numerous items affect the deposition efficiency of this method, such as nozzle geometry, particle size, velocity, temperature and working gas flow rate [26], [27], [29]. It is notable that the time it takes for the in-flight particles to reach their melting point from the injection point is one the most important factors in deposition efficiency [27]. This is because the desired adhesion and thickness for the coating can be obtained when most of the particles are molten before impingement. Therefore, particles must have adequate velocity and temperature to deform into the irregularities from previous splats otherwise the particles bounce off the coating at impact [30]. However in it is important to ensure that particles (or most of the particles) reach their melting temperature in order to achieve the desired deposition efficiency [6].

\subsubsection{High Velocity Oxygen-Fuel Spray}

High Velocity Oxygen-Fuel spray is a thermal spray coating method in which oxygen is premixed with gaseous or liquid fuel (propylene, acetylene, propane and hydrogen gases) at high pressure in a mixing chamber prior to the nozzle, as shown in Figure 2.5 [31]. The mixture is continuously ignited and accelerated along the nozzle to create a supersonic flame [32]. In this system powder particles are injected from the rear of the torch carried by the 
carrier gas as shown in Figure 2.5 [33]. The gas and the powder are mixed and accelerated along the barrel and finally the molten or semi molten particles hit the substrate and form the coating [34]. Particles will be heated to a molten or semi-molten state, depending on the size, melting point and the injection volume rate of the powder [35]. By varying the fuel/oxygen ratio in the mixing chamber, the final temperature and velocity of the mixture can be altered [32]. The relatively high velocity of the particles in this method causes the formation of a coating characterised by less porosity, less oxidation and better adhesion compared to plasma spraying [31].

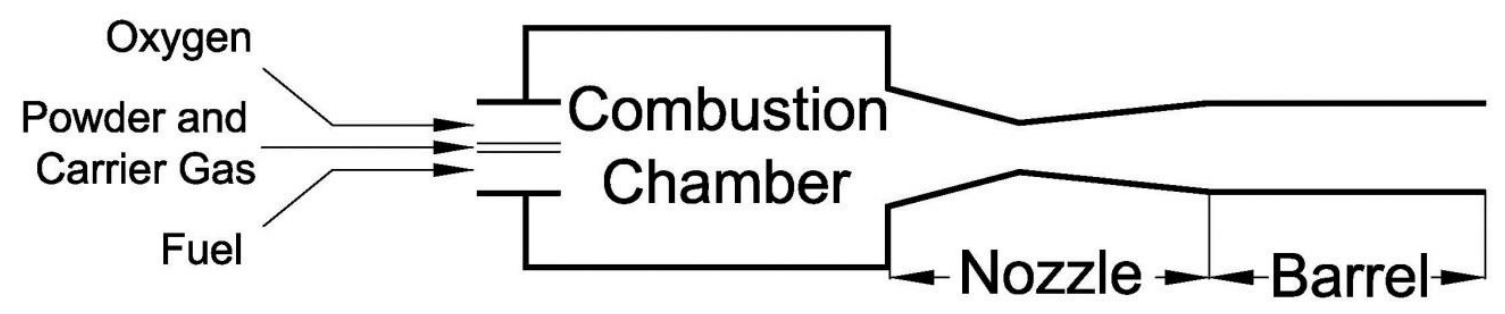

Figure 2.5 Schematic Figure of High Velocity Oxygen-Fuel Spraying System [34]

\subsection{Cold Spray}

Cold spray is a solid-state material consolidation technique in which particles never reach their melting point. In cold spray, the feedstock particles are accelerated to high velocities $(500-1200 \mathrm{~m} / \mathrm{s})$ by a supersonic inert gas jet flow and are projected onto the substrate or previously deposited layer to form a dense coating [5], [36], [37]. Particles start their path in the system from the powder feeder container with the aid of high pressure carrier gas. At the 
same time the propellant gas from the high pressure reservoir passes through a heater. The carrier and propellant gasses mix together and pass through the converging-diverging nozzle, which results in the acceleration of the particles and finally the formation of a dense coating upon impact on the substrate. Figure 2.6 shows a common configuration of a cold spray system. 


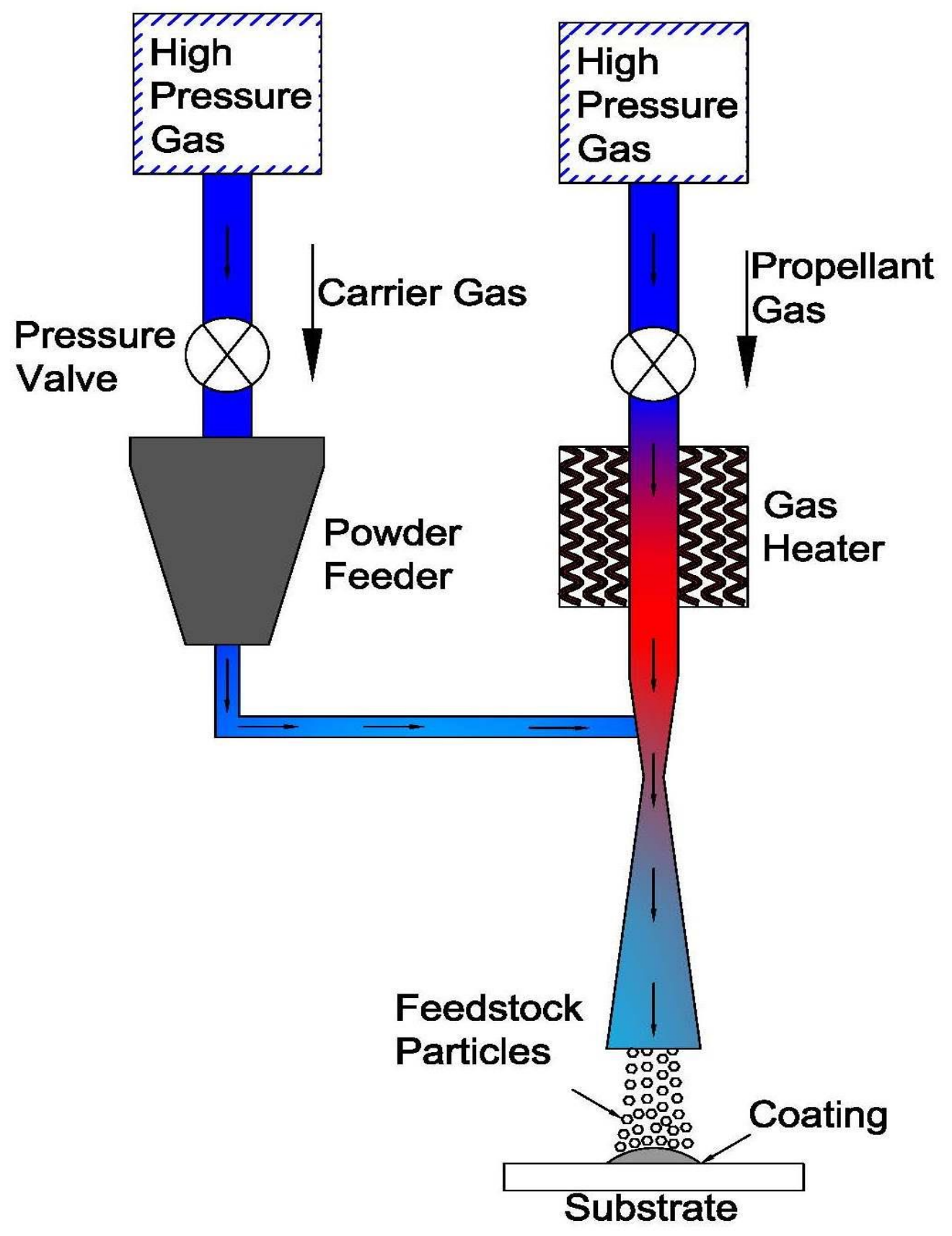

Figure 2.6 Schematic configuration of cold spray system 


\subsubsection{Critical velocity of the particles}

The formation of the coating is due to plastic deformation of particles during the impact process onto the substrate [38]. To this end, particles must have an impact velocity above a specific critical value or they rebound and do not form a coating on the substrate [39]. The energy for this process is provided solely by the kinetic energy of the particles during impact [40]. An estimation of the critical velocity can be obtained using numerical analyses of the impact process and its effect on the material properties and shear instabilities [39]. In general, the velocity of in-flight particles, similar to thermal spray methods, is a function of various parameters, such as size of the particles, temperature and pressure of the propellant gas. Figure 2.7 shows critical velocities for different materials calculated with analytical methods which verifies dependency of critical velocity to the material properties [5]. The black unit on top of each column bar in Figure 2.7 represents the uncertainty range for the value of the critical velocity for each associated material. 


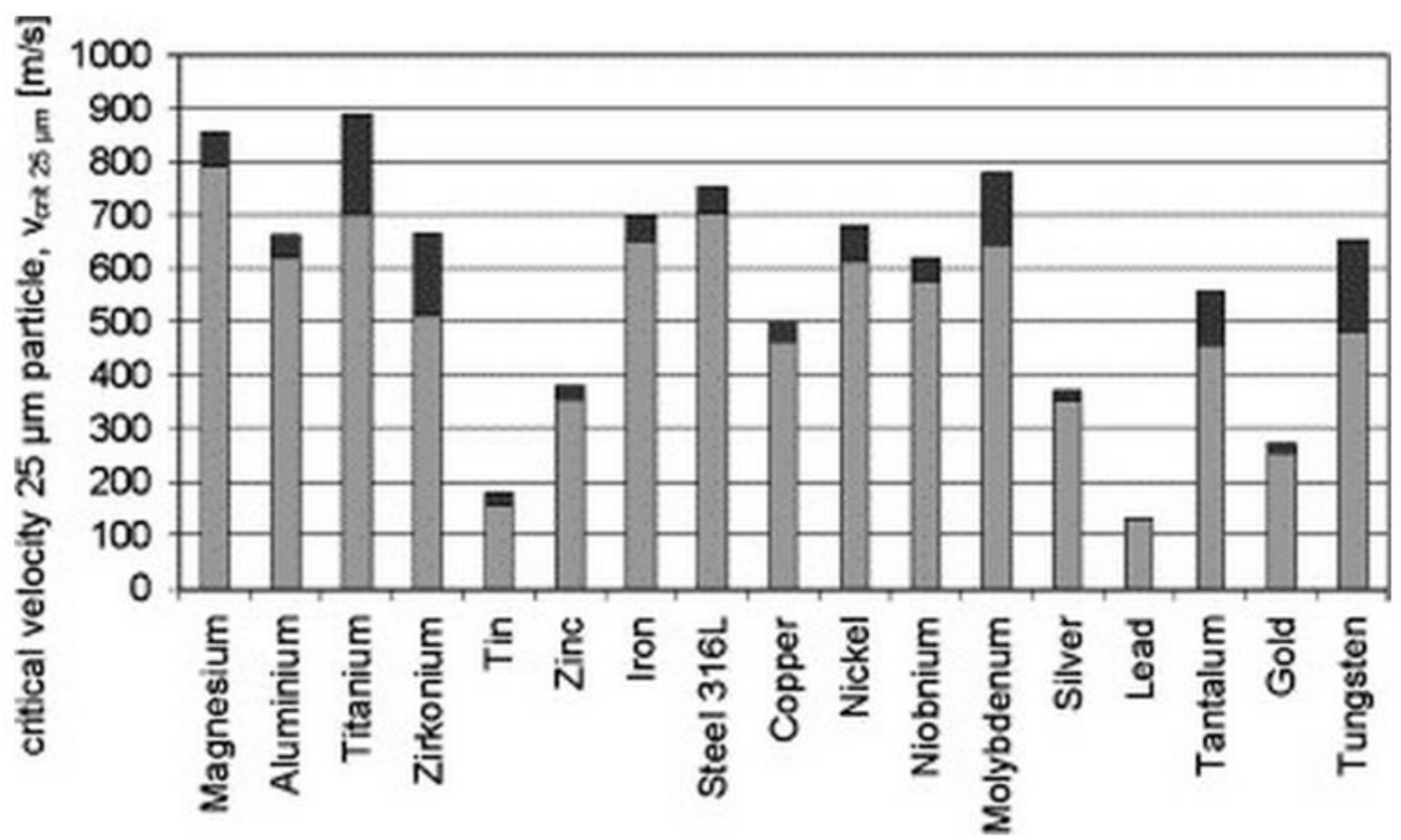

Figure 2.7 Theoretical critical velocities of a $25 \mu \mathrm{m}$ particle for different materials [5]

The values in Figure 2.7 are calculated based on impact temperature, melting temperature and the materials properties such as density and tensile strength [39]. In particular, the size of the particles has a significant effect on critical velocity and subsequently on particle bonding [39]. Figure 2.8 illustrates the critical velocity as a function of particle size [41]. 


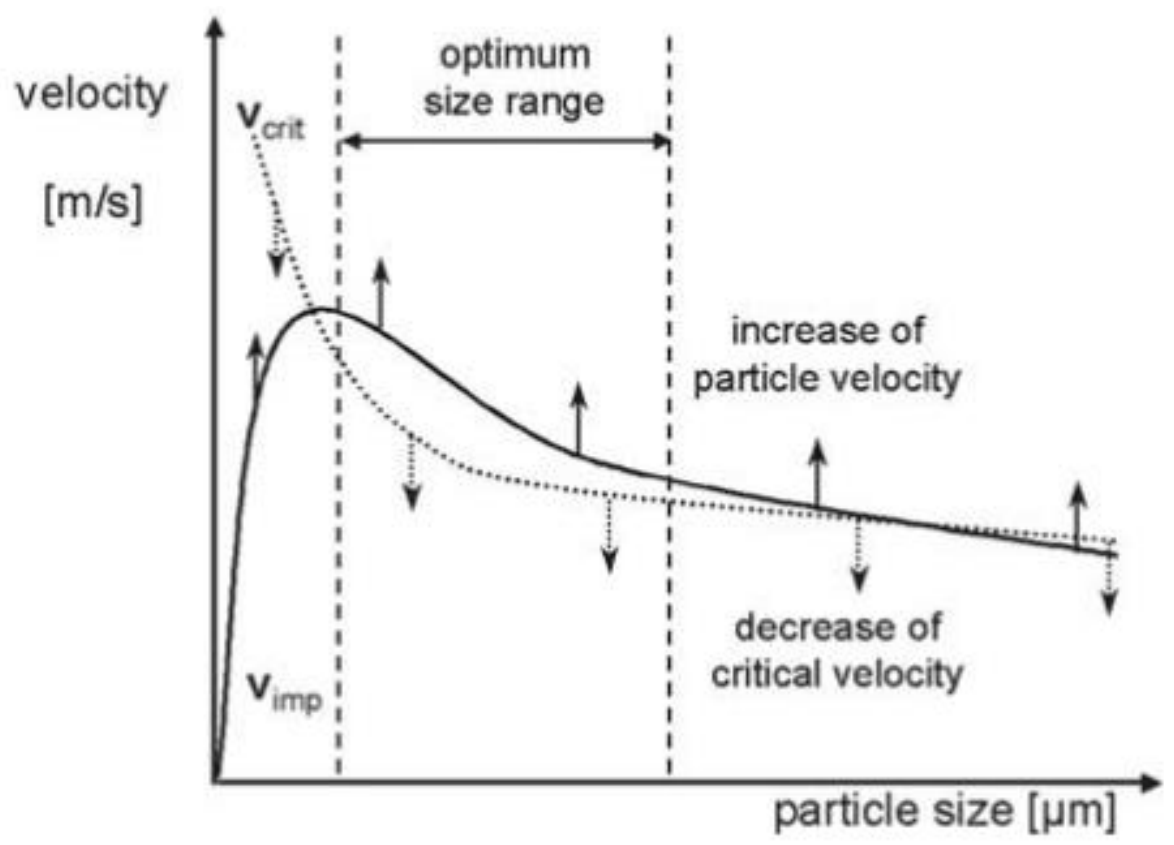

Figure 2.8 Schematic trend of critical and impact velocities as a function of particle size [41]

Coarser particles are larger in size and, as a result of their lower surface to volume ratio and thinner oxide layer compared to smaller particles; they have decreased critical velocity [41]. Finer particles on the other hand, are smaller in size and have a greater surface to volume ratio, resulting in increased oxide levels. Thicker oxide layers require greater kinetic energy upon impact to break through this layer and permit bonding. As smaller particles decelerate more readily adjacent to the substrate due to the bow shock created by the gas stream, this can prevent the oxide layer from breaking. Therefore, to optimize critical velocity, and ensure the oxide layer does not prevent bonding, particle size needs to be adjusted to an appropriate range. In Figure 2.8 the region between critical velocity and impact velocity graph is where the optimum deposition occurs. 
In conclusion, to optimize particle bonding and coating quality in the spray process, the particle size and the gas temperature and pressure of the propellant need to be adjusted to an appropriate range for each material to ensure optimal critical velocity, as seen in Figure 2.8.

\subsubsection{Particle deformation and bonding mechanism}

One of the main requirements of the cold spray process is to ensure that the sprayed particles exceed their critical velocity. This section focuses on defining and explaining particles deformation and bonding process in more detail.

Bonding mechanism in cold spray can be influenced by several parameters. These parameters can vary from spray feedstock powder parameters to thermomechanical and material related parameters [40]. If the particle impact velocity is greater than the critical velocity at initial point of impact the particle will plastically deform. Figure 2.9 (a) shows $0.01 \mu$ s after impact of a single $\mathrm{Cu}$ particle on a $\mathrm{Cu}$ substrate where, Figure 2.9 (b) shows $0.05 \mu$ s after impact. From Figure 2.9 (a) and (b) it can be seen that the particle is deformed as a result of conversion of the kinetic energy of the particle upon impact. In cold spray, kinetic energy mostly transforms into heat and deformation. Since the impact process takes place in a short period of time, heat cannot distribute equally throughout the particle and the substrate, resulting in localized heating. Consequently, this localized heating causes temperature rises at the interface of the particle/substrate or particle/particle [42]. 

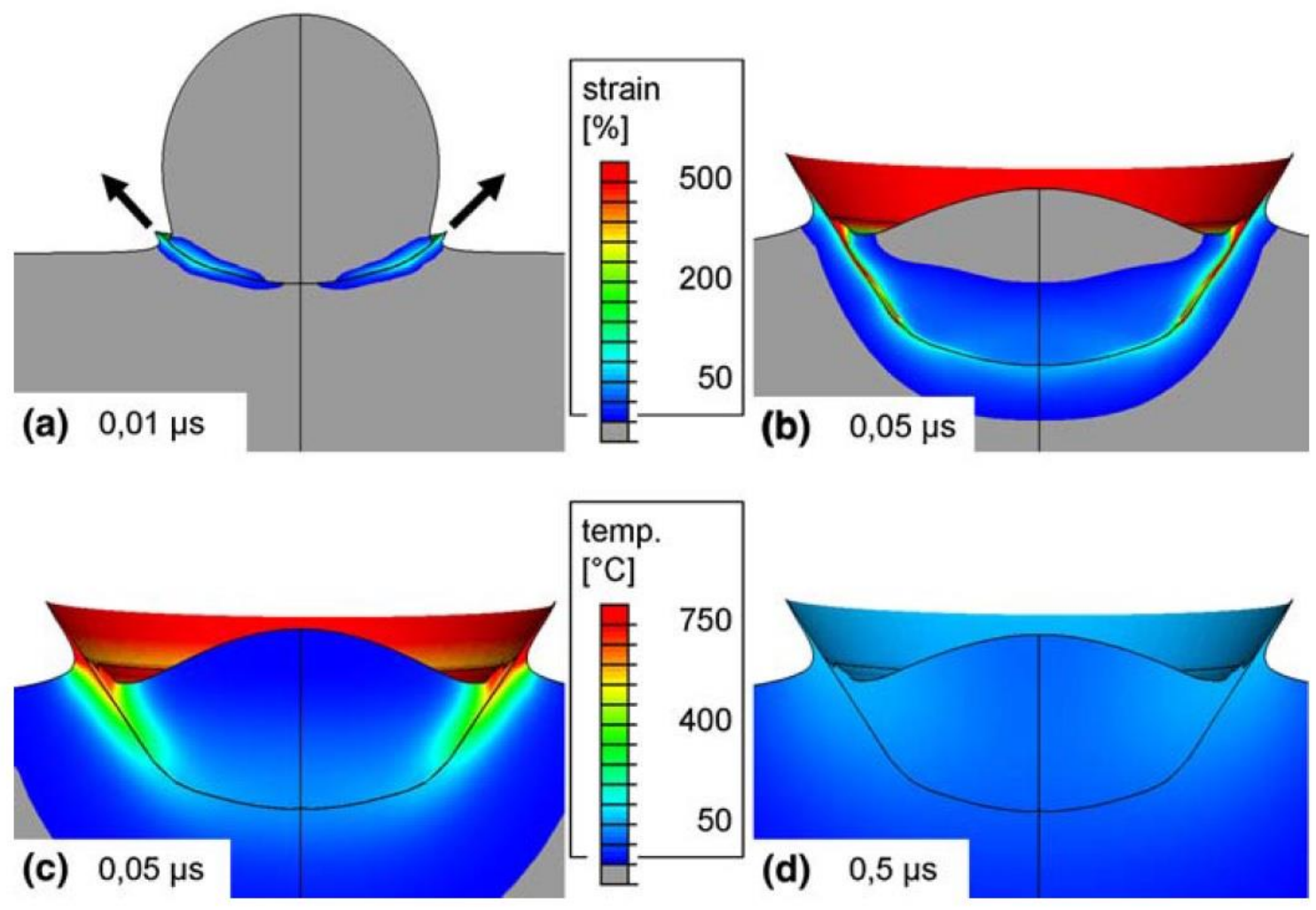

Figure 2.9 Impact sequences of a $25 \mu \mathrm{m}$ Cu particle on a Cu substrate with initial temperature of $20{ }^{\circ} \mathrm{C}$ and velocity of $500 \mathrm{~m} / \mathrm{s}$. (a) and (b) strain field (c) and (d) temperature field [42]

This temperature rise can be seen in Figure 2.9 (c). Figure 2.10 shows the temperature changes at the interface of the particle/substrate as a function of time during impact for different impact velocities. 


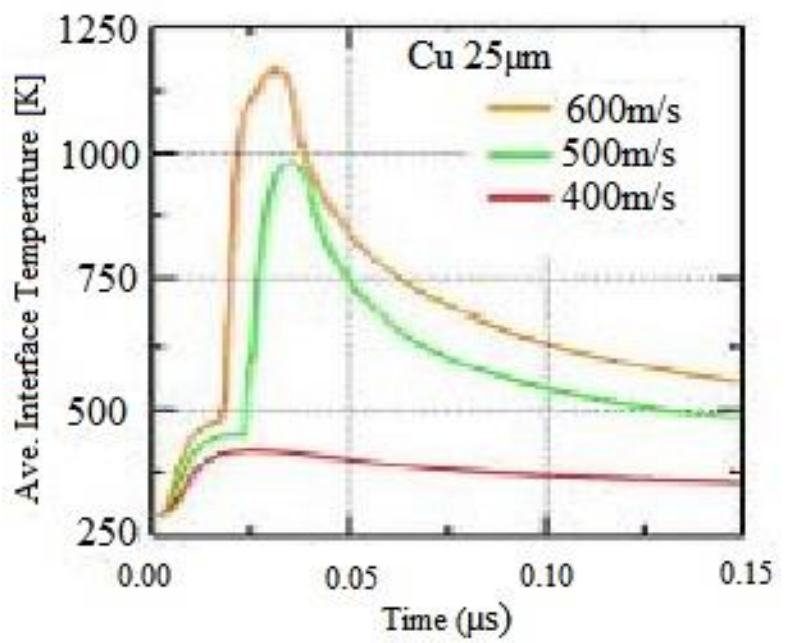

Figure 2.10 Average temperature changes as a function of time for $25 \mu \mathrm{m} C u$ particle at different impact veocities [42]

From Figure 2.10 it can be seen that for impact velocities greater than $400 \mathrm{~m} / \mathrm{s}$ a sudden jump in the interface temperature takes place. These results indicate shear instability at the interface of the particle/substrate or particle/particle [42]. It is notable that during impact the deformation is highly concentrated in the narrow region around the interface of the particle and the substrate, resulting in the formation of a jet composed of highly deformed material [43]. The formation of this jet is showed in Figure 2.11 at different time periods. 

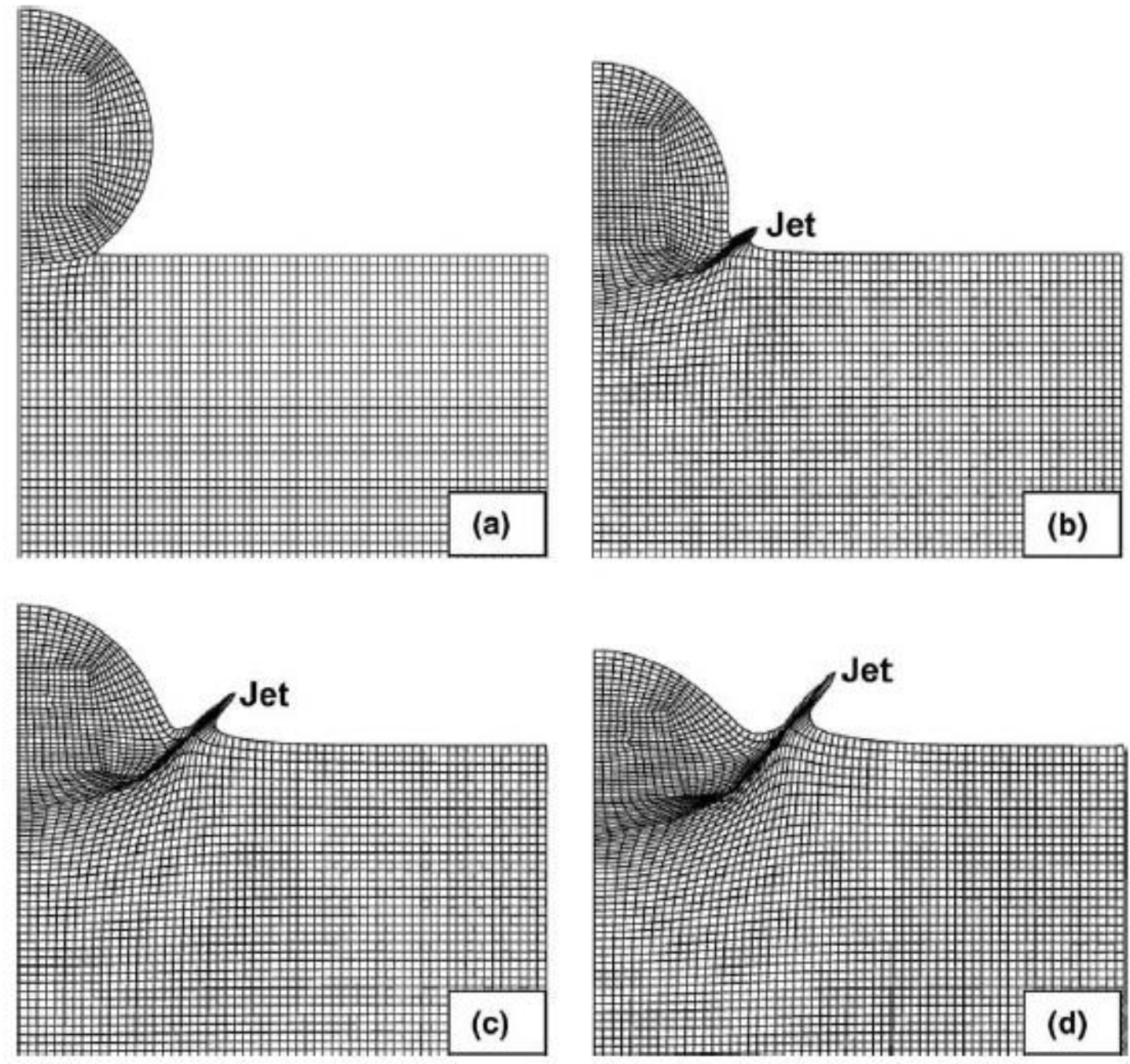

Figure 2.11 Simulation of the formation of a jet at different time periods for a collision of a substrate material at (a) $4.4 \mathrm{~ns}$ (b) $13.2 \mathrm{~ns}$ (c) $22 \mathrm{~ns}$ (d) $30.8 \mathrm{~ns}$ [43]

These jets during cold spray may lead to the production of mechanical interlocking or mechanical bonding. In order to enhance and increase mechanical interlocking some surface preparation can be performed on the substrate, such as grit blasting [44]. Figure 2.12 illustrates mechanical bonding and formation of jets around a $\mathrm{Cu}$ particle on a $\mathrm{Cu}$ substrate [40]. 


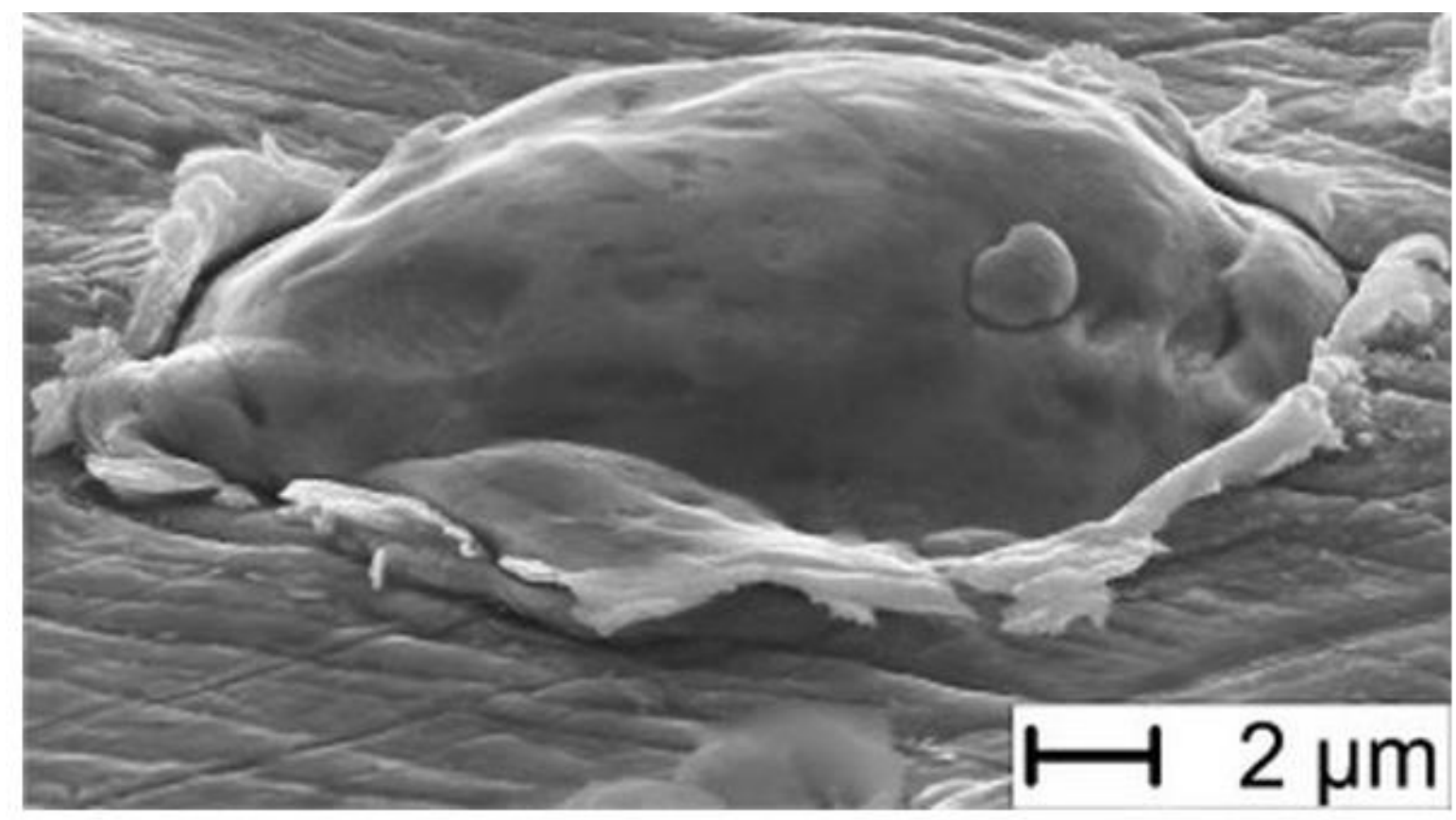

Figure 2.12 Mechanical bonding of $\mathrm{Cu}$ particle on the $\mathrm{Cu}$ substrate [40]

Depending on different parameters such as material type, temperature, substrate surface type, time and magnitude of impact, the surface oxide layer usually present on particle and substrate surfaces can be removed by the jetting material, thus cleaning the surface and allowing intimate contact between the particle and the substrate that can lead to metallurgical bonding [45]. Despite many studies performed on bonding mechanisms in cold spray, the bonding mechanisms are still under investigation. Nonetheless it is assumed in most cases that total bonding is a combination of mechanical and metallurgical bonding together [45]. 


\subsubsection{Cold Spray Parameters}

In the cold spray process a variety of parameters affect the outcome of the coating quality. Adjustment and optimization of these parameters can result in the desired coating characteristics such as thickness, porosity level, adhesion level to the substrate and cohesion within the coating and hardness. The following sections explain the effect of the main parameters on the coating quality.

\subsubsection{Temperature}

Temperature can be considered as one of the most significant parameters in the cold spray process. The injection of the particles into the carrier gas path exposes them to heat (before the expansion occurs in the nozzle) and in turn, increases their temperature. The more heat the particles receive the softer they become, which influences particle deposition. Although an increase in particle temperature affects deposition efficiency, the expansion process that occurs before and after the nozzle throat causes a cooling process in the gas temperature and subsequently a reduction in particle temperature [46]. Therefore the increase in impact temperature of the particle as a result of the exposure to the carrier gas may be insignificant depending on certain characteristics such as particle size and stand-off distance. The mentioned increase in the impact temperature of the particles can specifically be insignificant for smaller particles due to their lower mass and thermal inertia [46].

Gas temperature is directly related to gas velocity, which influences particles velocity in the spraying process. This can be explained with the aid of gas dynamics equations, where 
increasing the velocity of the gas causes an increase in the particle velocity [47]. The particle velocity mainly depends on gas velocity. Particle velocity at the cold spray nozzle exit can be estimated by the following equation [47]:

$$
\mathrm{V}_{\mathrm{P}}=\mathrm{v} \sqrt{\frac{C_{D} \cdot A_{P} \cdot \rho \cdot x}{M}}
$$

$V_{P}$ denotes the particle velocity, $v$ is gas velocity, $C_{D}$ is drag coefficient, $A_{\mathrm{P}}$ is cross-sectional area of the particle, $x$ is axial position of the particle parallel to the nozzle axis and $M$ is mass of the particle. From Eq (1) it can be seen that by increasing the gas velocity the particle velocity also increases.

\subsubsection{Pressure}

In cold spray acceleration of the particles takes place as a result of the drag forces. However, the drag forces are dependant of the pressure in the cold spray system. The drag force applied on the particle can be written as:

$$
F_{D}=\frac{C_{D} \cdot A_{P} \cdot \rho \cdot\left(v-V_{P}\right)^{2}}{2}
$$


with $F_{D}$ as drag force, $C_{D}$ as drag coefficient, $\rho$ as density and $\left(v-V_{P}\right)^{2}$ as the relative velocity of the gas with respect to the particle. Also with assuming the ideal gas condition we have:

$$
P=\rho \cdot R \cdot T
$$

From Eq (3) on can be seen that by increasing the pressure, the density will also increase. Given that and Eq (2) one can conclude that increasing the pressure will lead to increase in the drag force or particle acceleration. At the same time the velocity of the gas is dependent on the total temperature [47]. Based on this, one can conclude that temperature and pressure are two complementary parameters, and both of them play an important role in the cold spray process. Pressure contributes to the acceleration of the particles while temperature is associated to the velocity. These results show a consistency with the previously mentioned gas dynamics aspects of cold spray. Higher pressure leads to higher acceleration of the particles and, as a consequence, higher final velocity of particles. Furthermore, increasing pressure causes a decrease in the size and level of porosity due to higher velocity of the particles (more hammering effect) [48].

\subsubsection{Stand-off Distance}

Stand-off distance is the distance between the exit of the spray nozzle and the substrate. For each specific feedstock there is an optimal stand-off distance which depends on the density and the size of the particles. Maintaining the optimal stand-off distance during the cold spray 
process, results in higher deposition rates. . Li et al. [49] investigated stand-off distance of different feedstock materials. The results are shown in Figure 2.13.

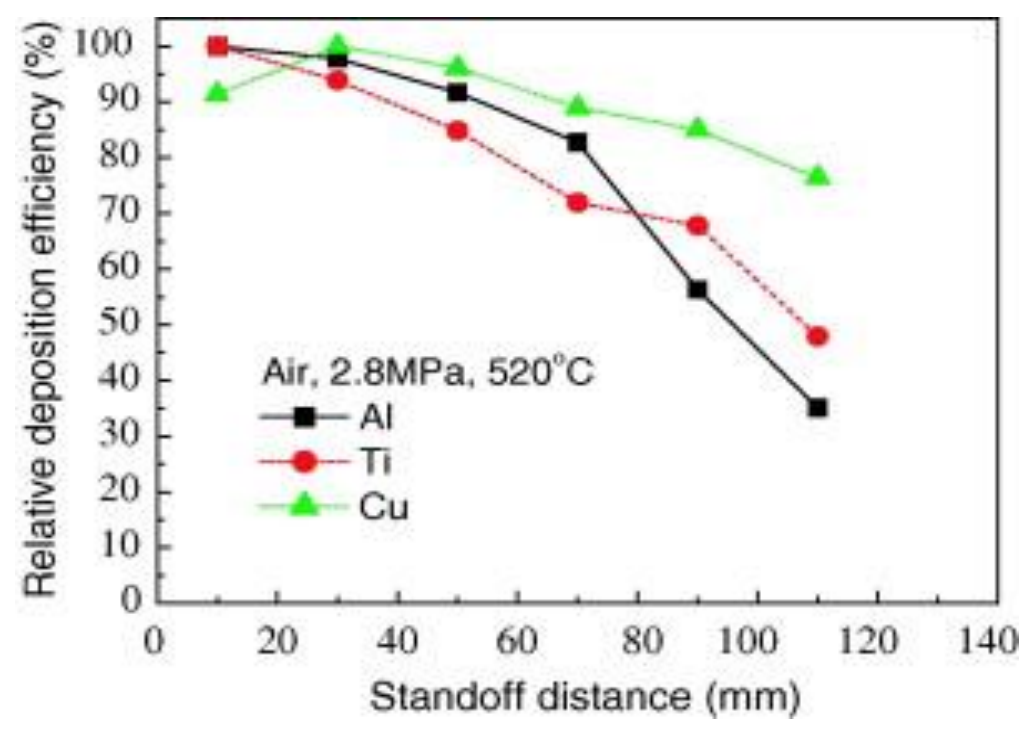

Figure 2.13 Changes of deposition efficiency as a function of stand-off distance for aluminum, titanium and copper particles [49]

From Figure 2.13 it can be concluded that increasing the stand-off distance beyond the optimal stand-off distance will reduce deposition efficiency. Reducing this distance may not necessarily lead to an increase in efficiency. The reason for this is that when the nozzle is too close to the substrate the bow shock produced at the exit of the nozzle may lie in the impingement zone which, in turn, reduces deposition efficiency [50]. For better demonstration of the effect of stand-off distance a brief behaviour trend of deposition efficiency as a function of stand-off distance is shown in Figure 2.14 [50]. 


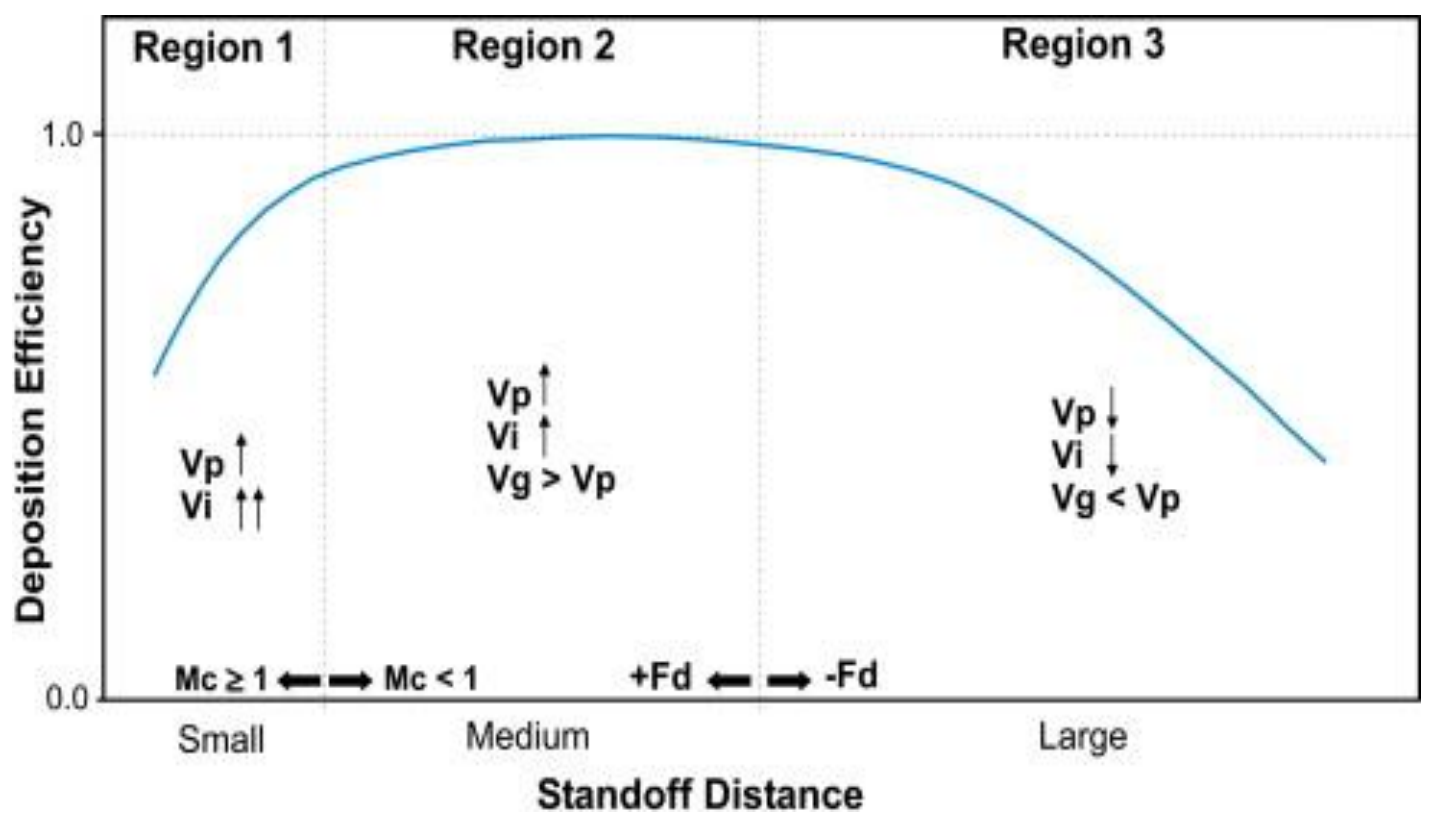

\section{Figure 2.14 Schematic behaviour deposition efficiency as a function of stand-off distance [50]}

In Figure $2.14 \mathrm{~F}_{\mathrm{d}}$ is the drag force, $\mathrm{M}_{\mathrm{C}}$ is the axial Mach number, $\mathrm{V}_{\mathrm{g}}$ is the gas velocity, $\mathrm{V}_{\mathrm{i}}$ is the particle impact velocity and $V_{P}$ is the in-flight particle velocity.

Strength of a bow shock can be defined as the difference between the Mach number immediately downstream and upstream of the shockwave [50]. Also by increasing the standoff distance the free-stream Mach number decreases [50]. This means smaller stand-off distances will result in stronger bow shocks. Therefore, by reducing the stand-off distance, the particle velocity is more affected by the drag forces produced by the bow shock. However, by increasing the stand-off distance the bow shocks affecting on the particle get weaker and as a result the impact velocity and deposition efficiency increases [50]. This is why in Figure 2.14 where region 1 represents a smaller stand-off distance (10 to $60 \mathrm{~mm}$ ) by increasing the stand-off distance the deposition efficiency increases. This is followed by 
region 2 in Figure 2.14 where by increasing the stand-off distance the bow shocks get weaker until the effect of bow shocks become negligible [50]. At this point by increasing the standoff distance the positive drags applied to the particles from the gas stream gradually start to reduce until it becomes zero and negative, respectively [50]. This is where in Figure 2.14 by increasing the stand-off distance, the disposition efficiency will decrease in region 2 [50]. Further increasing the stand-off distance reduces both impact and particle velocity as a result of the applied negative drag forces from the gas flow onto the particles due to the gas flow deceleration in Region 3[50]. From the above discussion, it can be concluded that stand-off distance is a key factor in deposition efficiency and the optimal distance depends on the physical characteristics of the feedstock powder.

\subsubsection{Powder Feeding Rate}

Variation of the powder feeding rate can affect coating thickness. Increasing the mass flow rate causes an increasing trend of the coating thickness which continues until the carrier gas flow becomes saturated with the feedstock particles. At this point the momentum transferred from the carrier gas flow to the feedstock particles is no longer adequate in ensuring critical particle velocity. This means that continuously increasing the feeding rate of the particles will not necessarily lead to a higher coating thickness. Also, it has been shown that increasing the powder mass flow rate can cause excessive particle bombardment which can lead to the peeling of the coating as a result of excessive residual stress [51]. 


\subsubsection{Feedstock Powders}

From early stages of cold spray, it became clear to the cold spray technology applicators that feedstock powder properties are one of the most important parameters [4]. For instance, the shape and size of the particle are important in terms of in-flight velocity that can be achieved [52]. Regardless of the deposition rate, the significance of the utilized feedstock particles is prominent in the mechanical properties of the coating. The characteristics of the cold spray process (such as being a solid-state process) have permitted the application of a variety coating materials with different mechanical properties [6]. The following sections explain the application and characteristics of the feedstock particles used in this work.

\subsubsection{Pure Aluminum and Alumina Feedstock Powders}

Commercially pure aluminum powder is a common feedstock powder used in cold spray and has many applications such as corrosion protection. Many studies have been conducted on aluminum coating production using cold spray [55-57]. In particular, it has been shown that the deposition efficiency of pure aluminum feedstock could be improved with the addition of harder feedstock particles such as alumina. Irissou et al. [10] have demonstrated that by adding alumina to pure aluminum powder, a porosity reduction of $1-7 \%$ in the coating is obtained. Furthermore, the bonding strength between aluminum-alumina coating and 
substrate shows an increase of $50 \%$ compared to cases where only pure aluminum is used [10]. Also, the presence of alumina particles in the aluminum-alumina coatings results in similar corrosion behaviour compared to pure aluminum coatings [10]. In addition, aluminum-alumina powder can be sprayed using low pressure cold spray systems and alleviates the risks of nozzle clogging [56].

\subsubsection{Cold spray and other thermal spray processes: Comparison}

In general, spraying processes can be compared by their operating characteristics such as particle velocity adhesion strength and cost. Figure 2.15 summarizes the different thermal spray methods regarding the operating gas temperature and particle velocity. From Figure 2.15 it can be seen that plasma spraying has the highest operating gas temperature and that cold spray has the lowest. For other thermal spray methods, such as powder flame, wire flame and high velocity oxygen-fuel, the operating temperature is almost the same however their particle velocities are different, where the High Velocity Oxygen-Fuel has the highest particle velocity after cold spray. It is clear that due to the nature of each method, some types may be more appropriate than others for specific applications. Compared to thermal spray methods, cold spray has the lowest operating temperature with the highest particle velocity.

Cold spray has many advantages over other thermal spray methods when working with oxygen and temperature sensitive materials. For instance, one of these advantages is that in cold spray, in-flight particles never reach their melting point due to low operating temperatures of the process, where in other thermal spray processes the particles may melt 
before hitting the substrate [57]. Finally, the coatings produced by cold spray have typically less porosity, higher hardness and lower oxide concentration than the coatings from thermal spray processes [4].

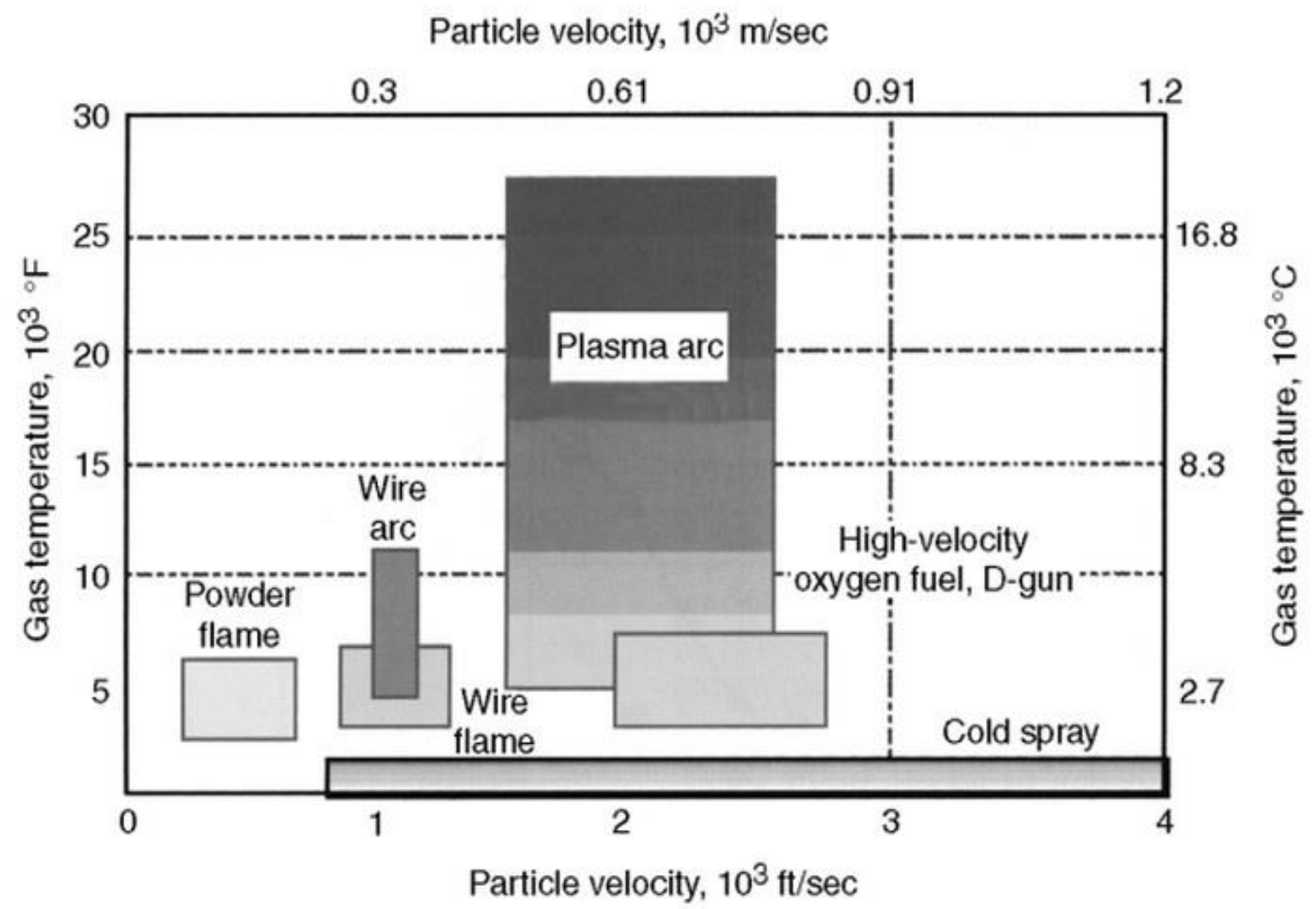

Figure 2.15 Comparison of different thermal spray methods [29]

\subsubsection{Advantages and Disadvantages of Cold Spray}

The present section discusses some of the benefits and limitations regarding cold spray. It is clear that this process is an applicable method that has many advantages. However, there are 
also some drawbacks and limitations when using cold spray. The brief advantages and disadvantages are listed below.

\section{Advantages:}

- High deposition efficiency for most of the metals and composites feedstock powders.

- Dense coating due to adequate plastic deformation of the particles during impact process.

- In cold spray, using a wide variety of feedstock/substrate is possible. In many industrial applications dissimilar substrate and feedstock powder must be used [4]. Such processes might be difficult to implement by other conventional processes. In conventional methods, this can be related to the formation of intermetallic phases when the molten particles hit the substrate. This process may cause premature failure in the coating as the substrate and particle material types are not a suitable intermetallic match [4]. Whereas with cold spray, because the particles do not melt, no premature failure due to high particles temperature occur [4].

- In cold spray due to low operating temperature, minimal oxidation occurs.

- Thermal defects caused by the temperature of spray jet in traditional spraying methods are avoided in cold spray. This feature is significantly useful for temperature sensitive materials such as magnesium and polymers [4].

- Lacks of combustion and flame jet make the cold spray process more environmentally friendly.

- Enhanced fatigue performance of the coating resulting from compressive residual stresses. High temperature in other thermal spray methods causes the coating to 
experience tensile stress, which in some cases leads to cracks or defects in bonding to the substrate [4].

\section{Disadvantages:}

- Proportion of brittle feedstock particles cannot exceed more than some specific levels because they cannot plastically deform and simply bounce off the substrate or coating.

- At relatively high temperatures, the spraying the nozzle can become clogged.

\subsubsection{Compact Heat Exchanger \& Cold Spray}

As mentioned earlier in section 2.1.3, manufacturing WMHE using traditional folding wire meshes causes various issues. These issues include the limitation in the number of times that the meshes can be folded, the small connection area between wire meshes and the separating plates, high energy consumption and large costs to produce the heat exchanger. A novel solution for the aforementioned problems has been developed with the assistance cold of spray [23]. This method utilizes metallic woven wire mesh sheets which are cut and stacked on each other like matrices and instead of brazing the tips of the wires to the parting plates, thermal spray processes such as cold spray are used to seal them [23]. Figure 2.16 (a) shows the traditional configuration of WMHE, with wire mesh brazed to opposing thin plates at the top and the bottom of the system and Figure 2.16 (b) illustrates the schematic of the new version of WMHE using thermal spray processes. 


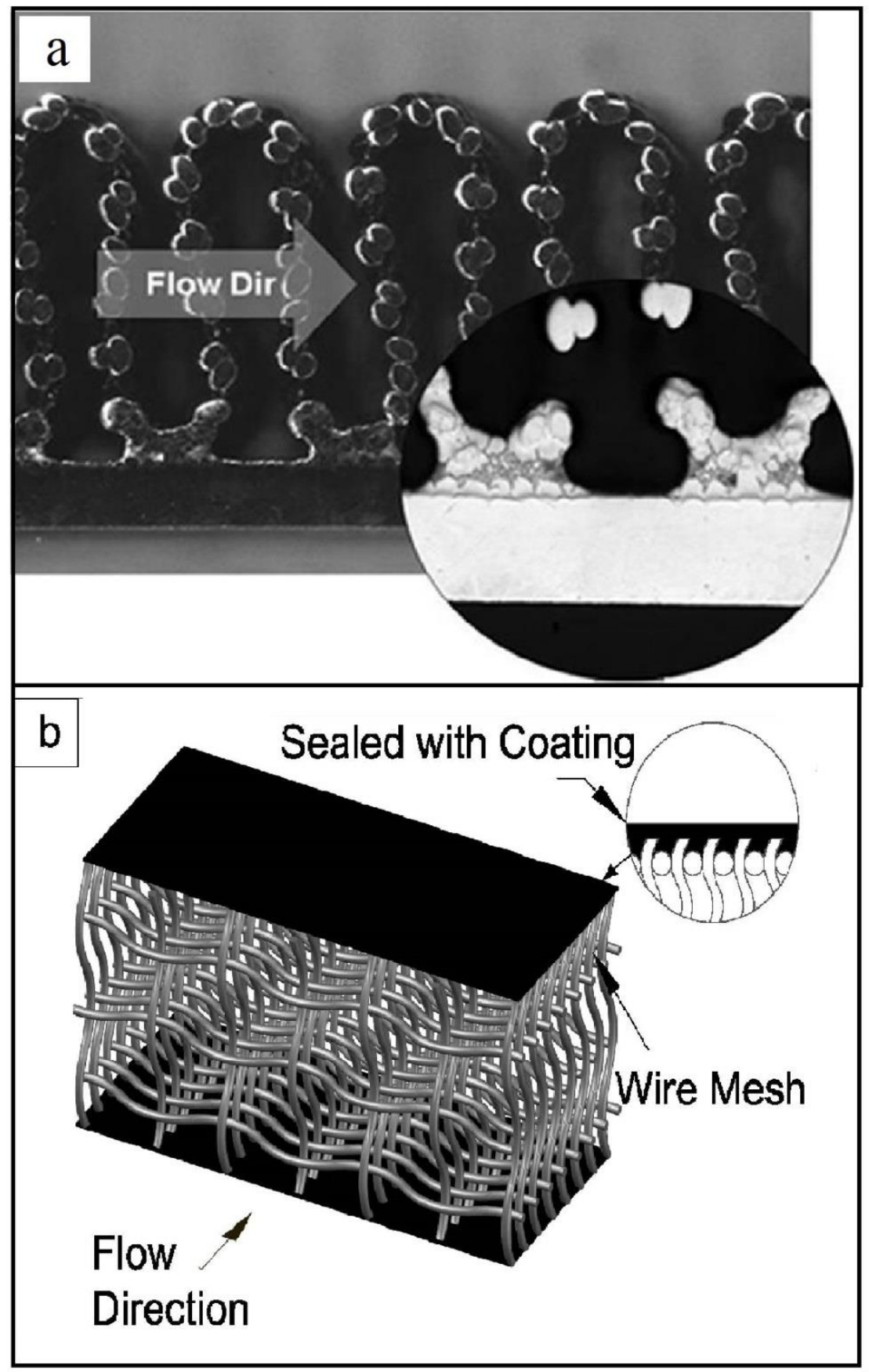

Figure 2.16 (a) Folded mesh heat exchanger with the zoom brazed area (b) Schematic of WMHE produced with additive manufacturing 
In order to improve the efficiency of the WMHE, fins can be added to the top and the bottom of the separating plates. Previously, rectangular fins produced by machining processes used to be applied on these surfaces. However, in terms of creating turbulence and mixing flow the rectangular fins are not particularly efficient. This can be improved by changing the geometrical shape of the fins. To this end, as a novel method, pin fins can be applied on the surface of separating plates using cold spray technique as an additive manufacturing process instead of using traditional machining processes. Pyramidal pin fin types allow for more turbulence and mixing, which enhances heat transfer. In comparison, Figure 2.17 represents the new configuration of WMHE using thermal spray techniques for sealing the top and bottom of the stacked wire mesh and cold spray to produce external fins. 


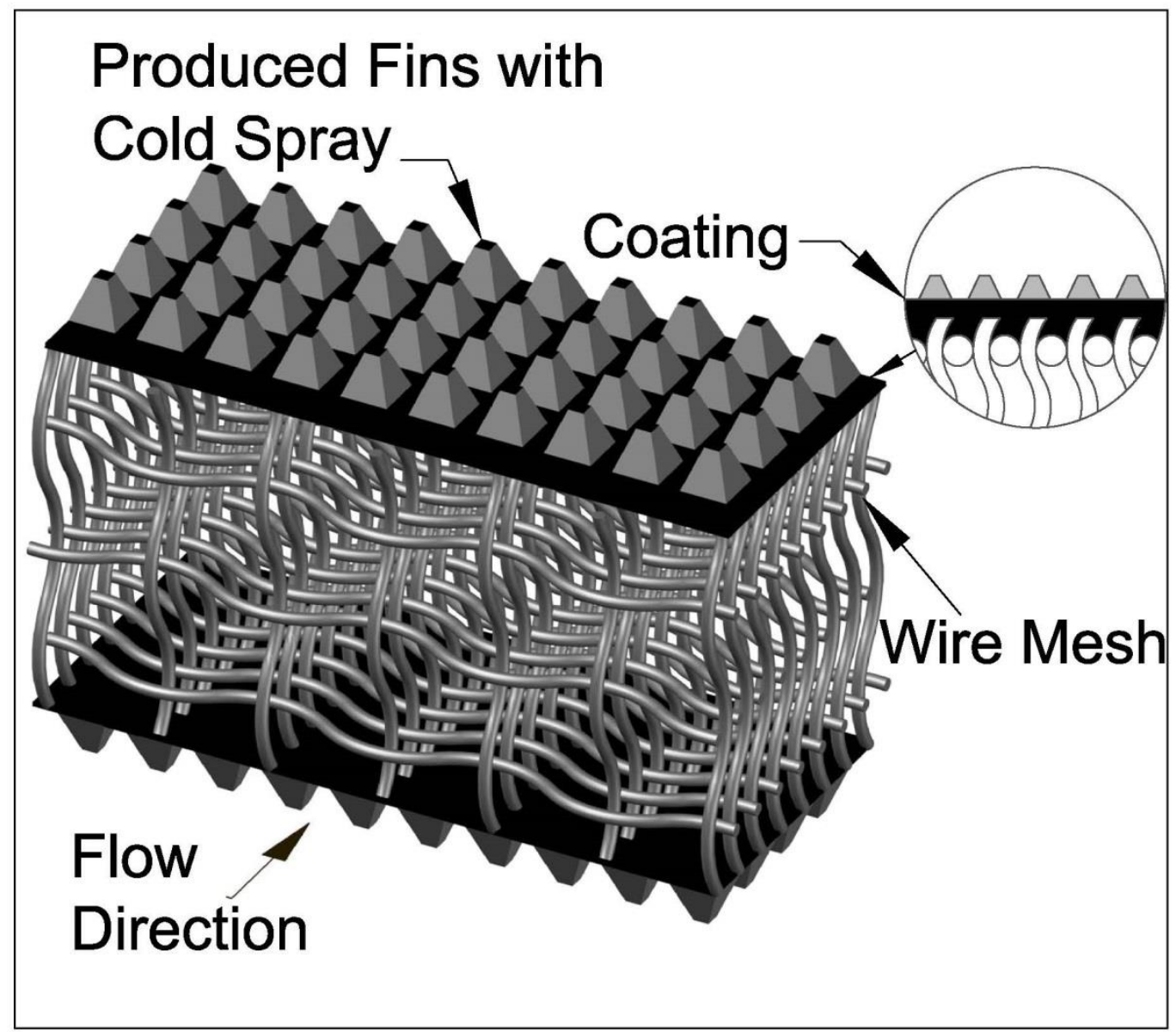

Figure 2.17 Wire mesh heat exchanger with fins produced by cold spray

A significant amount of work has been performed on WMHE as well as the production of pyramidal pin fins produced by additive manufacturing cold spray process [7-9], [23], [25], [60-62]. The thermal performance enhancement of heat exchanger surfaces by additive manufacturing of fins using the cold spray technique (as illustrated in Figure 2.17) is an innovative idea for which limited investigation work has been done. One of the benefits of using cold spray for additive manufacturing of fins compared with other thermal spraying techniques is that it avoids issues such as clogging of the mask and allows building up large structures quickly. Figure 2.18 shows a schematic of fin production using cold spray. 
Depositing fins using high temperature thermal spray techniques can lead to clogging of the mask due to melting of particles or mask, while in the cold spray technique the feedstock particles or mask never get to their melting points due to low operating temperature of the cold spray technique [8].

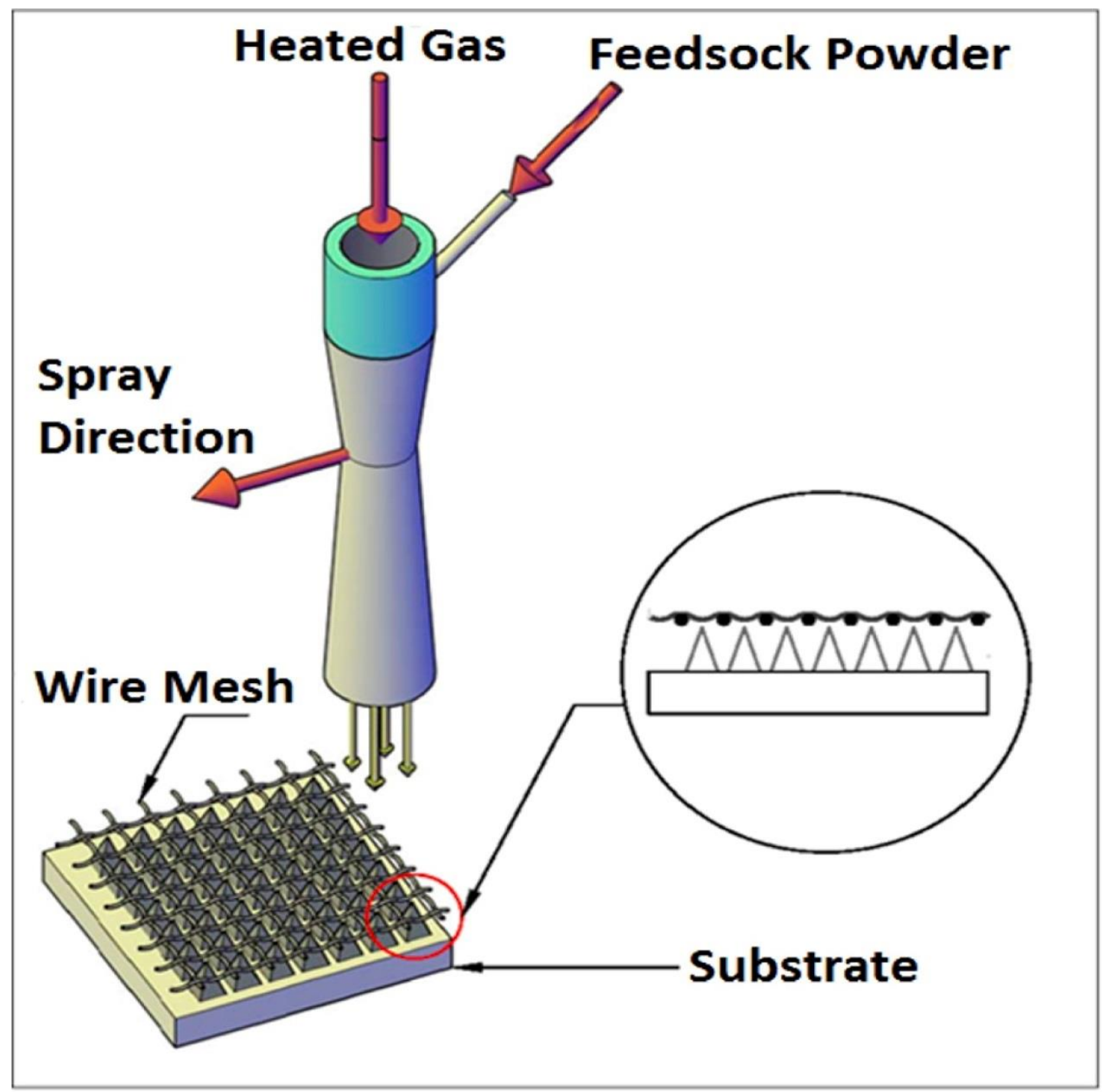

Figure 2.18 Cold spray apparatus set-up using wire mesh masks

Cormier et al. [9] investigated the process feasibility and manufacturability of aluminum and stainless steel pyramidal pin fin arrays using the cold spray method. The fins were 
manufactured using steel wire mesh masks. Different fin densities from 12 up to 30 fins per inch were examined. Moreover, different fin heights ranging from $1.0 \mathrm{~mm}$ up to $2.2 \mathrm{~mm}$ were manufactured and tested. The results of the aforementioned tests for four different samples, US, Al-4, SC-B and SC-C can be seen in Figure 2.19.A description of each sample can be found below:

US: A $5.1 \mathrm{~mm}$ by $5.1 \mathrm{~mm}$ unfinned plain surface. The bulk material block has the same dimensions as the other samples used in Figure 2.19.

Al-4: A $5.1 \mathrm{~mm}$ by $5.1 \mathrm{~mm}$ substrate with pure aluminum pyramidal pin fins. This sample was produced with a fin density of 24 fins per inch and a $1.4 \mathrm{~mm}$ fin height.

SC-B: A $5.1 \mathrm{~mm}$ by $5.1 \mathrm{~mm}$ substrate produced by subtracting rectangular fins from the bulk material using machining operations. The fin density for this sample was 24 fins per inch and the fin height was set to $1.7 \mathrm{~mm}$.

SC-C: This sample is very similar to the SC-B sample except that a layer of pure aluminum was sprayed on the surface of the substrate and rectangular fins were subtracted from the coating with at height of $1.4 \mathrm{~mm}$ using machining operations.

When the pyramidal fin arrays were compared with rectangular fins manufactured through more traditional manufacturing processes, the results showed that the pyramidal fins performed better for Reynolds numbers higher than 1000. For Reynolds numbers lower than 1000 the flow is mainly in the laminar region which results in a smaller recirculation behind the pyramidal fins, leading to similar performance to straight cut fin samples. By increasing the Reynolds number, the turbulence level in the recirculation zones behind the pyramidal 
fins increases and consequently the thermal conductance as seen in Figure 2.19, grows with a sharper slope compared to the straight cut fin samples.

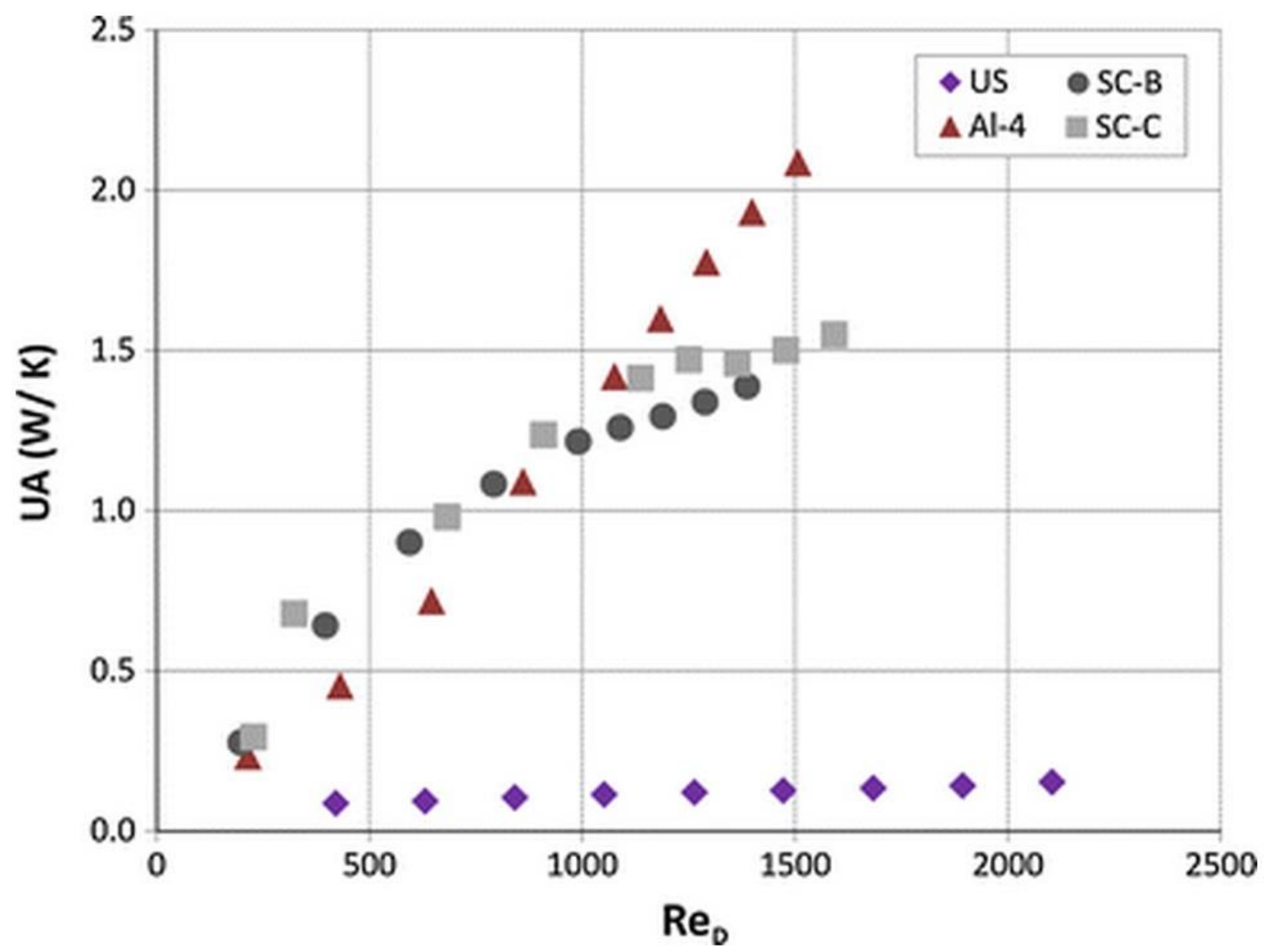

Figure 2.19 Thermal conductance as a function of Re number [9]

Dupuis et al. [8] investigated the hydrodynamic performance of cold spray pyramidal and trapezoidal fins (produced by grounding the tip of pyramidal fins) as well as rectangular fins machined using traditional processes. The global performance between ground and assprayed fins was found to be very similar; meaning that the pyramid tips may not have a significant effect on heat transfer properties for the configurations tested. The new type of fins also showed a better performance compared to traditional plain rectangular fins. The 
effect of base angle variation at constant height in pyramidal pin fin arrays produced with cold spray was also studied. It was observed that increasing the base angle of the fins caused a reduction in convective heat transfer, while the total available heat transfer area was increased as the base angle was increased. The effect of the two mentioned conflicting parameters showed negligible net difference in the thermal conductance of the tested samples. 


\section{Research Objectives}

The main objective of this thesis is to study the effect of adding alumina to the aluminum feedstock particles, which are often used in cold spray processes, for the fabrication of pyramidal fins. Primarily, the objectives of this research can be divided into the two categories of experimental and numerical objectives. Briefly, the general experimental objectives were manufacturing and studying the performance of the new compositions (alumina-aluminum vs pure aluminum) of pyramidal pin fins. The objectives of the numerical modelling were to understand different features of the process in more details. The mentioned objectives are discussed in more details in the following section.

\subsection{Experimental work Objectives}

Previous relevant studies suggest that using new techniques such as thermal spray for the production of new types of WMHEs can effectively lower the production costs and avoid manufacturing problems that exist with other production methods such as brazing.. Also, the idea of using secondary surfaces (or fins) was proposed in order to improve the thermal efficiency of WMHE. However, the fin material and geometrical shape as well as manufacturing method have always been areas of development. It is notable that one of the most efficient fin type in terms of production cost and performance is the pyramidal fin shape produced by cold spray additive manufacturing.

In the past few years, at the University of Ottawa, a novel method for applying pyramidal pin fins on new WMHE using the cold spray method was developed, where pyramidal fins were 
fabricated and tested with different feedstock powders [9], but never aluminum-alumina powders. Using aluminum-alumina powder mixtures increases deposition efficiency and contributes to preventing nozzle clogging. It has been shown that adding alumina particles to the pure aluminum feedstock particles can enhance some of the coating mechanical properties and improve coating quality by reducing porosity level [10]. However, special nozzles such as polymer nozzles are usually used for spraying pure aluminum feedstock powder. These nozzles are more costly compared to steel nozzles that can be used for spraying aluminum-alumina powder mixtures. Furthermore, polymer nozzles wear out faster than steel nozzles. Therefore, this study aims to investigate the results of using the aluminum-alumina feedstock powder mixtures for the fins instead of pure aluminum. Although, the mentioned characteristics make alumina a suitable candidate for pin fin manufacturing, there are also some disadvantages. For example, there is a restriction in the deposition rate of alumina due to lack of deformation of alumina particles during the cold spray process. Its low thermal conductivity can also be considered as another disadvantage which can directly affect the thermal efficiency of the fin array. However, the overall performance of the fin array is a function of all of the mentioned parameters combined which makes the manufacturing and evaluation of the alumina pin fins worthwhile.

This research evaluates the potential production and application of alumina-aluminum pin fins, as opposed to pure aluminum pin fins, where both are produced using cold spray as an additive manufacturing process. Two pin fin arrays with different alumina percentages are produced using the cold spray process to produce pyramidal fins, as well as pure aluminum pin fin array as a comparison. The use of alumina-aluminum feedstock powder could potentially be beneficial in terms of coating density, improved mechanical properties, and 
minimized nozzle and mask clogging (or the requirement of using more expensive nozzle designed to minimize clogging thus allowing easier industrialisation of the process). Thermal performance and pressure loss of aluminum-alumina samples are tested and compared with the equivalent pure aluminum sample.

\subsection{Numerical Model Objectives}

Many numerical modelling works have been previously performed for the study of cold spray [61]-[65]. These works have examined various aspects of cold spray, from the operations and process of cold spray to designing equipment such as the spraying nozzle. The results of these modelling works can be used to optimize and better understand the cold spray technique. Since the process of manufacturing pyramidal pin fin arrays with cold spray is a fairly new approach, the numerical modelling of such configuration has yet to be accomplished. Therefore, the primary numerical objective was to replicate the manufactured pyramidal pin fins using numerical modelling in order to better investigate the obtained results from the experimental tests. It is notable that some of the major parameters (such as heat flux and inlet temperature) were directly imposed to the numerical model from the experimental test results. Predefining the values of these parameters was a necessary step to simulate the model with the experiment's operating conditions. This permitted the study to investigate the problem in the areas where experiment tests could not, without employing complex and costly operations such as visualizing the flow stream. Therefore, the created 
numerical model cannot be considered as a prediction tool except for the pressure drop and the substrate temperature along the flow channel.

In this study a three-dimensional numerical model was developed for better understanding of the flow behaviour as well as prediction of pressure loss for an array of pyramidal pin fins. Moreover, the model can be used to visualize the temperature distribution and flow across the test channel and in the fins. Verification of the results obtained from the modelling against the ones obtained from experimental tests is performed. This is a vital step, as without verification of the model's performance with the experimental results, relying on the results obtained from the model would be invalid. To this end, comparisons are performed between the results of the model and the experiments. These comparisons are discussed in detail in following sections. Once the model is validated, with sets of experimental results, it allows for the possibility of attaining similar outcomes without actually performing experiments. This process can be beneficial in saving time and cost. 


\section{Experimental Approach}

This chapter explains the procedures and parameters used for both experimental and simulation works performed in this research. The equipment and approaches used are presented. More specifically, this chapter will define the used cold spray system, the required spray rig configuration to produce pyramidal pin fins and also the parameters used to manufacture the fin arrays. Subsequently, feedstock materials used are characterised. Sample preparation methods for microstructure analysis are described. Heat transfer and pressure loss tests setup as well as governing equations to calculate the required parameters are presented in detail.

\subsection{Cold Spray Equipment}

In this study, a commercially available low pressure cold spray system (Centerline (Windsor) Ltd. (Windsor, ON, Canada)) was used. Figure 4.1 shows an image of the main components of the cold spray system. This system consists of:

- Spray chamber: where the actual spray process occurs. While spraying, the chamber is closed by the enclosure shown in Figure 4.1. The spray chamber is utilized with the ventilation system to ensure that the particles that do not adhere to the substrate are directed into the filtering unit. 
- Automatic spray gun: the spray gun showed in Figure 4.1 includes a gas heater, a powder heater and the nozzle assembly. The gun is directed by the computer base controller. The controller is programmed with the Matlab code. The code makes user capable adjusting parameters which are related to the displacement of the nozzle such as traverse speed, number of spraying passes, distance between each pass and the required travel distance.

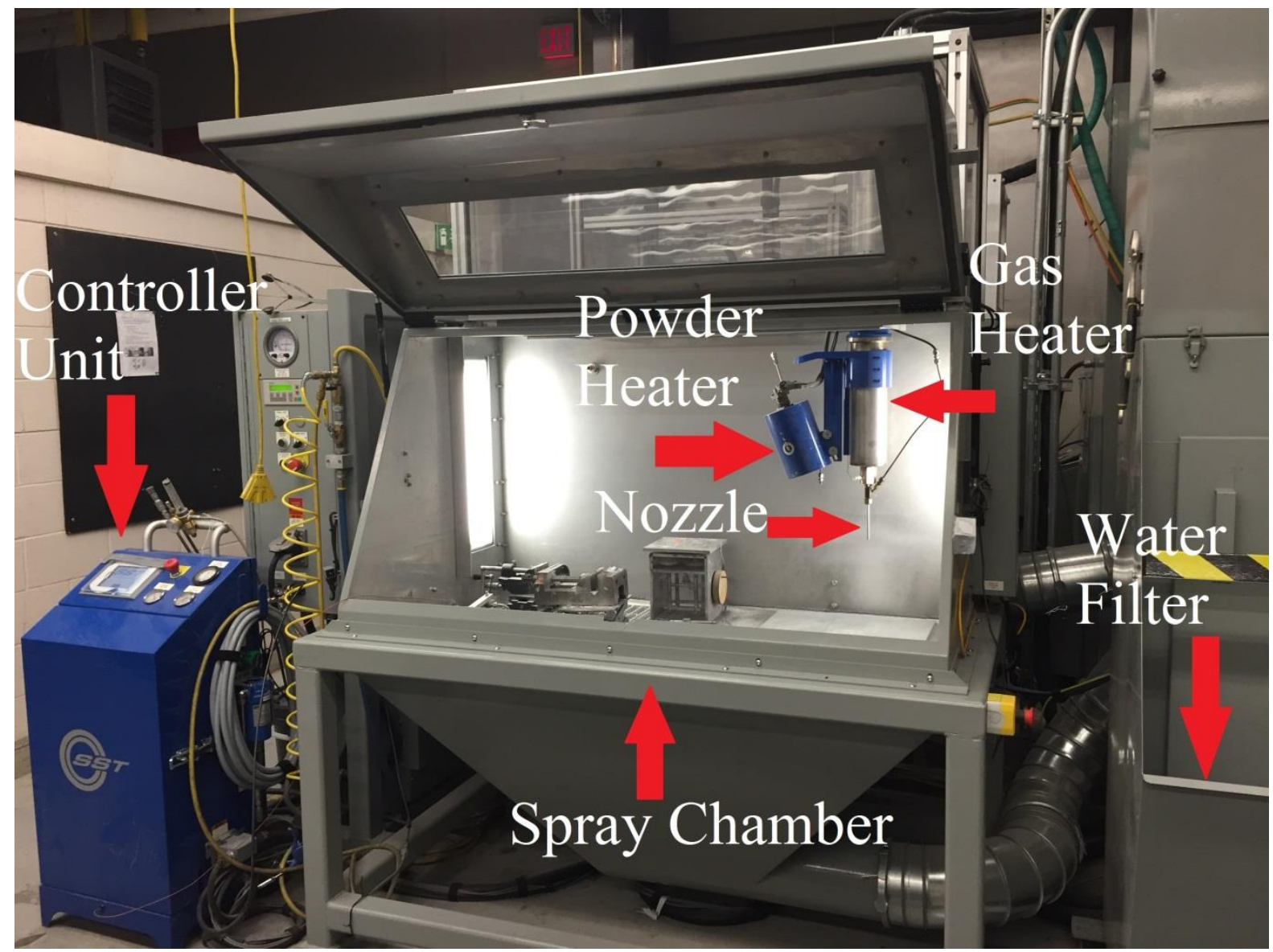

Figure 4.1 Low pressure cold spray system at the university of Ottawa laboratory

- Controller unit: Adjusts the stagnation pressure and temperature of the carrier gas. The controller unit is directly connected to the gas supply. 
- Powder filtering system: It operates based on suction of the air from the bottom of the spray chamber to transfer the non-deposit particles to the water container to prevent the release of particles in the air, for safety issues. Also, the leftover of the particles that did not trap in the water filter will be collected by an auxiliary air filter to ensure that no excess powder in remained in the air.

- Carrier gas bottle packs: The gas cylinders are connected in parallel to provide the highest possible consistency in the gas supply as fluctuations in the carrier gas pressure may cause changes in the results (Figure 4.2). 


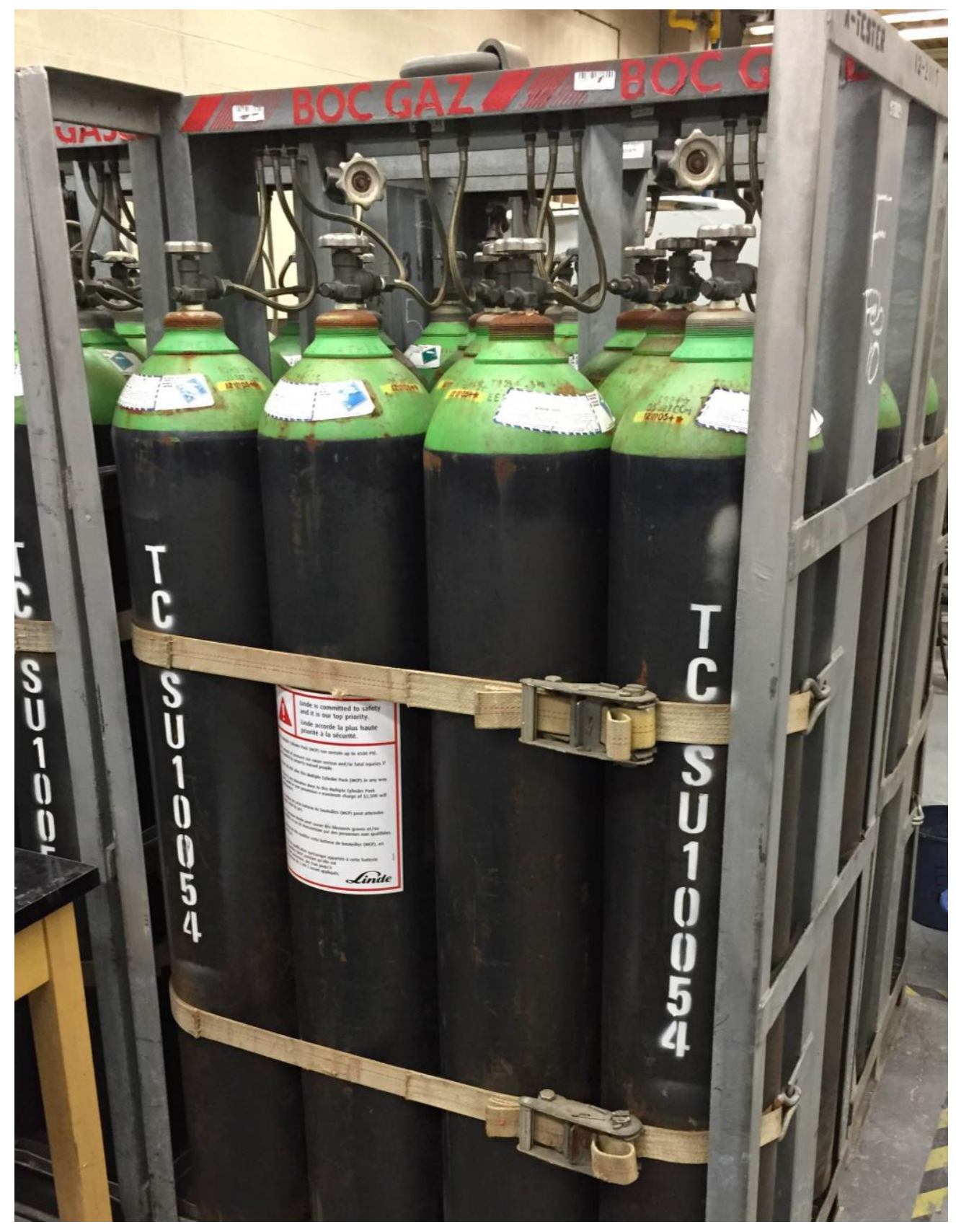

Figure 4.2 Nitrogen gas bottle packs

- Powder feeder: In order to adjust the amount of feedstock particles that is injected into the carrier gas flow, a powder feeder is used. Figure 4.3 shows the powder feeder used in this research. Particles in the feeder are kept in the canister where they mix 
with the gas supplied form the bottle packs. After particles are passed through a rotating wheel inside the canister, they are propelled and injected to the main carrier gas stream through the output shown in Figure 4.3.

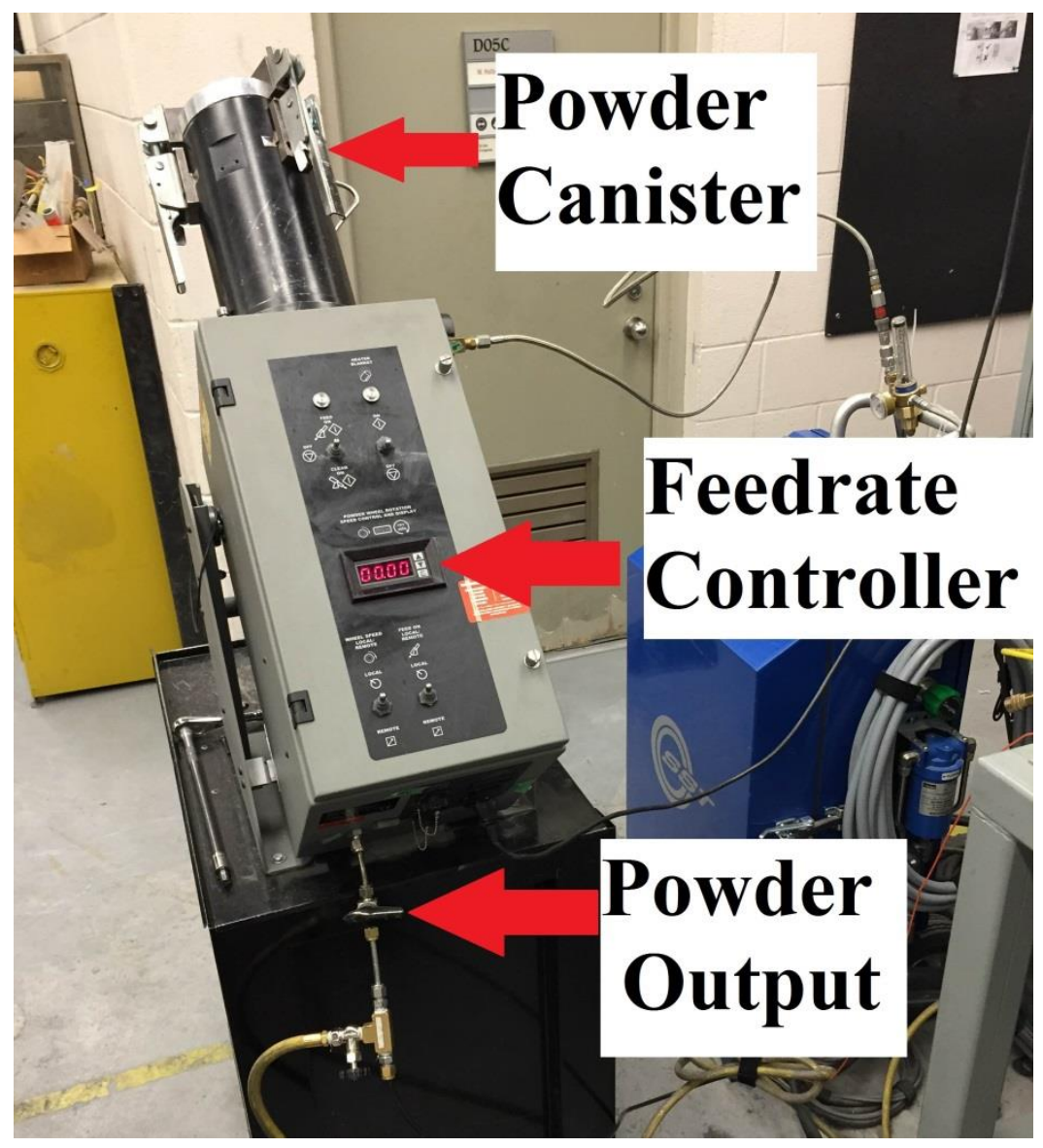

Figure 4.3 Powder feeder (Model 1264 from Praxair Surface Technologies)

- Nozzle: The role of the nozzle in the cold spray process is to accelerate the feedstock particles to achieve bonding of the particles to the substrate surface. The nozzle assembly (Figure 4.4) can be screwed in the gas heater of the spray gun. This nozzle 
assembly consists of tightening nut, brass orifice, collet and the heater nut. Two different nozzle materials are used in this study. A steel nozzle was used for producing samples that contain alumina particles and a polymer nozzle, with the same internal geometry, was used for producing pure aluminum samples to avoid clogging issues. One advantage of using polymer nozzles is that it prevents clogging when spraying pure aluminum. However, polymer nozzles wear out considerably faster than steel nozzles and are more expensive than steel nozzles by 2 order of magnitudes. Pure aluminum feedstock powder cannot be sprayed by steel nozzle due to fast clogging of the nozzle. This occurs because aluminum particles have a tendency to stick to the internal wall of the nozzle under higher temperatures. This results in local accumulation of the particles and consequently clogging of the nozzle, thus the requirement for using a polymer nozzle.

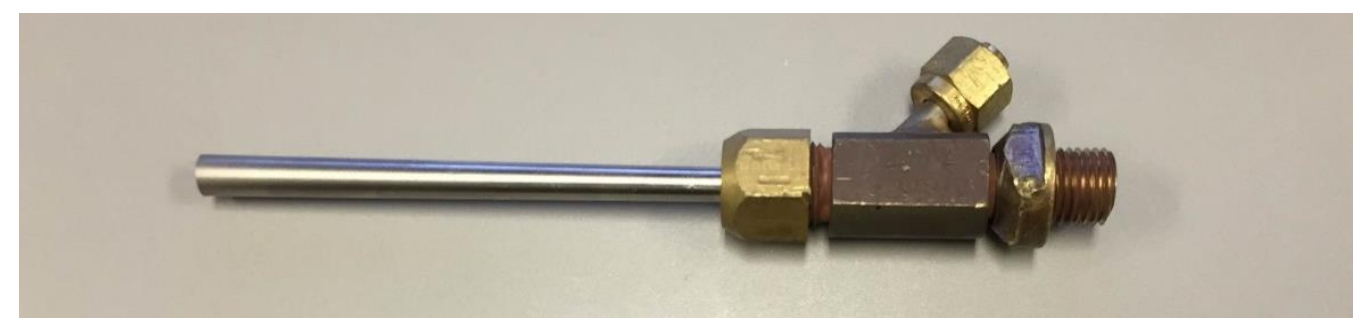

Figure 4.4 Steel nozzle assembly

\subsection{Manufacturing of Pyramidal Fins}

Pyramidal pin fins were deposited on aluminum substrates (Al 6061-T6) with pure aluminum and a blend of aluminum-alumina feedstock powders under commercial names of SSTA5001 and SST-A0050 (Centerline (Windsor) Ltd. (Windsor, ON, Canada)), respectively. 
For pure aluminum samples the nozzle inlet gas temperature and pressure were $350{ }^{\circ} \mathrm{C}$ and 1.7 $\mathrm{MPa}$, respectively, and the nozzle traverse speed was set to $30 \mathrm{~mm} / \mathrm{s}$. For aluminumalumina samples, the applied gas temperature and pressure were $300{ }^{\circ} \mathrm{C}$ and $2.0 \mathrm{MPa}$, respectively, with traverse speed of $50 \mathrm{~mm} / \mathrm{s}$. All of the samples were sprayed using nitrogen as the propellant gas and the nozzle / wire mesh mask distance was kept at $15 \mathrm{~mm}$.

In order to manufacture pyramidal pin fins a steel woven wire mesh mask (McMaster-Carr, Aurora, OH, USA) was placed between the spray nozzle and the substrate as a patterned selective obstacle as shown earlier in Figure 2.18.

The configuration of the fins results directly from the square grid pattern of the wire mesh screen. Using the mask makes fins built up aligned with the center of the mask holes with the pyramid pin fin's peak aligning with the holes of screened area. There is little to no deposition occurring on the substrate underneath the mask wires as the spray process is a line of sight process. In order to prevent vibrations induced by the spraying gas that could reduce the consistency of the manufacturing process, the mask was fixed tightly at the nominal distance with respect to substrate using a sample holder fixture. In this study the reported results associated with the rectangular fins sample are obtained from a machined bulk aluminum sample. In order to be able to compare the samples, rectangular fins were produced with the same fin density and hydraulic diameter as the pyramidal pin fins with fins height of $1.0 \mathrm{~mm}$. Figure 4.5 presents the typical fin arrays manufactured by the cold spray additive manufacturing technique. 


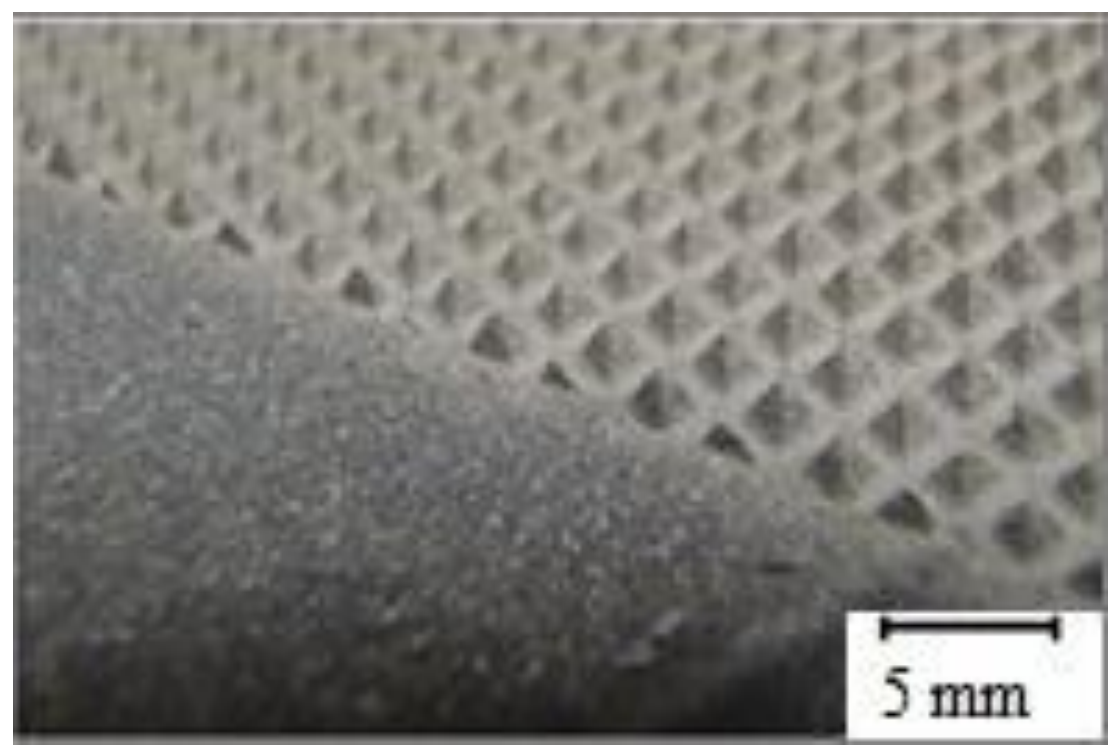

Figure 4.5 Pyramidal fin arrays produced with cold spray

\subsection{Sample Preparation and Analysis}

Pure aluminum and aluminum-alumina powders were mechanically mixed to produce feedstock powders with alumina volume percentage of $22 \%$ and $40 \%$. According to the literature, it has been shown that the percentage of retained alumina in the coating is smaller when the percentage of alumina in the feedstock increases [10]. For example increasing volume percentage of alumina in the feedstock powder from $40 \%$ to $67 \%$ ( approximately from $50 \%$ to $75 \%$ alumina weight percentage) only increase $0.02 \%$ of alumina volume percentage in the coating [10]. Therefore, in this study $40 \%$ and $22 \%$ volume percentage of alumina were picked to achieve a good deposition deficiency in order to better study the effect alumina particles in the pyramidal pin fins. Fin arrays were sprayed to an average height of $1.3 \mathrm{~mm}$ and ground down to the target height of $1.0 \mathrm{~mm}$ using a conventional 
sanding belt with 320 grit sandpaper. The height and spacing of the fins on the produced samples were measured using a digital 3D microscope (Keyence model VHX-2000, Mississauga, ON, Canada) shown in Figure 4.6.

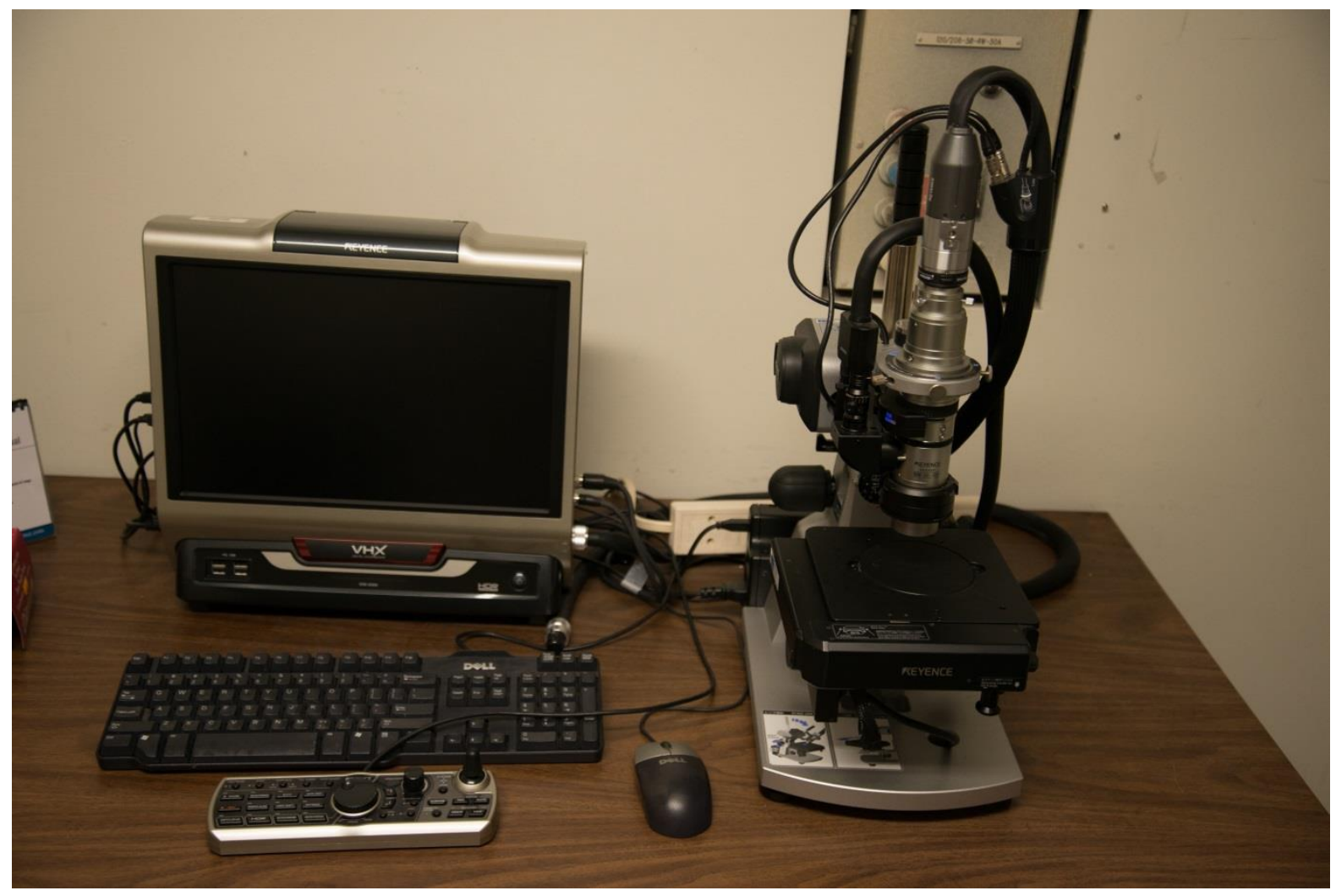

\section{Figure 4.6 Keyence VHX three dimension microscope}

These geometrical data were directly used when required in the heat transfer and pressure loss calculations. These geometrical parameters are illustrated in Figure 4.7 (a); B represents the pyramid base width, $S$ represents the distance between the base edges of neighboring fins (only half of this distance is shown in the Figure 4.7 (a) due to symmetric configuration of the fins) and $H$ represents the fin's height. Figure 4.7 (b) shows an actual 3D shape of a pyramidal fin. 


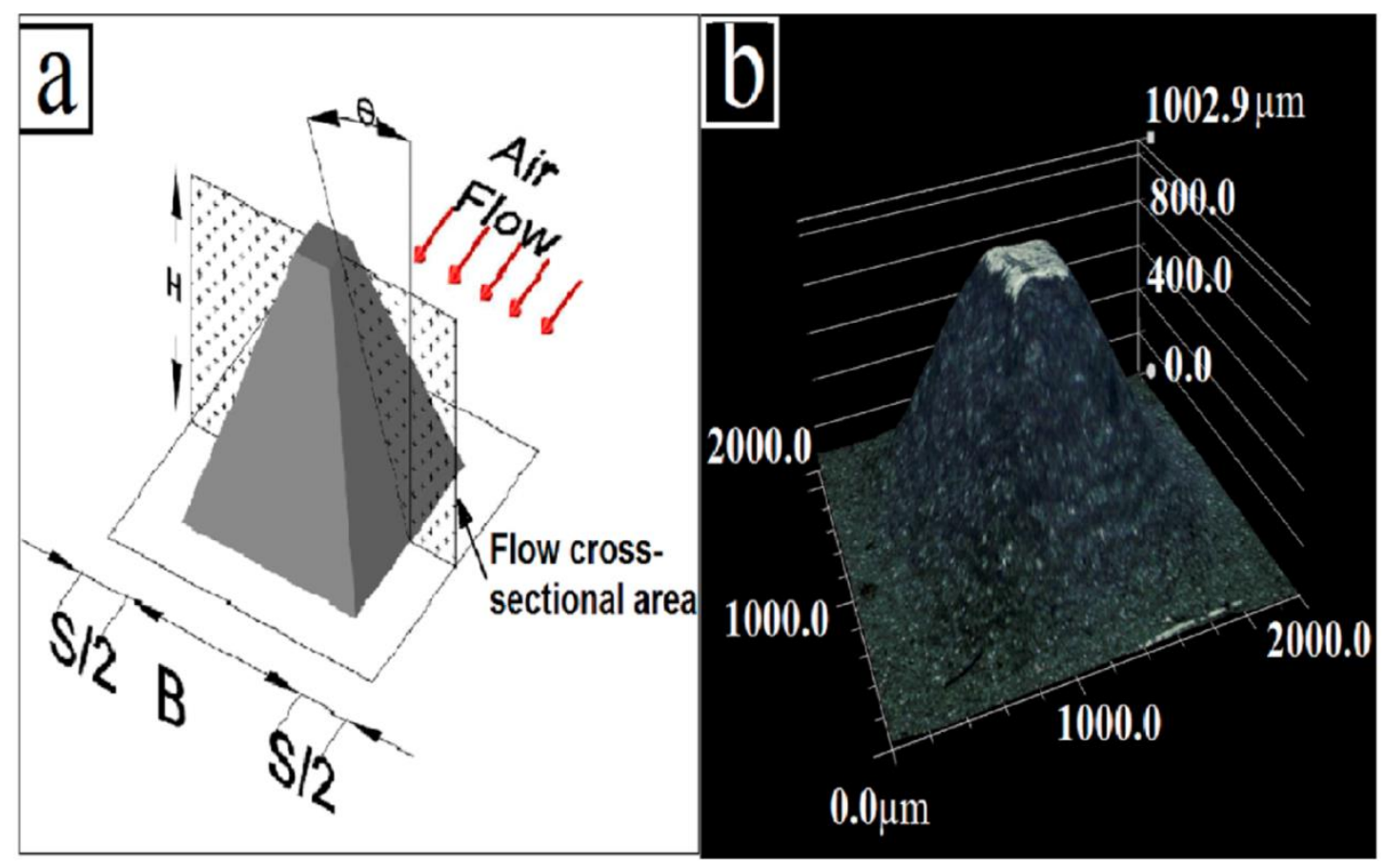

Figure 4.7 (a) Schematic view of one pyramid fin (b) Actual 3D shape of pyramid fin taken by 3D microscope

For calculations and simulations all of the fins have been considered as ideal pyramidal fins with the averaged geometric dimensions based on the actual fin measurements taken with the 3D microscope. It is clear that modeled (Figure 4.7 a ) and real (Figure 4.7 b ) pyramidal fin geometries made by cold spray will not have the exact same dimensions and geometries due to the physics of cold spray and the random adhesion of particles during the spraying process. After completion of the heat transfer and pressure loss tests, standard metallographic procedures were performed on the samples to produce cross-sections of the fins. These processes include cutting, mounting and polishing of the samples. Samples were cut using an automatic saw (Struers, Secotom-10) shown in Figure 4.8. After that samples 


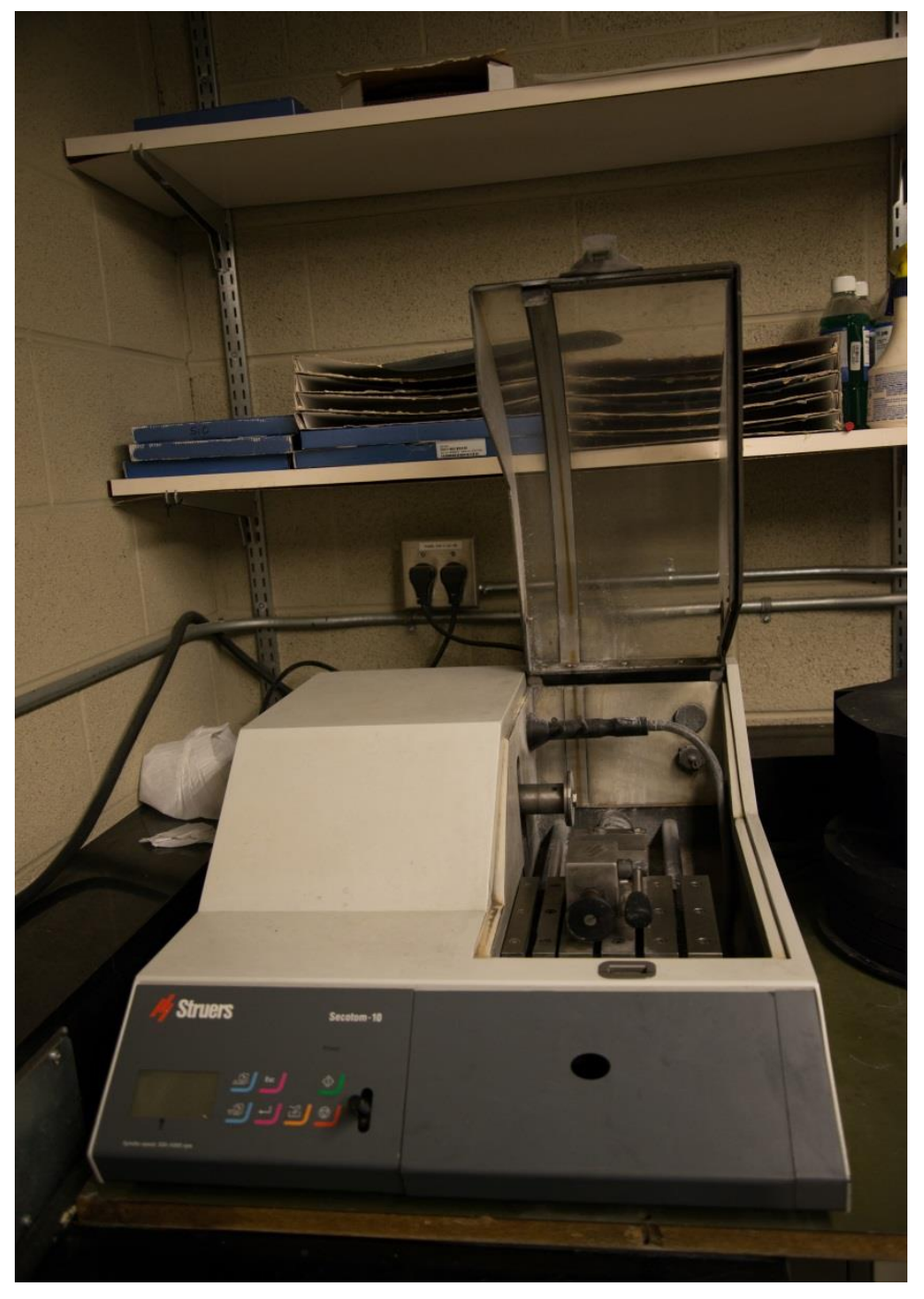

Figure 4.8 Cutting saw (Struers, Secotom-10)

were sectioned by the cutting saw they were mounted in a thermosetting epoxy resin (Struers LaboPress-3) shown in Figure 4.9. 


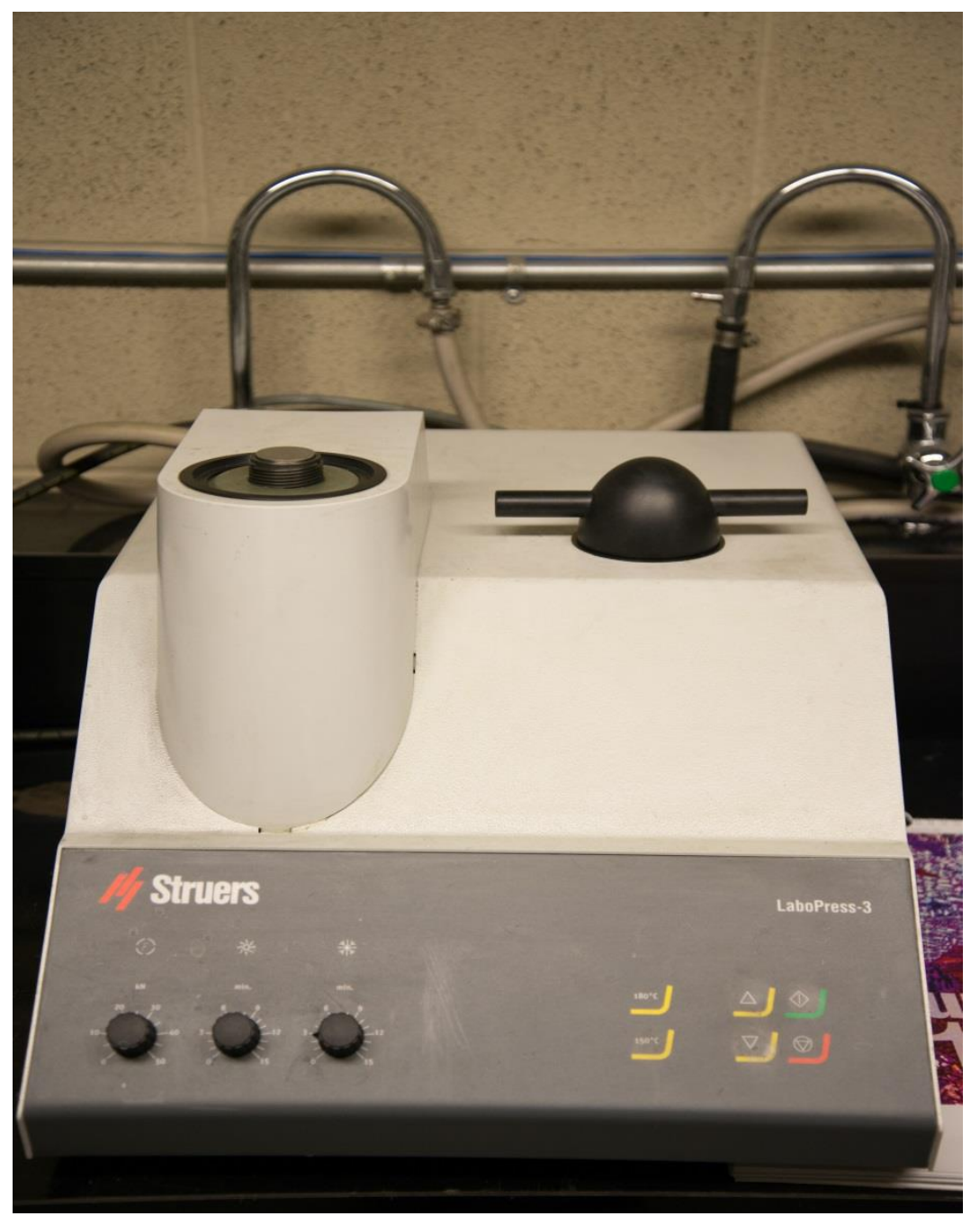

Figure 4.9 Thermosetting resin mounting machine (Struers LaboPress-3)

In the mounting process samples in the machine are compressed with the polymeric powder at the temperature of up to $150{ }^{\circ} \mathrm{C}$. When samples were mounted the polishing process was performed as the last step for sample preparation. Polishing process was performed using the machine shown in Figure 4.10. 


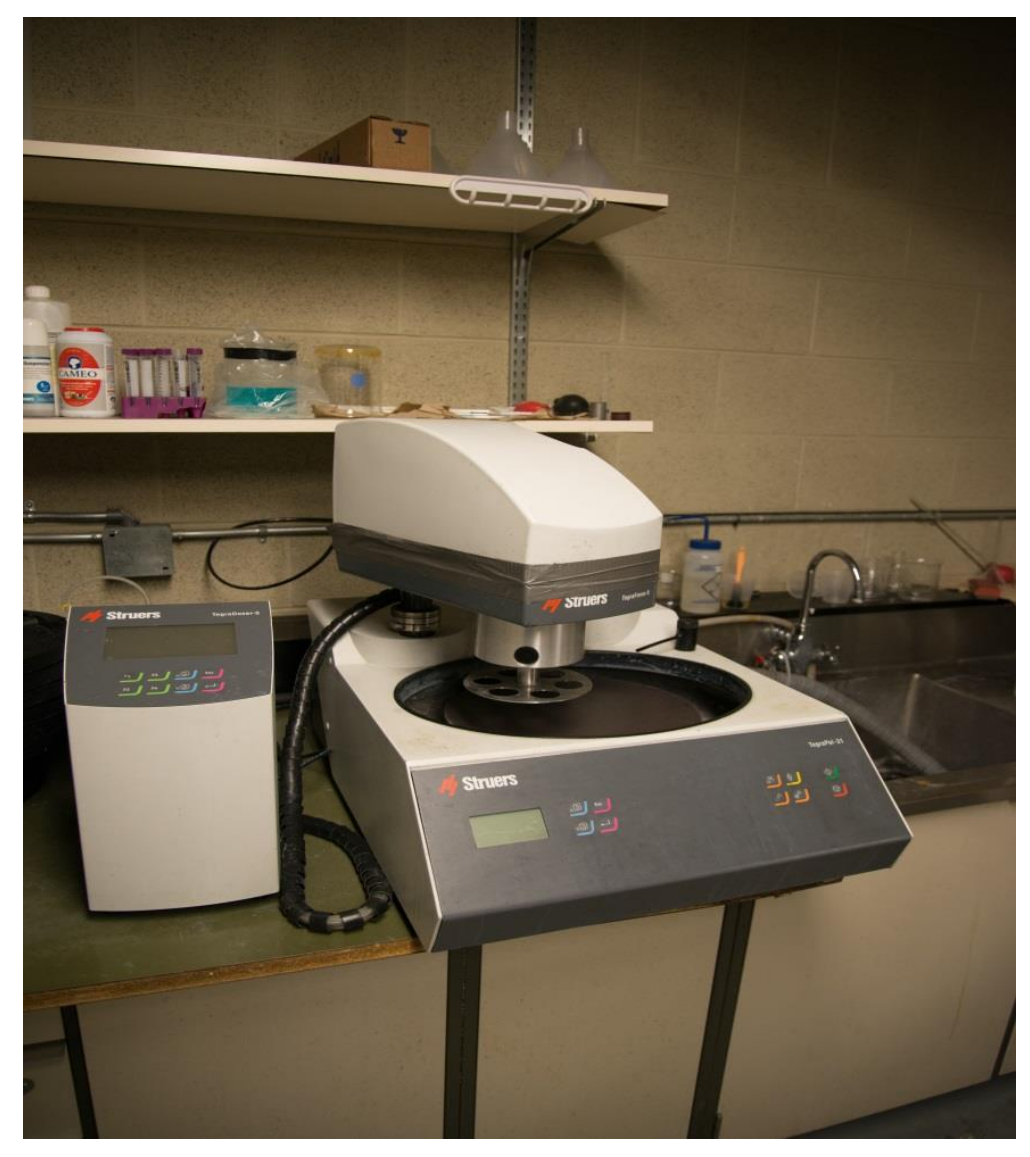

Figure 4.10 Polishing machine (Struers Tegrapol, TegraForce-5 and TegraDoser-5)

Figure 4.11 shows final product of preparation steps. The preparation steps must be taken in order to able to perform microstructural examination. 


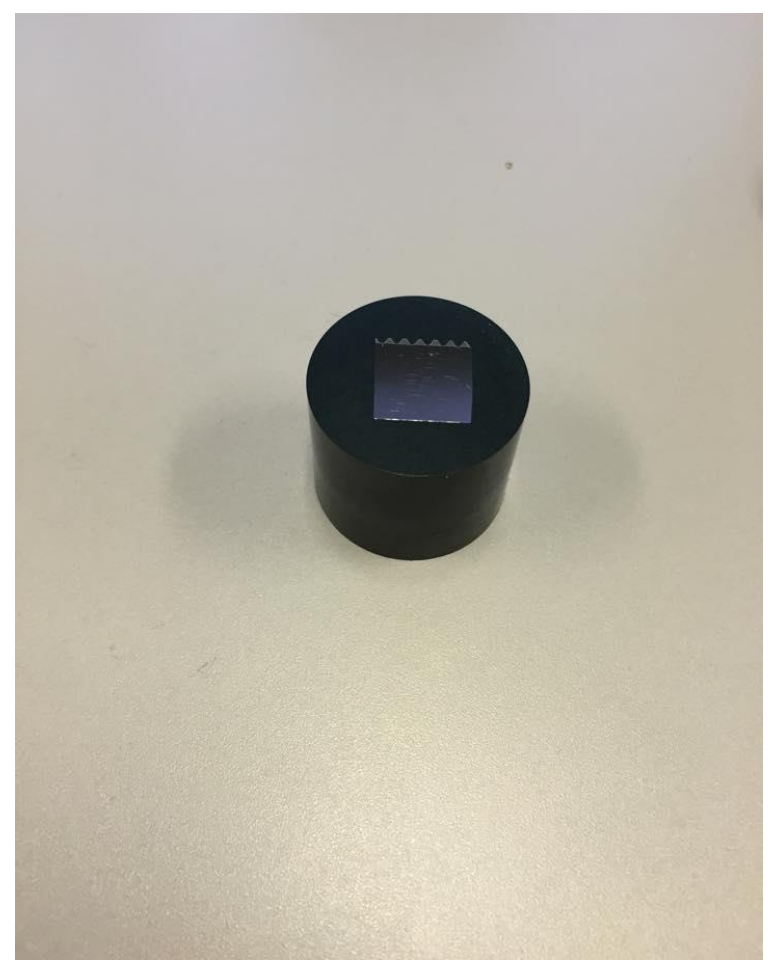

Figure 4.11 Example of polished sample embedded in polymeric resin

For microstructural examination an optical microscope (Kingdak NMM-800TRF) shown in Figure 4.12 was used. The proportion of alumina and aluminum contents were measured by differentiating colors of alumina and pure aluminum particles in the cross-section of the fins using Clemex Vision Lite (Clemex Technologies Inc., Longueuil, QC, Canada) image analysis software. It is assumed that a sample size of six fins is statically significant and adequately represents the alumina content throughout the entire fin array sample for the optical microscope microstructural examination process. 


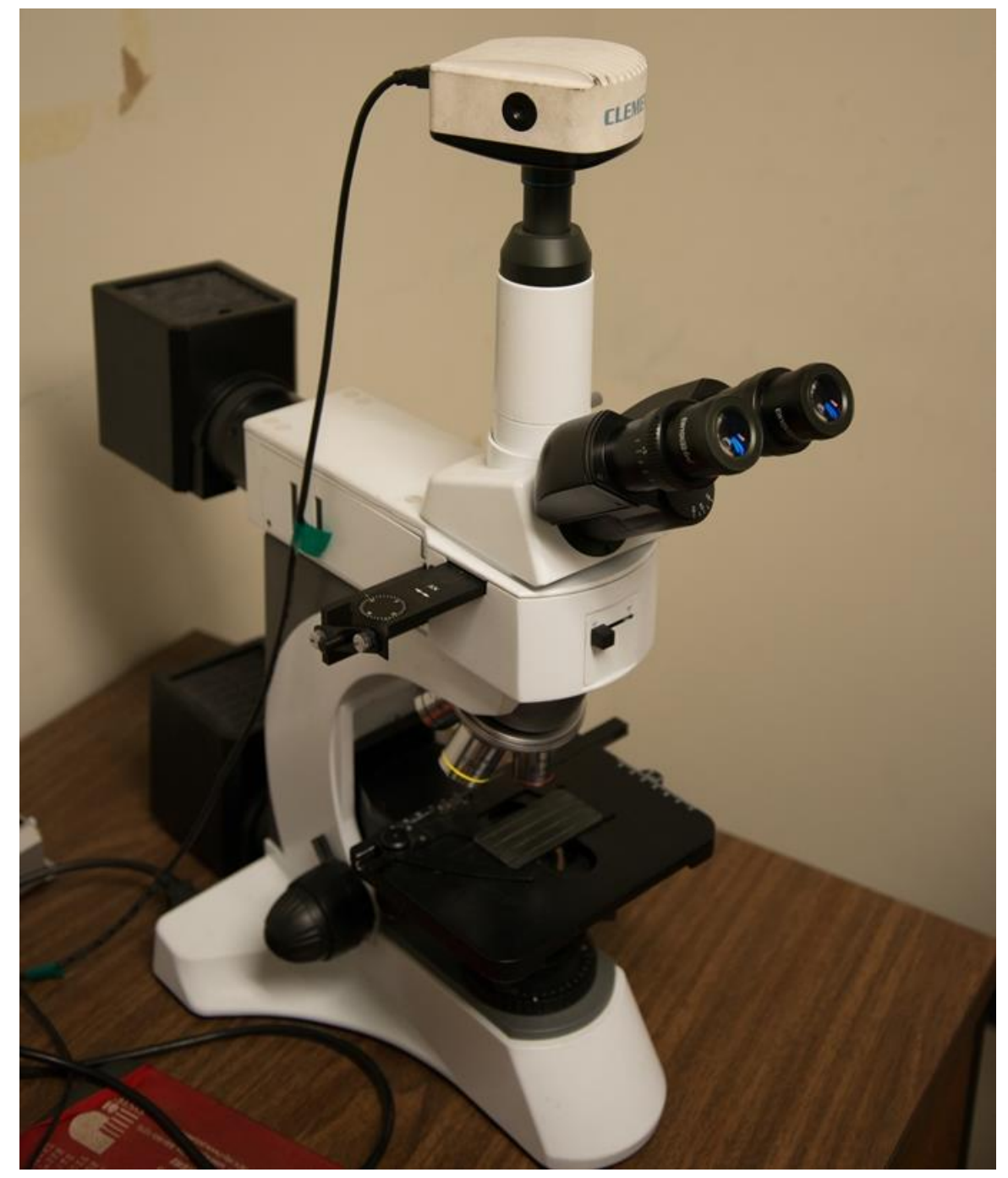

Figure 4.12 Kingdak NMM-800TRF Optical Microscope

\subsection{Heat Transfer Tests}

Figure 4.13 shows a schematic of the heat transfer experimental fixture. Flows matching different Reynolds numbers corresponding to typical industrial usage of CHE were used. 


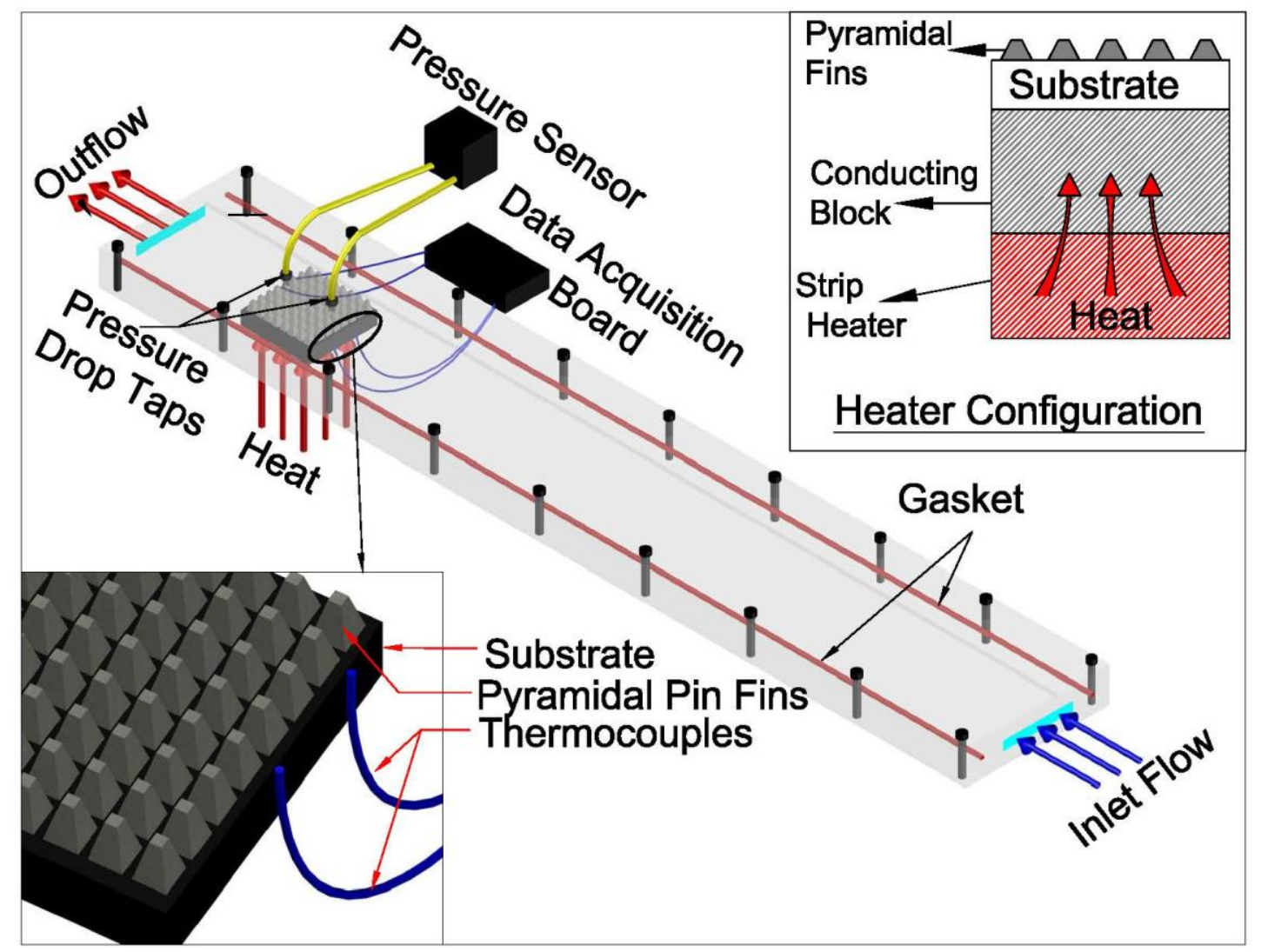

Figure 4.13 Schematic of the heat transfer fixture

Volume flow rates were measured using a flow meter (OMEGA, model FMA1612A) installed upstream of the fixture. Thermocouples were installed at the front and back of the sample in the heat transfer fixture to measure fin array's base temperature for both first and last array of fins perpendicular to the flow direction. For more result accuracy, two thermocouples were used on each side of the sample, one on the centerline of the sample, while the other one was located near the lateral side of the sample as shown in Figure 4.13. The inlet and outlet flow temperatures were measured using thermocouples immediately before and after the sample in the flow channel (not shown in Figure 4.13). 
Measurements took place once a steady-state regime was reached, with a total of five measurements taken at each flow rate to ensure the precision of the results. The error bars for figures in results section are not shown as the deviation of measurements from the mean value were less than $5 \%$ and the error bars were smaller than markers in each figure. Reynolds numbers ranging from approximately 400 to 2800 were tested. Through the entire heat transfer process a constant heating rate was applied from the thermal source at the bottom of the sample as illustrated in Figure 4.13. A strip heater was used as a thermal source as well as, a conducting block distribute the heat evenly onto the substrate's surface as shown in Figure 4.13.

To compare flow conditions associated with different flow rates, Reynolds number was used. The Reynolds number based on hydraulic diameter is calculated using Eq 4.

$$
R e_{D h}=\frac{\rho_{\text {air }} \cdot V \cdot d_{h}}{\mu}=\frac{\dot{m} \cdot d_{h}}{W \cdot F D \cdot A_{\text {flow }} \cdot \mu}
$$

where $\rho_{\text {air }}$ is the density of air, $V$ is the velocity of the air, $d_{h}$ is the hydraulic diameter, $\mu$ is the dynamic viscosity of the fluid, $W$ is the sample width, $F D$ is the fin density and $A_{\text {flow }}$ is the channel cross-sectional area that air flows through. Also, $d_{h}$ could be calculated by considering the pyramid geometry in Figure 4.7 as shown in Eq 5.

$$
d_{h}=\frac{4 \cdot A_{\text {flow }}}{P_{\text {flow }}}=\frac{2 \cdot A_{\text {flow }}}{\frac{H}{\cos (\theta)}+S+H \cdot \tan (\theta)}
$$




$$
A_{\text {flow }}=(S+H \cdot \tan (\theta))
$$

$P_{\text {flow }}$ is considered as the pyramid's wetted perimeter by the passing air. The parameters $S, H$ and $\theta$ are shown in Figure 4.7.The heat transfer rate $q$ that the passing flow will receive from the surface of the sample, including the pyramid's surfaces and the area between pyramids, can be determined using Eq 7 .

$$
q=\dot{m} \cdot\left(T_{\text {out }}-T_{\text {in }}\right) \cdot C_{p}
$$

with $\dot{m}$ as mass flow rate, $T_{\text {out }}-T_{\text {in }}$ as the overall temperature difference upstream and downstream of the sample, and $C_{p}$ as the specific heat capacity. To calculate the heat transfer value, $T_{i n}$ and $T_{\text {out }}$ were measured by installed thermocouples downstream and upstream of the sample in the fixture, respectively. For the convective heat transfer coefficient we have the relation shown in Eq 8.

$$
h=\frac{q}{\Delta T_{l m} A_{t o t} \eta_{o}}
$$

with $A_{\text {tot }}$ as the total heat transfer area, $\Delta T_{l m}$ the log-mean temperature difference, and $\eta_{o}$ as the overall surface efficiency as derived below in Eq 9 and 10, respectively.

$$
\Delta T_{l m}=\frac{\Delta T_{1}-\Delta T_{2}}{\ln \left(\frac{\Delta T_{1}}{\Delta T_{2}}\right)}
$$




$$
\eta_{o}=1-\frac{A_{f}}{A_{t o t}}\left(1-\eta_{f}\right)
$$

In Eq 9, $\Delta T_{1}$ and $\Delta T_{2}$ are temperature gradient between fin surfaces and cooling air at entrance and exit, respectively. In Eq 10, $\eta_{f}$ characterizes the single fin efficiency as shown in $\mathrm{Eq} 11$.

$$
\eta_{f}=\frac{2}{m H} \frac{I_{2}(2 m H)}{I_{1}(2 m H)}
$$

with:

$$
m=\sqrt{\frac{4 H}{k_{m} B}}
$$

$H$ denotes the fin height, $I_{1}$ and $I_{2}$ represent first and second order Bessel functions respectively, $k_{m}$ is thermal conductivity of the fins and $B$ is the size of fin's base which is indicated in Figure 4.13. By using the above relations ( adopted from Incropera's work [2] the performance of a fin array can be evaluated considering all important aspects of performance.

One of the important factors in evaluating performance of a CHE is the overall heat transfer coefficient. The overall heat transfer coefficient, or thermal conductance, is associated to the total thermal resistance of the fins $\left(R_{e q}\right)$. This parameter can be derived as shown in Eq 13.

$$
U A=\frac{1}{R_{e q}}=h \cdot A_{t o t} \cdot \eta_{o}
$$


In order to obtain $U A$ per unit volume the thermal conductance value from Eq 13 is simply divided by the total volume as shown in Eq 14 .

$$
U A_{V}=\frac{U A}{V}
$$

\subsection{Pressure Loss Tests}

The pressure head loss through the fin arrays has been measured using the fixture presented in Figure 4.13. Five consecutive measurements were obtained for Reynolds numbers in the range of 400 to 2800 using two pressure taps as shown in Figure 4.13. The pumping power per unit volume from Sahiti's work [66] can be written as shown in Eq 15.

$$
e_{v}=\frac{\dot{V}_{f} \cdot \Delta P_{f i n}}{\eta \cdot V}
$$

with $\dot{V}_{f}$ as the volumetric flow rate of the fluid, $\Delta P_{f i n}$ as the pressure difference created by each fin, $V$ as the volume of the fin array, and $\eta$ as the fan efficiency. In this study $\eta$ was assumed to be 0.8 which is taken from Sahiti's [66] work as standard value for this category of fans in industry. 


\section{Simulation Approach}

A Computational Fluid Dynamics (CFD) model was developed using the commercially available software Fluent. Computational simulations allow a better understanding of the fluid flow's interaction with the fin arrays that otherwise requires the use of complex flow visualisation techniques. The use of CFD tools is useful when trying to design improved fin geometries and compositions to increase efficiency.

The mass, momentum and energy equations were solved using a coupled implicit scheme. The flow was assumed to be in a steady-state regime and incompressible. All of the surrounding surfaces of the domain are taken as adiabatic to be consistent with the experimental set-up, except for the inlet, outlet as well as the substrate's base where the heating rate is applied. At the domain inlet, the flow was assumed to be uniform and normal to the inlet cross-section. The pressure at the outlet was considered as atmospheric pressure. The effect of gravity on the flow was neglected. The applied boundary conditions are listed in Table 5.1.

In the simulation, each sample was subjected to three different mass flow rates $\left(4.0 \times 10^{-4}\right.$

$\mathrm{kg} / \mathrm{s}, 8.0 \times 10^{-4} \mathrm{~kg} / \mathrm{s}, 1.4 \times 10^{-3} \mathrm{~kg} / \mathrm{s}$ ) in order to evaluate the influence of flow regime on performance of the pin fins. The three values for flow rates that were used were selected based on the actual applied flow rates in experiments. Experiments involved more than just the three chosen flow rates for each sample but these additional cases were not simulated. 


\begin{tabular}{|l|l|}
\hline Boundary & Applied boundary condition \\
\hline Flow channel inlet & Mass flow rate (uniform profiles) \\
\hline Flow channel outlet & Pressure (atmospheric pressure) \\
\hline Flow channel top side, substrate front & Insulated \\
\hline Flow channel and substrate lateral sides & Symmetry \\
\hline Substrate bottom side & Heat flux known \\
\hline
\end{tabular}

Table 5.1 Simulation boundary conditions

For the laminar regime (flow rate of $4.0 \times 10^{-4} \mathrm{~kg} / \mathrm{s}$ ) and turbulent regime (flow rates of $8.0 \times 10^{-4} \mathrm{~kg} / \mathrm{s}$ and $\left.1.4 \times 10^{-3} \mathrm{~kg} / \mathrm{s}\right)$, the laminar and $\mathrm{k}-\omega$ models were used, respectively. For the k- $\omega$ model, a turbulent kinetic energy of $1 \mathrm{~m}^{2} / \mathrm{s}^{2}$ and a turbulent dissipation rate of 1 $\mathrm{m}^{2} / \mathrm{s}^{3}$ were picked as boundary conditions. These values were picked because for the range of the applied Reynolds number it was assumed that the total fluid shear and the friction between the flow and the surfaces is negligible. The k- $\omega$ model was used instead of the k- $\varepsilon$ model due to better performance of $\mathrm{k}-\omega$ model in flow separation behind fins and curved streams in recirculation zones [67].

The thermal conductivity $\mathrm{k}_{\mathrm{m}}$ of the fins in each sample varies according to the volume percentage of alumina. Litovky et al. [68] performed experimental measurements on similar cold spray samples. In the cited work, coated samples were produced by deposition of coating on both sides of a metallic plate with known mass and specific heat (sample 
sandwich). Coated and uncoated samples with the same dimensions were immersed in liquid nitrogen in order to measure the cooling rate of the samples as well as the heat flux passing through the coatings. The temperatures of the center of sample sandwich and of the surfaces were also measured [68]. Obtaining heat flux passing through the coating in the coated sample, external heat transfer coefficient of uncoated sample and associated temperatures at outer surface and center of the sample made determination of the thermal conductivity coefficient possible [68]. The values for $\mathrm{k}_{\mathrm{m}}$ used in the current work were adapted from those proposed by Litovsky et al. [68]. When the data could not be found directly in the cited work, a linear interpolation between the closest values was used. More details on process and determination of thermal conductivity can be found in Litovsky et al. [68]. The applied $\mathrm{k}_{\mathrm{m}}$ values for pure aluminum, $22 \%$ and $40 \%$ volume percentage of alumina in the model are $1.14,0.87$ and $0.71 \mathrm{~W} /(\mathrm{m} \cdot \mathrm{K})$.

For the solution domain, both the solid zone (pyramids and the base of the sample) and the fluid zone (flow) were modeled in three dimensions. The modeled fin dimensions are taken has the average values from 3D microscope measurements of the three sprayed samples for 25 random fins within each sample. The domain includes a single row of 25 pyramidal fins. Since the sample could be considered symmetric along the flow direction only one half row has been modeled using a symmetry plane to reduce the computation time required. Figure 5.1 represents the arrangement of pyramids and the sample's base in the computational domain. The red plane in Figure 5.1 is the symmetry plane within the domain which continues until the bottom of the base. The domain was discretized using tetrahedral volume mesh using the commercially available software Gambit. The whole domain was meshed into 169914,379547 and 577263 nodes in order to check grid independency of the 
solution. The differences in the results were less than $1 \%$ (the detailed values are given in Appendix I), therefore the grid with 169914 nodes was picked for final calculations in order to minimize the calculations time. The solution results for the average pressure and temperature at the outlet were monitored to prove the convergence of the model. The consistency at the end part of each graph demonstrates that the values are reached to the stable level where the results will not change in further iterations. This information is displayed in Appendix II as convergence history graphs. The convergence criteria for absolute residuals was set to maximum of $10^{-6}$.

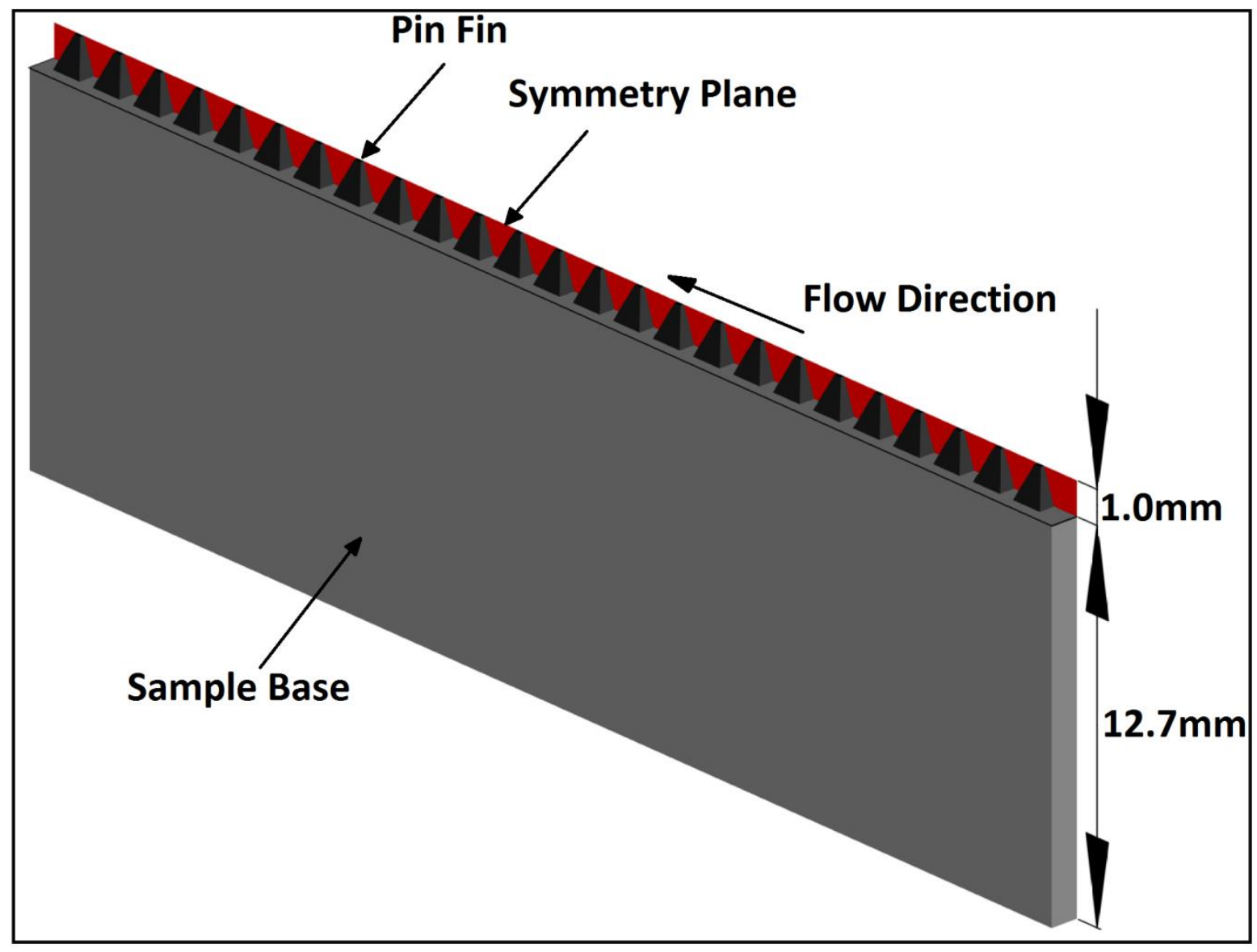

Figure 5.1 Arrangement of the model 


\section{Results}

\subsection{Experimental Results}

The content of alumina in the fins produced using the feedstock powders containing $22 \%$ and $40 \%$ volume percentage of alumina was measured to be $19 \%$ and $29 \%$ respectively. This is attributed to the fact that alumina particles cannot be deposited onto alumina particles which are already incorporated into the coating and they simply bounce off due to lack of deformation of alumina [10]. Figure 6.1 (a) illustrates cross-section image of pure aluminum sample where Figure 6.1 (b) and (c) illustrate cross-sectional images of aluminum-alumina samples obtained when using the $22 \%$ and $40 \%$ volume percentage alumina content feedstock powders. The darker spots in the Figure 6.1 (b) and (c) correspond to alumina particles. From Figure 6.1 (b) and (c) it can be observed that the alumina particles have been uniformly distributed within the fins. Also the mean geometrical values measured using the 3D microscope for all of the manufactured samples are listed in Table 6.1.

\begin{tabular}{|c|c|c|c|}
\hline Parameter & $\mathbf{B}(\boldsymbol{\mu m})$ & $\mathbf{S} / \mathbf{2}(\boldsymbol{\mu m})$ & $\mathbf{H}(\boldsymbol{\mu m})$ \\
\hline Pure aluminum & $1369 \pm 85$ & $380 \pm 64$ & $1038 \pm 21$ \\
\hline $\mathbf{1 9 \%}$ alumina & $1483 \pm 60$ & $309 \pm 23$ & $1029 \pm 14$ \\
\hline $\mathbf{2 9 \%}$ alumina & $1272 \pm 85$ & $394 \pm 29$ & $1169 \pm 19$ \\
\hline
\end{tabular}

Table 6.1 Geometrical values of pyramidal fins measured with 3D microscope 


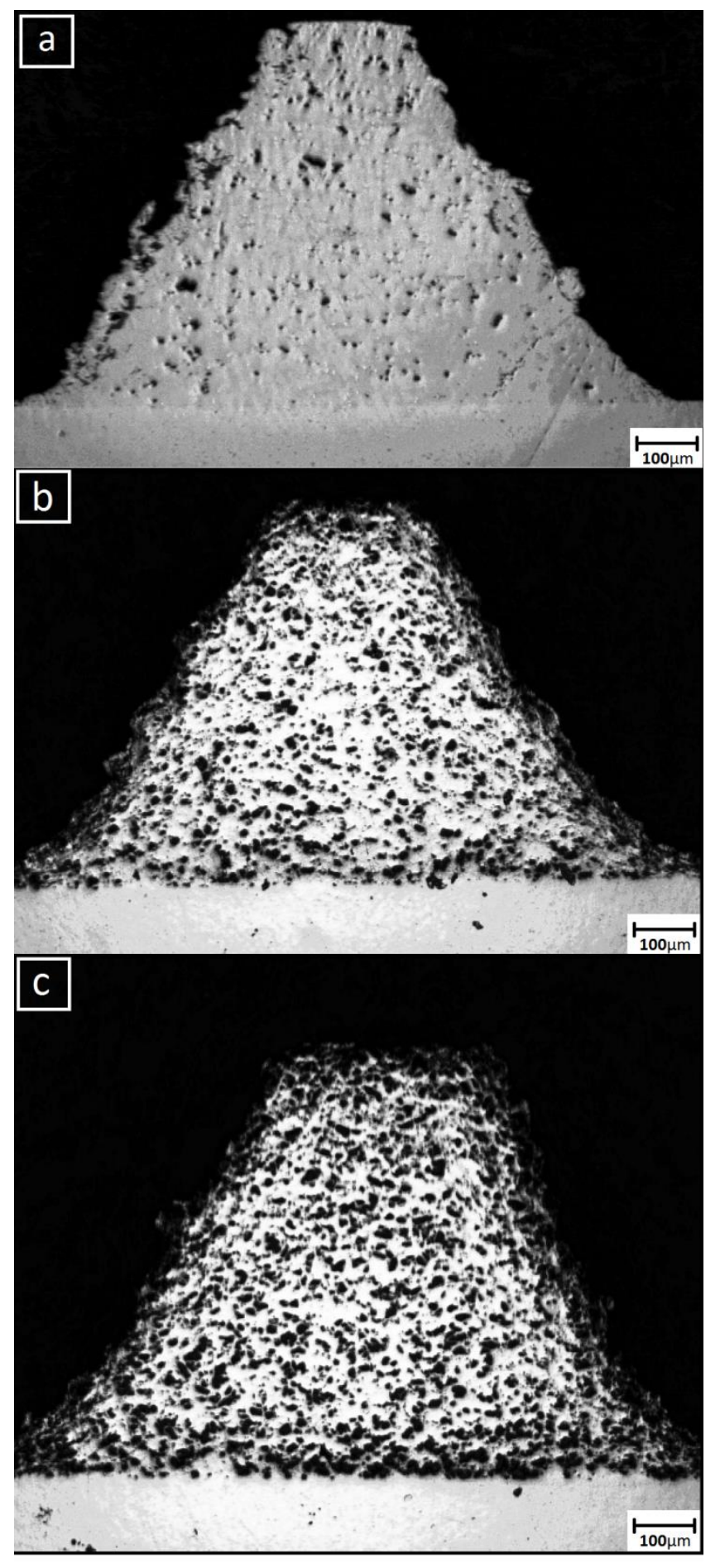

Figure 6.1Cross-sectional view of sprayed fin using optical microscope (a) Pure aluminum (b) $19 \%$ volume fraction of alumina particles (c) $29 \%$ volume fraction of alumina particles 
The overall heat transfer coefficient $U A$ as a function of Reynolds number for each sample is shown in Figure 6.2. These results show that by increasing the Reynolds number the corresponding overall heat transfer coefficient $U A$ for each sample increases linearly for both laminar and transition regimes. Increasing the Reynolds number from a laminar to a transition regime causes the interruption in thermal boundary layer and turbulent level enhancement occurs [69].

These results are in agreement with Žukauskas [70] theory for a bank of tubes, where at low Reynolds numbers $\left(\mathrm{R}_{\mathrm{Dh}}<1000\right)$ the flow is identified as predominantly laminar with large scale vortices in the zone behind the tubes. By increasing Reynolds number $\left(1000<R_{\mathrm{Dh}}<\right.$ 10,000) the flow remains largely laminar but the level of turbulence behind the fins increases. In this regime the flow can be considered as in transition between predominantly laminar and turbulent. This trend continues until small vortices appear in the recirculation zone and the flow transitions to turbulent $\left(R_{D h}>200,000\right)$. In the current study, the shift in the flow regime from predominantly laminar to the appearance of transition seems to occur near $1000 R_{D h}$ and $1500 R_{D h}$, where in Figure 6.2 the slope for each sample slightly changes near this Reynolds number. 


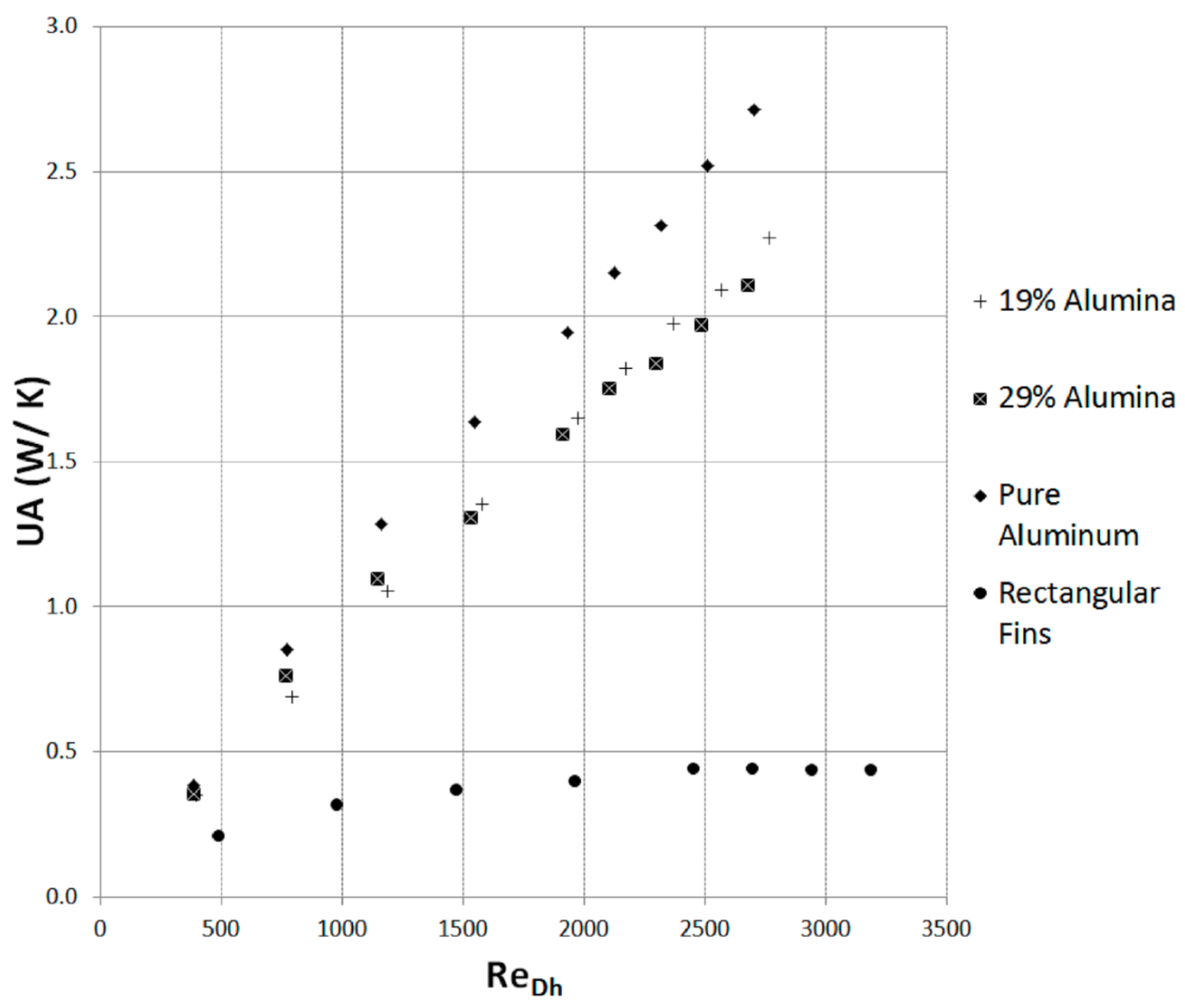

\section{Figure 6.2 Comparison of overall heat transfer coefficient associated with different alumina volume fractions}

A decrease of $U A$ was observed for both fin arrays containing alumina particles when compared with the pure aluminum fin array. It is also noticed that both alumina containing fin arrays have very similar $U A$ values with a limited variance compared to each other. The drop in the $U A$ values of alumina containing samples never exceeds more than $23 \%$ for the studied samples and the difference is more predominant for the higher Reynolds number (passed the onset of transition flow). This drop in $U A$ values between the pure aluminum 
sample and the alumina containing samples is attributed to the presence of low thermal conductivity alumina particles affecting the thermal conduction path in the pin fins. Although the presence of alumina particles caused a drop in the $U A$ values when compared to the pure aluminum sample, the performance of alumina containing pyramidal fins was shown to significantly exceed the performance of the traditional fins.

Figure 6.3 illustrates the overall performance of the produced samples and also rectangular fins sample. The overall efficiency increased in all samples when the pumping power was increased. The trends showed in Figure 6.3 again indicate that alumina particles in the fin arrays affect the overall efficiency of the samples when compared with pure aluminum and a slight difference between the two alumina containing fin arrays can be observed. Reductions in performance of the alumina containing samples are more noticeable beyond the laminar regime. 


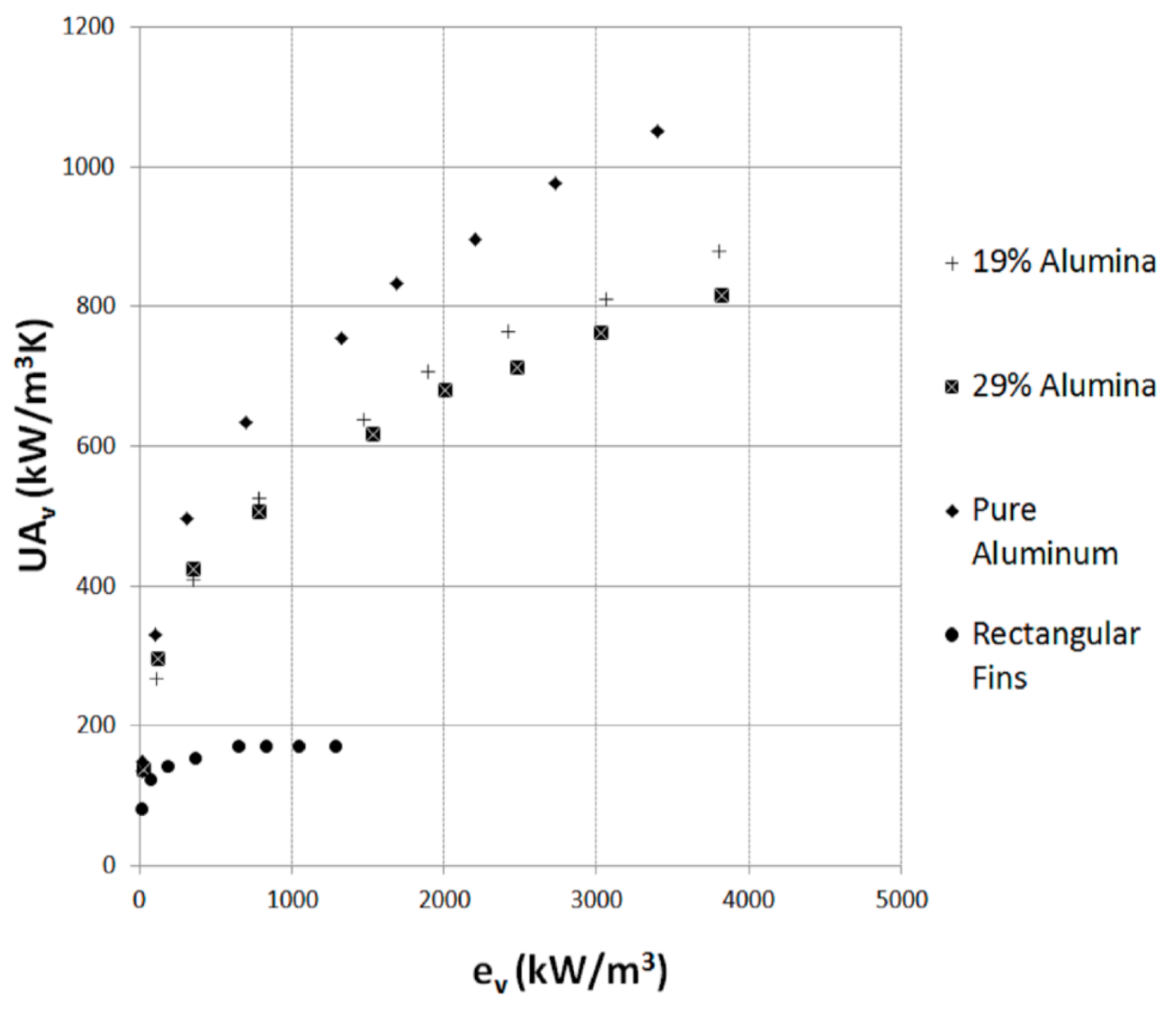

Figure 6.3 Comparison of different sample's volume based heat transfer surface efficiency for different alumina volume fractions

Although this reduction can be considered as important, the aluminum-alumina fins are still outperforming traditional fins to a large extent. In addition, the pressure loss along the pyramidal fins is nearly unaffected by the alumina contents. This can be concluded from Figure 6.4 where for the produced samples the results of pressure loss along the fins are almost the same. This was expected since the internal composition of the fins cannot affect the flow structure in the channels. 


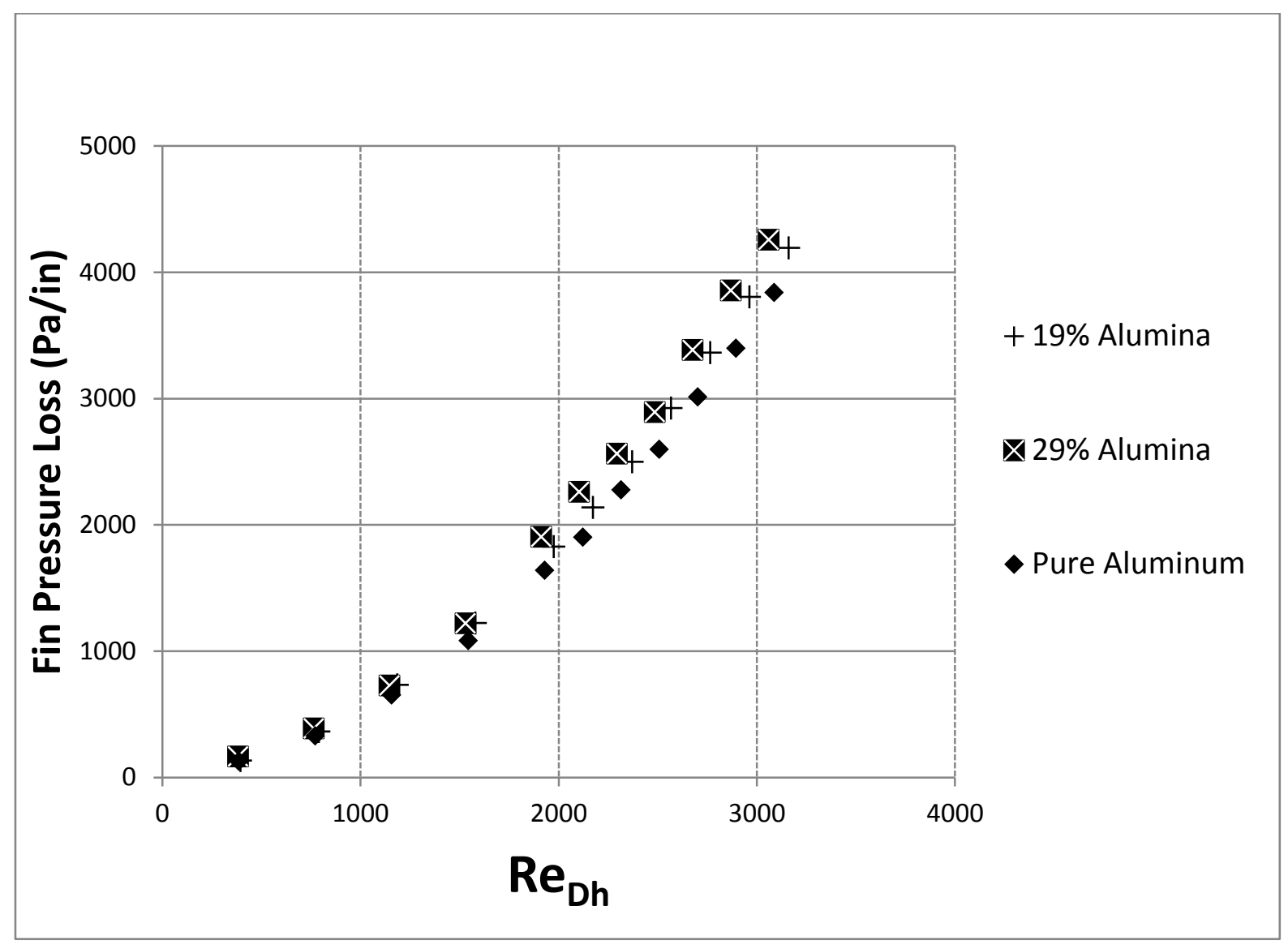

Figure 6.4 Fin pressure loss as a function of Reynolds number

\subsection{Simulation Results}

A fin array of pure aluminum and a fin array for each associated sample containing alumina were modeled. For each case the previously obtained experimental values listed in

Table 5.1 were used in the model as the boundary conditions. The values used for each modelling case is brought in Appendix III. The modeling results are illustrated in Figure 6.5, where typical temperature contours for three modeled fin arrays at mass flow rate of 
$8.0 \times 10^{-4} \mathrm{~kg} / \mathrm{s}$ with varied alumina percentage are compared. The direction of the applied heat and the flow is as shown for all of the samples.

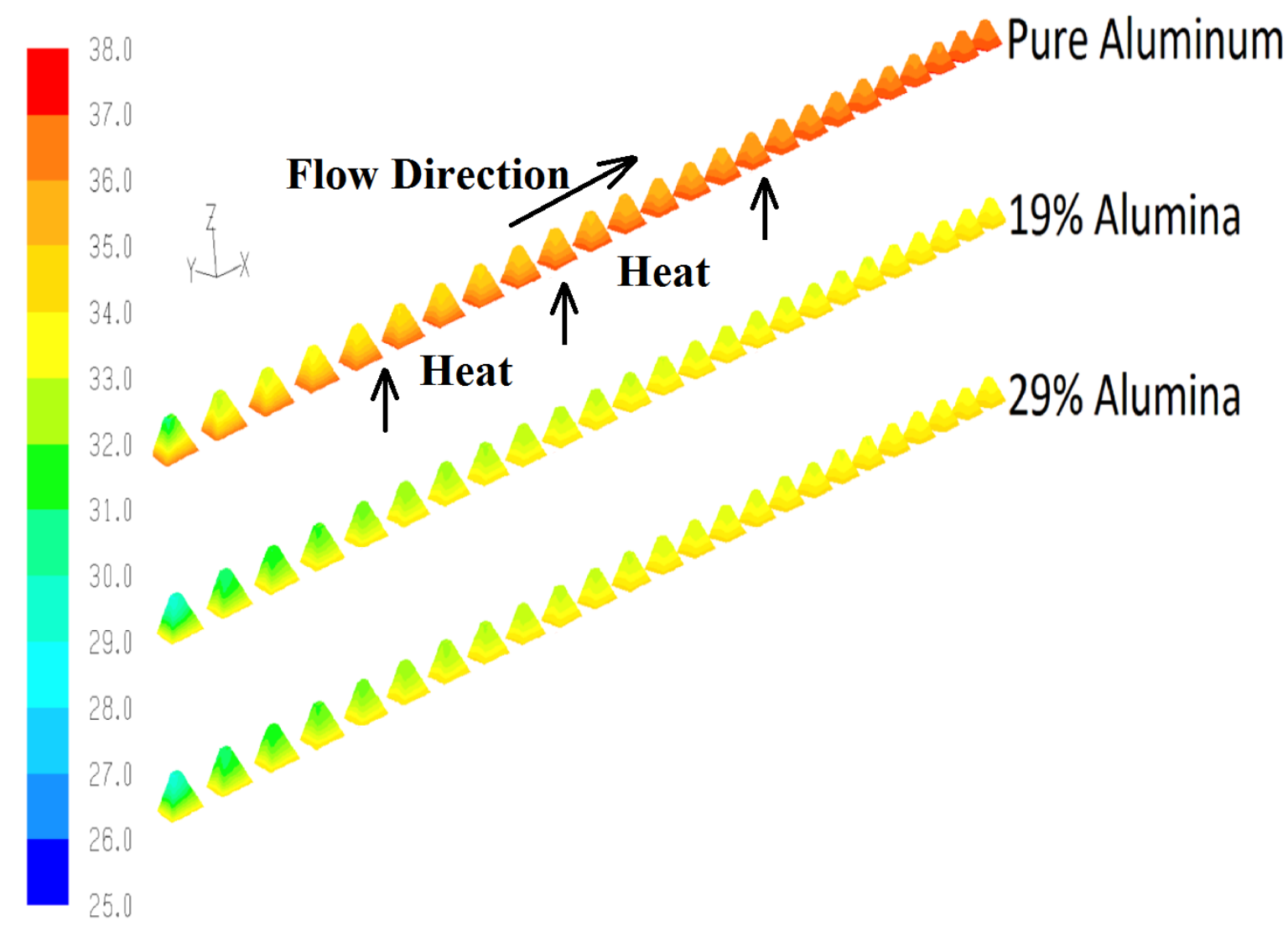

Figure 6.5 Temperature $\left({ }^{\circ} \mathrm{C}\right)$ contours with mass flow rate of $8.0 \times 10^{-4} \mathrm{~kg} / \mathrm{s}$ for the pure aluminum, $\mathbf{1 9 \%}$ volume fraction alumina and $29 \%$ volume fraction alumina pin fins. The fin temperature scale is on the left

These results defined the thermal behaviour of each sample with respect to alumina volume fraction values. The same trend was observed for other flow rates. From Figure 6.5 one can observe that the pure aluminum fins attain relatively higher temperatures than the samples containing alumina. This result shows that the presence of alumina particles slightly affects 
the thermal performance of the fins. In addition, the flow temperature as it passes through the fins is shown in Figure 6.6.

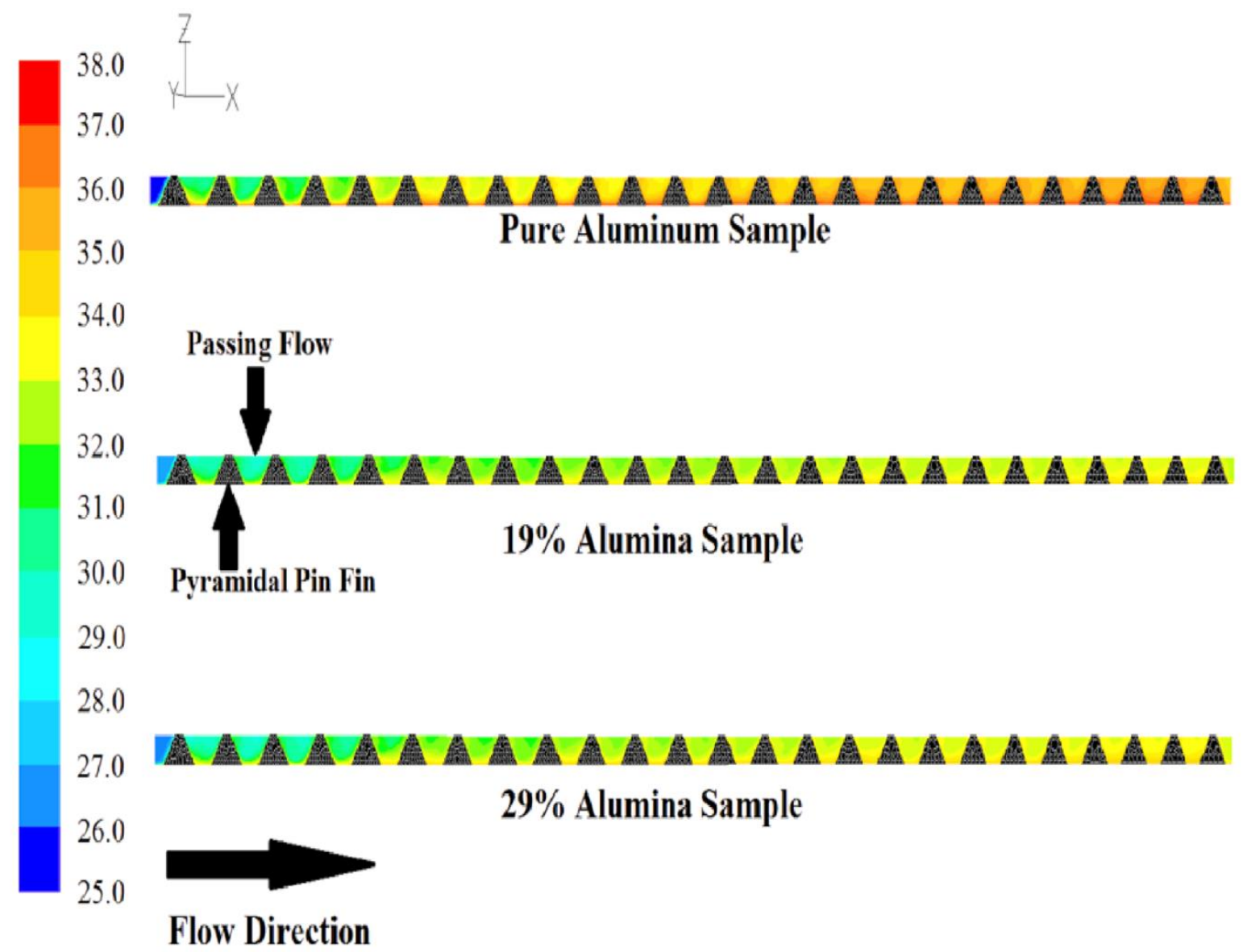

Figure 6.6 Cross-section view of the flow channel for pin fin pyramids with mass flow rate of $8.0 \times 10^{-4} \mathrm{~kg} / \mathrm{s}$ for pure aluminum, $19 \%$ and $29 \%$ volume fraction alumina containing samples. The flow temperature $\left({ }^{\circ} \mathrm{C}\right)$ scale is on the left

It is expected that the values of the outlet air temperature from the model be in close agreement with the experimental data because of the values of heat flux, mass flow rate and flow channel inlet temperature are imposed, with the insulated substrate side walls condition. 
Table 6.2 presents both the values obtained from the simulation and those obtained from the experiments for the $29 \%$ alumina sample.

\begin{tabular}{|c|c|c|c|c|c|c|c|c|}
\hline \multicolumn{3}{|c|}{ Boundary conditions } & \multicolumn{6}{|c|}{ Results } \\
\hline \multirow{2}{*}{$\mathbf{R e}$} & \multirow{2}{*}{$\begin{array}{l}\text { Inlet air } \\
\text { temp. }\left({ }^{\circ} \mathrm{C}\right)\end{array}$} & \multirow{2}{*}{$\begin{array}{l}\text { Applied } \\
\text { heat flux } \\
\qquad\left(\frac{W}{m^{2}}\right)\end{array}$} & \multicolumn{2}{|c|}{$\begin{array}{l}\text { Air temp. }\left({ }^{\circ} \mathrm{C}\right) \\
\text { at outlet }\end{array}$} & \multicolumn{2}{|c|}{$\begin{array}{c}\text { Substrate } \\
\text { temp. }\left({ }^{\circ} \mathrm{C}\right) \text { at } \\
\text { the exit }\end{array}$} & \multicolumn{2}{|c|}{$\begin{array}{c}\text { Pressure (Pa) } \\
\text { drop }\end{array}$} \\
\hline & & & Exp. & Mod. & Exp. & Mod. & Exp. & Mod. \\
\hline 790 & 27.6 & 1385.3 & 36.5 & 36.2 & 38.3 & 38.4 & 775 & 735 \\
\hline 1570 & 26.0 & 1792.9 & 31.8 & 31.8 & 33.5 & 33.3 & 2438 & 2110 \\
\hline 2750 & 24.8 & 2013.5 & 28.5 & 28.4 & 29.8 & 29.9 & 6768 & 6011 \\
\hline
\end{tabular}

Table 6.2 Experiment (Exp.) and model (Mod.) results comparison for 29\% alumina sample at different Reynolds numbers (model validation)

In the worst case, the error between the experimental and simulation results for the outlet air temperature was $0.8 \%$. All samples with pyramidal fins showed similar results as listed in

Table 6.2 where the difference between experimental and simulation values for the outlet air temperature were always below $1 \%$. The results in 
Table 6.2 for the outlet air temperature are an averaged value of temperature profile at the outlet of the flow channel. The predicted pressure losses from the model are compared to the experiments in

Table 6.2. Error values for the pressure loss are attributed to various factors, such as the difference in geometry and dimensions of the real pyramids and the modeled pyramids, as described in the 4.3. The largest error between the experimental and simulation results regarding pressure loss never exceeded 14\%. Simply the purpose of the model is not to predict the applied heat flux or the outlet temperature but better analysis of the flow structure inside the channel and better explanation of the outperforming pyramidal fins compared to the rectangular fins.

In order to better understand the temperature distribution at the outlet the temperature contours are presented in Figure 6.7. Figure 6.7 (a) and (b) show the location of the outlet with respect to the last fin in the pin fin array. The spacing between the last fin and the outlet is equal to the spacing between each consecutive fin. The modeling results for the outlet shown in Figure 6.7 is illustrated in Figure 6.8. The temperature contours shown in Figure 6.8 are associated with $29 \%$ alumina samples at three different mass flow rates at the exit of the channel normal to the flow. From Figure 6.8 it can be seen that the difference between minimum and maximum temperature in the flow at the exit of the array will decrease by increasing the mass flow rate. 


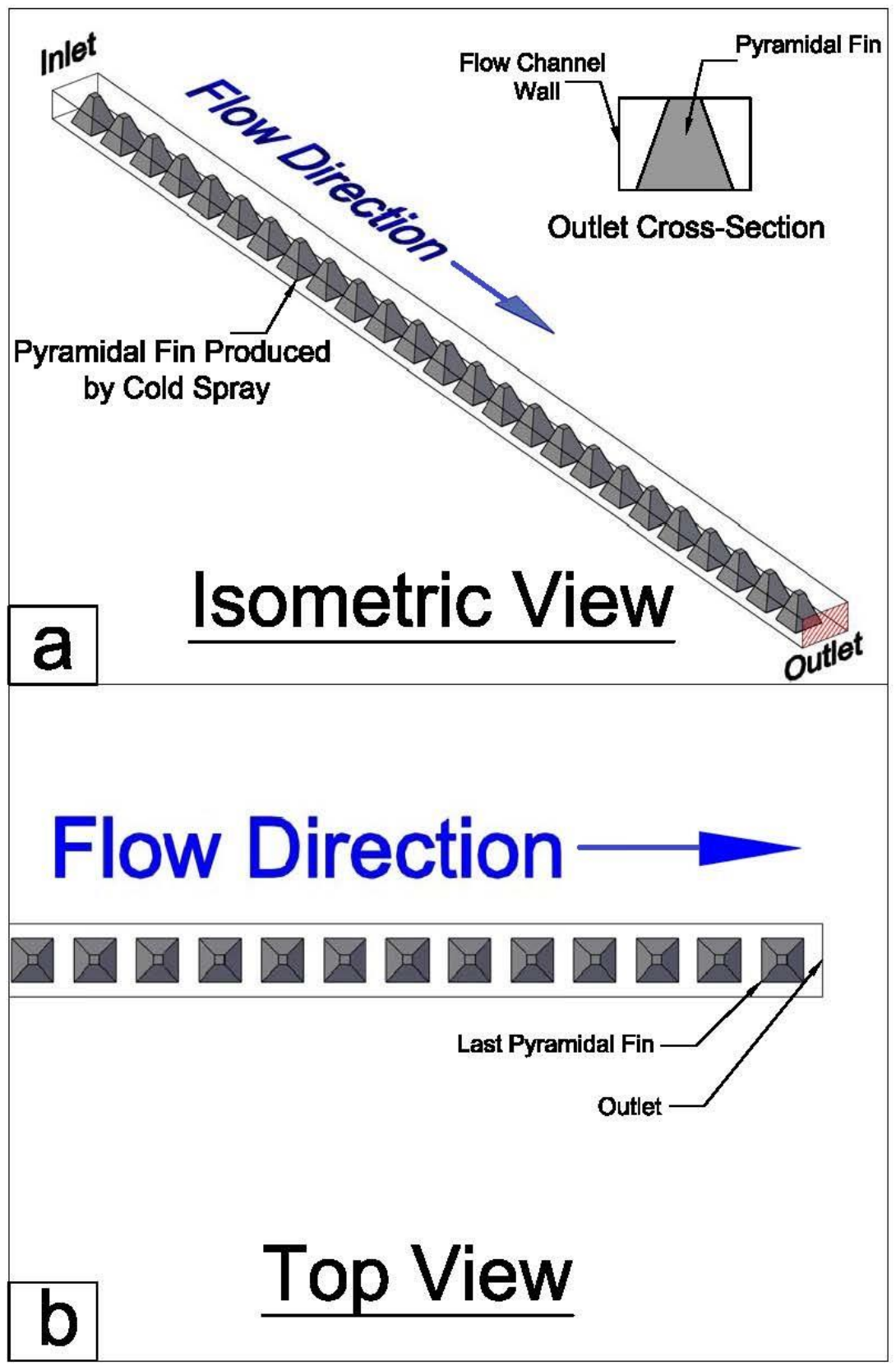

Figure 6.7 Schematic of pin fin array (a) Isometric view (b) Top view 


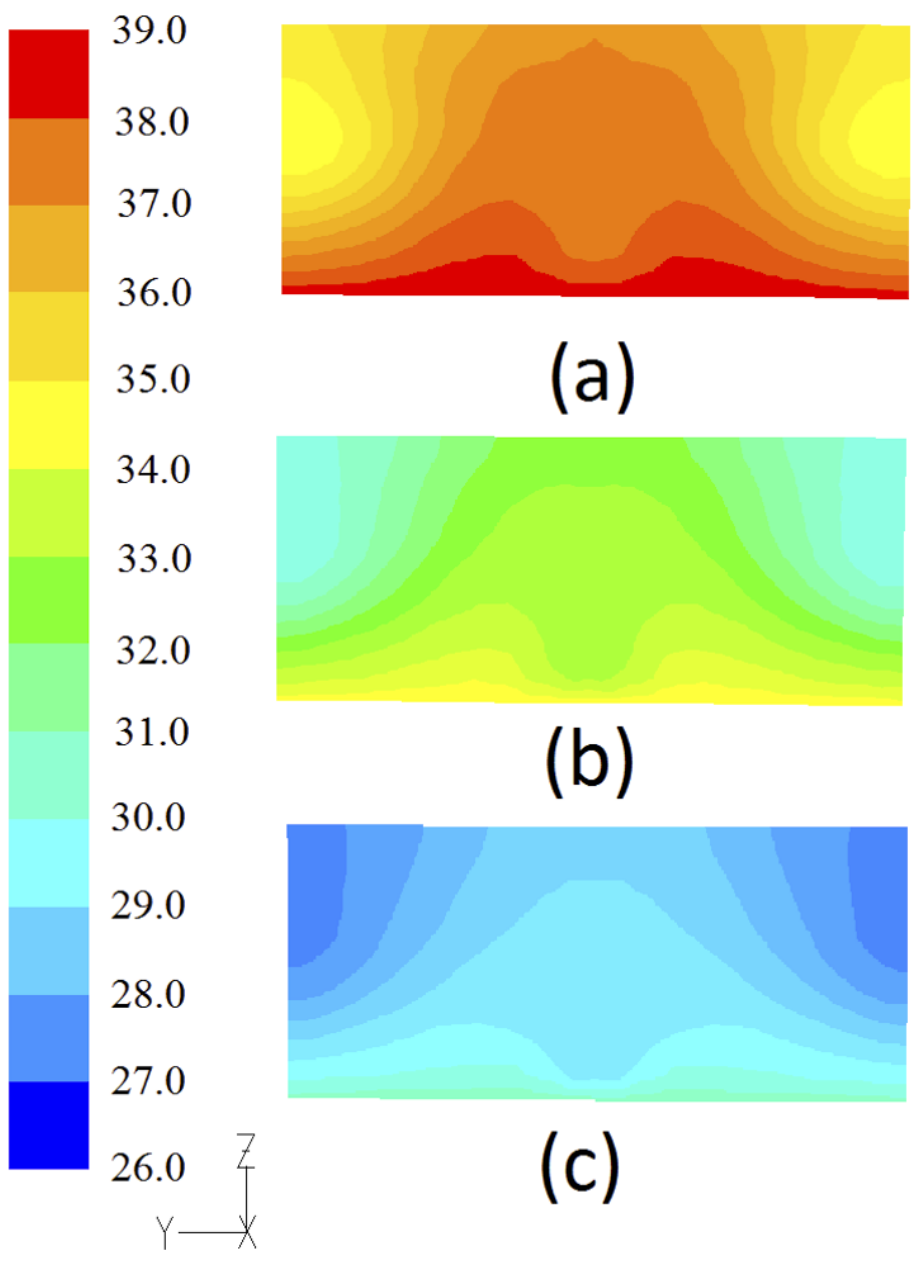

Figure 6.8 Outflow temperature $\left({ }^{\circ} \mathrm{C}\right)$ contours for $29 \%$ alumina sample at mass flow rate $(\mathrm{kg} / \mathrm{s})$ of (a) $4.0 \times 10^{-4}$ (b) $8.0 \times 10^{-4}$ (c) $1.4 \times 10^{-3}$. The flow temperature variation is illustrated by the scale on left

The regions with the highest temperature in Figure 6.8 are associated to the central section of the channel where the recirculation zones behind the fins are produced.

Heat fluxes passing through surfaces of the fifth and the tenth fins from the inlet were calculated from the model and the results are shown in Figure 6.9. The heat flux through each wall is calculated by the model using Eq 16: 


$$
q=h_{f}\left(T_{w}-T_{f}\right)+q_{r a d}
$$

with $q$ as the heat flux, $h_{f}$ as the fluid-side local heat transfer coefficient, $T_{w}$ as the wall temperature, $T_{f}$ as the local fluid temperature and $q_{r a d}$ as the radiative heat flux. Since, in this study the value heat flux is not high enough to initiate a significant radiative heat flux; it is assumed that the radiative heat flux is negligible. The fluid-side heat transfer at the wall can be calculated by Eq 17 (Fourier's law):

$$
q=k_{f}\left(\frac{\partial T}{\partial n}\right)_{\text {wall }}
$$

Model uses Eq 17 in order to calculate the fluid side heat transfer coefficient used in Eq 17. 


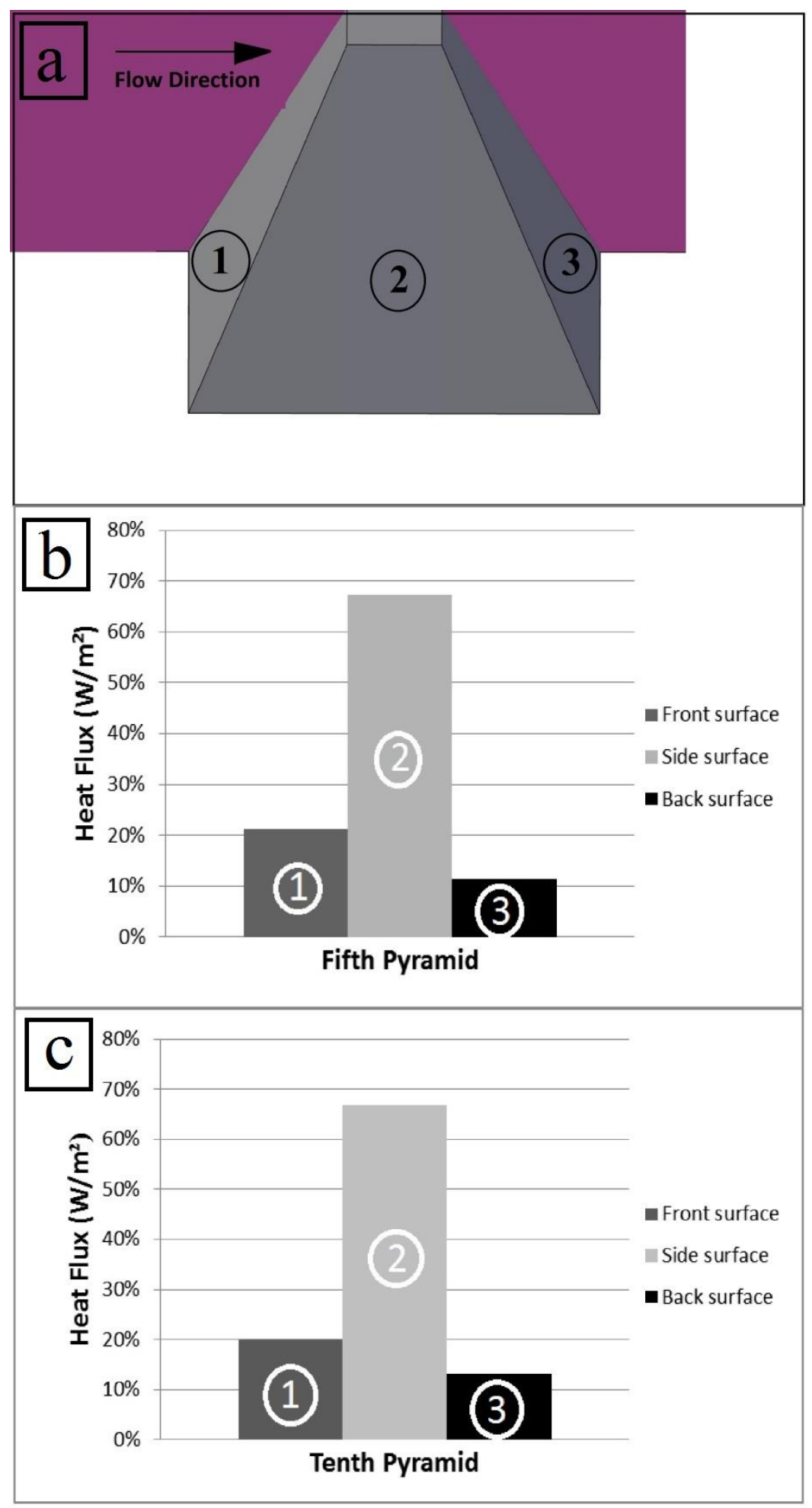

Figure 6.9 (a) Configuration of pyramids sides and numbering of the sides for heat flux $\left(\mathbf{W} / \mathbf{m}^{2}\right)$ percentage of $(b)$ Fifth pyramid surfaces $(c)$ Tenth pyramid surfaces 
Figure 6.9 (a) shows the numbering order used for Figure 6.9 (b) and (c). From Figure 6.9 (b) and (c) one can conclude that the thermal performance of the fifth and the tenth fin are very close. This shows that the consistency in the fins thermal performance of the fins array starts near the beginning of the fin array. These results demonstrate the higher heat transfer rate of the lateral sides of the pyramids which is due to their contact with higher velocity flow. In comparison to rectangular fins for which the flow velocity is primarily on the sides of the fins, the turbulence and mixing effects of pyramidal fins allows for increased thermal performance. The mentioned outcomes can be proven using Figure 6.10. In Figure 6.10 (a) stream lines around a rectangular fin is shown, where the flow streams initially divide at the beginning of the fin and stay almost straight for the rest of the flow path. In comparison in Figure 6.10 (b), it can be seen that after each pyramidal fin, local circulation zones are created. This trend explains the reasons that the pyramidal fins have a higher performance compared to that of the rectangular fins. 


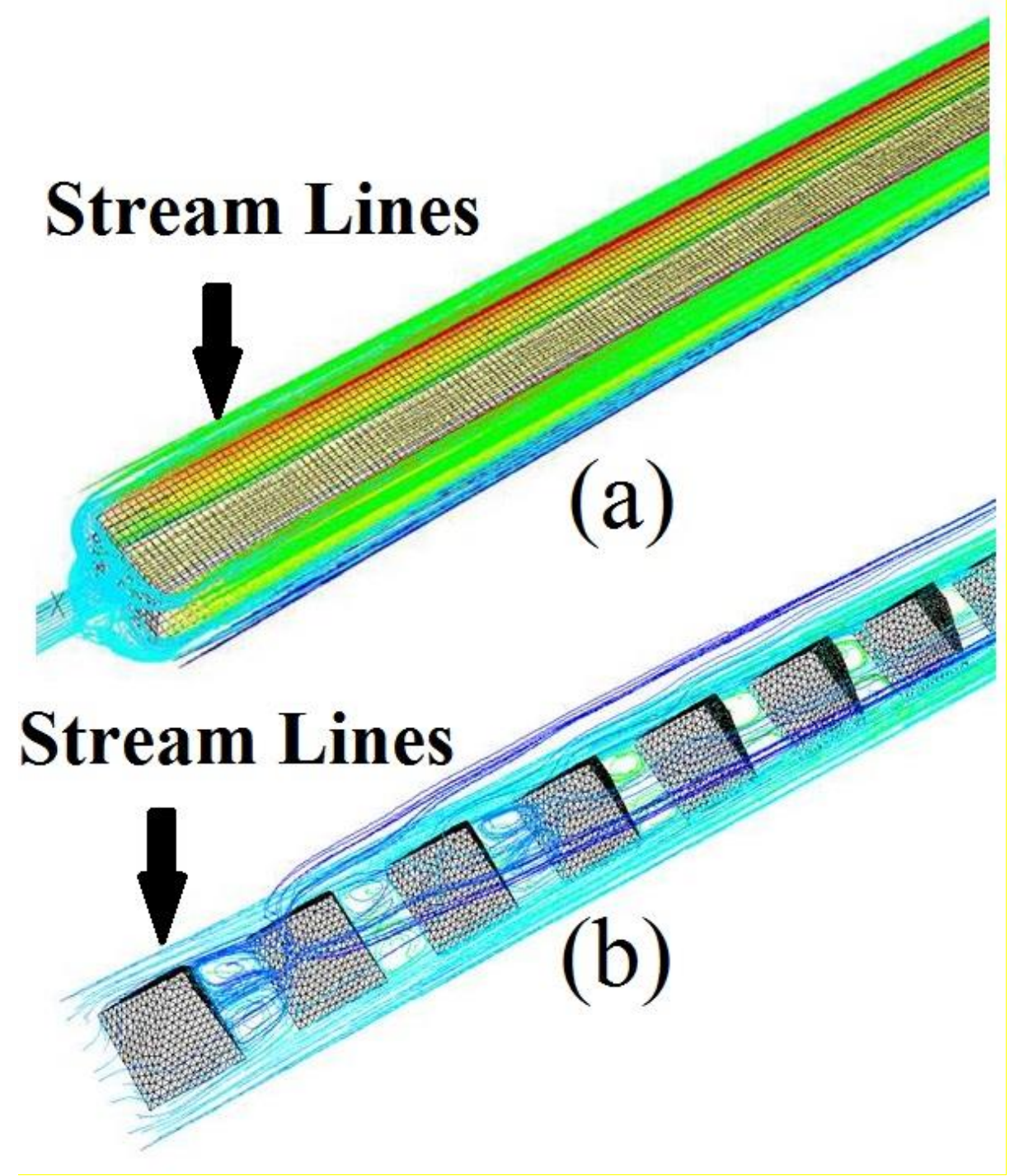

Figure 6.10 Comparison between the stream lines of (a) rectangular fins and (b) pyramidal pin fins

It is worth noting that the created model can be beneficial for different applications such as analyzing the local heat transfer through the domain or visualizing the passing flow in the channel. Finally, the numerical model features can provide a variety of useful information which is a valuable tool for further development and analysis. 


\section{Conclusion and Future works}

Pyramidal fin arrays with different volume fraction of aluminum-alumina were produced using cold spray as an additive manufacturing process.

The samples were analyzed using optical microscopy to compare the proportion of alumina particles and the fins geometry was characterized. The performance of the fin arrays was evaluated and a numerical model was developed to attain a better understanding of the heat transfer and the pressure drop process for different samples. Different comparisons and analyses were performed based on the experimental and simulation results. The simulation results were in a good agreement with the experimental results. The outcomes from assessing the results from both experiments and simulations are:

1. Manufacturing pyramidal fins using the cold spray technology offers a great potential for commercial use due to its simplicity and robustness.

2. The use of aluminum-alumina feedstock powder as an alternative to pure aluminum prevents the use of costly polymer nozzles that usually wear out rapidly but at the expense of a performance reduction due to the presence of alumina in the fins that reduced the thermal properties of the latter.

3. Although the presence of alumina particles caused a reduction in thermal performance compared to pure aluminum fin arrays, of the alumina-aluminum arrays were found to perform thermally significantly better than the traditional straight cut fins. 
4. The pressure loss along the fins is independent of the fins contents since the pressure loss is majorly dependant on the geometrical shape of the fins.

5. The developed CFD model is a powerful tool in explaining the difference in performance of the pyramidal fins vs. rectangular fins as well as predicting the pressure loss of the sprayed fins. According to the results there is a possibility of examining different fin shapes and different operating condition of the same fins composition with no investment other than computational time.

6. Created model provided valuable information and conclusions. Obtaining this information about the performance of the fins was not possible without creating the model. Some of these main conclusions are listed below:

- The consistency in the fins thermal performance was achieved near the beginning of the fin array. The highest temperature zones in the flow passing through the fins are found in the recirculation zones in the central part of the array behind the fins. These zones increase the thermal performance of the pyramidal fins over the traditional straight cut fins.

- The lateral sides of the pyramidal fins provide the most heat transfer compared to the other sides of the pyramid.

Producing fins using cold spray technology is a fairly new method that still has many areas that can be studied and investigated for future works. The current study showed that creating a CFD model for fins manufactured by cold spray is possible. Based on this many new research opportunities can be initiated. Some of these research works are listed below:

1. In this study, only pyramidal pin fins were investigated and modeled. However, there are possibilities of manufacturing different shapes and geometries of the fins. Clearly, 
different geometries have different impact and influence on thermal performance of the fins. These new shapes can be sprayed and be modeled using numerical modelling methods. Study of new shapes can help in optimizing and finding the best possible fin shapes which can be a useful data in designing of WMHE.

2. Location of fins relative to each other can also be another area of interest. In this study only array of inline pyramidal pin fins were considered but different configurations such as staggered configuration is another area that can be investigated. Specially, modelling of these new configurations and using numerical modelling to find out the optimum spacing between the fins or the most efficient fin density can be beneficial. In this study it was showed that alumina containing samples have lower thermal performance compared to pure aluminum samples. Perhaps using different fins configuration for alumina containing samples enhance the thermal performance of these samples and result in an equivalent thermal performance with pure aluminum sample with inline fins configuration. 


\section{References}

[1] D. Reay, C. Ramshaw, and A. Harvey, "Chapter 4 - Compact and Micro-heat Exchangers," in Process Intensification (Second edition), D. Reay, C. Ramshaw, and A. Harvey, Eds. Oxford: Butterworth-Heinemann, 2013, pp. 91-120.

[2] F. P. Incropera, A. S. Lavine, and D. P. DeWitt, Fundamentals of Heat and Mass Transfer. John Wiley \& Sons, 2011.

[3] S. Kakaç, H. Liu, and A. Pramuanjaroenkij, Heat Exchangers: Selection, Rating, and Thermal Design, Third Edition. CRC Press, 2012.

[4] V. K. Champagne, The Cold Spray Materials Deposition Process: Fundamentals and Applications. Elsevier, 2007.

[5] A. Papyrin, V. Kosarev, S. Klinkov, A. Alkhimov, and V. M. Fomin, Cold Spray Technology. Elsevier, 2006.

[6] J. R. Davis, Handbook of Thermal Spray Technology. ASM International, 2004.

[7] Y. Cormier, P. Dupuis, A. Farjam, A. Corbeil, and B. Jodoin, "Additive manufacturing of pyramidal pin fins: Height and fin density effects under forced convection," Int. J. Heat Mass Transf., vol. 75, pp. 235-244, Aug. 2014.

[8] P. Dupuis, Y. Cormier, A. Farjam, B. Jodoin, and A. Corbeil, "Performance evaluation of near-net pyramidal shaped fin arrays manufactured by cold spray," Int. J. Heat Mass Transf., vol. 69, pp. 34-43, Feb. 2014.

[9] Y. Cormier, P. Dupuis, B. Jodoin, and A. Corbeil, "Net Shape Fins for Compact Heat Exchanger Produced by Cold Spray," J. Therm. Spray Technol., vol. 22, no. 7, pp. 12101221, Jul. 2013.

[10] E. Irissou, J.-G. Legoux, B. Arsenault, and C. Moreau, "Investigation of Al-Al2O3 Cold Spray Coating Formation and Properties," J. Therm. Spray Technol., vol. 16, no. 5-6, pp. 661-668, Oct. 2007.

[11] S. Kakaç, H. Liu, and A. Pramuanjaroenkij, Heat Exchangers: Selection, Rating, and Thermal Design, Third Edition. CRC Press, 2012.

[12] R. K. Shah and A. L. London, Laminar Flow Forced Convection in Ducts: A Source Book for Compact Heat Exchanger Analytical Data. Academic Press, 2014.

[13] J. E. Hesselgreaves, Compact Heat Exchangers: Selection, Design and Operation. Gulf Professional Publishing, 2001.

[14] S. Mahjoob and K. Vafai, "A synthesis of fluid and thermal transport models for metal foam heat exchangers," Int. J. Heat Mass Transf., vol. 51, no. 15-16, pp. 37013711, Jul. 2008.

[15] L. Tianjian, "Ultralight porous metals: From fundamentals to applications," Acta Mech. Sin., vol. 18, no. 5, pp. 457-479, Oct. 2002.

[16] H. R. S. Jazi, J. Mostaghimi, S. Chandra, L. Pershin, and T. Coyle, "Spray-Formed, Metal-Foam Heat Exchangers for High Temperature Applications," J. Therm. Sci. Eng. Appl., vol. 1, no. 3, pp. 031008-031008, Apr. 2010.

[17] F. Azarmi, T. Coyle, and J. Mostaghimi, "Young's modulus measurement and study of the relationship between mechanical properties and microstructure of air plasma sprayed alloy 625," Surf. Coat. Technol., vol. 203, no. 8, pp. 1045-1054, Jan. 2009. 
[18] M. Taheri, S. Chandra, and J. Mostaghimi, "Analytical and Numerical Modeling of Conductive and Convective Heat Transfer Through Open-Cell Metal Foams," pp. 10131021, Jul. 2012.

[19] F. Azarmi, T. Coyle, J. Mostaghimi, and L. Pershin, "A new approach to develop high temperature foam core sandwich structures using air plasma spraying," Int. J. Adv. Manuf. Technol., vol. 44, no. 9-10, pp. 900-905, Oct. 2009.

[20] S. Salavati, L. Pershin, T. W. Coyle, and J. Mostaghimi, "Effect of Porosity Content of Arc-Sprayed Alloy 625 Skins on the Flexural Behavior of Nickel Foam Core Sandwich Structures," J. Therm. Spray Technol., Nov. 2014.

[21] R. L. Shaner, "Heat exchanger having metal wire screens, and method of making stack of Screens Therefor," 4840228, 20-Jun-1989.

[22] J. Chisholm, "Method of making a crimped wire mesh heat exchanger/sink," US4843693 A, 04-Jul-1989.

[23] J. Assaad, A. Corbeil, P. F. Richer, and B. Jodoin, "Novel Stacked Wire Mesh Compact Heat Exchangers Produced Using Cold Spray," J. Therm. Spray Technol., vol. 20, no. 6, pp. 1192-1200, Jun. 2011.

[24] A. G. Evans, J. W. Hutchinson, N. A. Fleck, M. F. Ashby, and H. N. G. Wadley, "The topological design of multifunctional cellular metals," Prog. Mater. Sci., vol. 46, no. 3-4, pp. 309-327, 2001.

[25] J. Tian, T. Kim, T. J. Lu, H. P. Hodson, D. T. Queheillalt, D. J. Sypeck, and H. N. G. Wadley, "The effects of topology upon fluid-flow and heat-transfer within cellular copper structures," Int. J. Heat Mass Transf., vol. 47, no. 14-16, pp. 3171-3186, Jul. 2004.

[26] H.-P. Li and E. Pfender, "Three Dimensional Modeling of the Plasma Spray Process," J. Therm. Spray Technol., vol. 16, no. 2, pp. 245-260, May 2007.

[27] H. Herman, "Plasma Spray Deposition Processes," MRS Bull., vol. 13, no. 12, pp. 6067, Dec. 1988.

[28] R. B. Heimann, Plasma-Spray Coating: Principles and Applications. John Wiley \& Sons, 2008.

[29] K. Remesh, S. C. M. Yu, H. W. Ng, and C. C. Berndt, "Computational study and experimental comparison of the in-flight particle behavior for an external injection plasma spray process," J. Therm. Spray Technol., vol. 12, no. 4, pp. 508-522, Dec. 2003.

[30] H. Singh, B. S. Sidhu, D. Puri, and S. Prakash, "Use of plasma spray technology for deposition of high temperature oxidation/corrosion resistant coatings - a review," Mater. Corros., vol. 58, no. 2, pp. 92-102, 2007.

[31] J. He, M. Ice, and E. Lavernia, "Particle melting behavior during high-velocity oxygen fuel thermal spraying," J. Therm. Spray Technol., vol. 10, no. 1, pp. 83-93, Mar. 2001.

[32] J. A. Hearley, J. A. Little, and A. J. Sturgeon, "The effect of spray parameters on the properties of high velocity oxy-fuel NiAl intermetallic coatings," Surf. Coat. Technol., vol. 123, no. 2-3, pp. 210-218, Jan. 2000.

[33] H. Herman, S. Sampath, and R. McCune, "Thermal Spray: Current Status and Future Trends," MRS Bull., vol. 25, no. 07, pp. 17-25, Jul. 2000. 
[34] X. Yang and S. Eidelman, "Numerical analysis of a high-velocity oxygen-fuel thermal spray system," J. Therm. Spray Technol., vol. 5, no. 2, pp. 175-184, Jun. 1996.

[35] J. Stokes and L. Looney, "HVOF system definition to maximise the thickness of formed components," Surf. Coat. Technol., vol. 148, no. 1, pp. 18-24, Nov. 2001.

[36] M. P. Dewar, A. G. McDonald, and A. P. Gerlich, "Interfacial heating during lowpressure cold-gas dynamic spraying of aluminum coatings," J. Mater. Sci., vol. 47, no. 1, pp. 184-198, Jan. 2012.

[37] M. R. Rokni, C. A. Widener, and V. R. Champagne, "Microstructural Evolution of 6061 Aluminum Gas-Atomized Powder and High-Pressure Cold-Sprayed Deposition," J. Therm. Spray Technol., vol. 23, no. 3, pp. 514-524, Feb. 2014.

[38] S. H. Zahiri, W. Yang, and M. Jahedi, "Characterization of Cold Spray Titanium Supersonic Jet," J. Therm. Spray Technol., vol. 18, no. 1, pp. 110-117, Mar. 2009.

[39] T. Schmidt, F. Gärtner, H. Assadi, and H. Kreye, "Development of a generalized parameter window for cold spray deposition," Acta Mater., vol. 54, no. 3, pp. 729-742, Feb. 2006.

[40] H. Assadi, F. Gärtner, T. Stoltenhoff, and H. Kreye, "Bonding mechanism in cold gas spraying," Acta Mater., vol. 51, no. 15, pp. 4379-4394, Sep. 2003.

[41] B. R. Marple, Thermal Spray 2006: Building 100 Years of Success. ASM International, 2006.

[42] T. Schmidt, H. Assadi, F. Gärtner, H. Richter, T. Stoltenhoff, H. Kreye, and T. Klassen, "From Particle Acceleration to Impact and Bonding in Cold Spraying," J. Therm. Spray Technol., vol. 18, no. 5-6, pp. 794-808, Aug. 2009.

[43] M. Grujicic, C. L. Zhao, W. S. DeRosset, and D. Helfritch, "Adiabatic shear instability based mechanism for particles/substrate bonding in the cold-gas dynamic-spray process," Mater. Des., vol. 25, no. 8, pp. 681-688, Dec. 2004.

[44] P. Richer, B. Jodoin, and L. Ajdelsztajn, "Substrate roughness and thickness effects on cold spray nanocrystalline Al-Mg coatings," J. Therm. Spray Technol., vol. 15, no. 2, pp. 246-254, Jun. 2006.

[45] "Bonding Mechanisms in Cold Spraying: The Contributions of Metallurgical and Mechanical Components - Springer."

[46] T. Schmidt, F. Gaertner, and H. Kreye, "New developments in cold spray based on higher gas and particle temperatures," J. Therm. Spray Technol., vol. 15, no. 4, pp. 488494, Dec. 2006.

[47] R. C. Dykhuizen and M. F. Smith, "Gas dynamic principles of cold spray," J. Therm. Spray Technol., vol. 7, no. 2, pp. 205-212, Jun. 1998.

[48] S. H. Zahiri, D. Fraser, S. Gulizia, and M. Jahedi, "Effect of processing conditions on porosity formation in cold gas dynamic spraying of copper," J. Therm. Spray Technol., vol. 15, no. 3, pp. 422-430, Sep. 2006.

[49] W.-Y. Li, C. Zhang, X. P. Guo, G. Zhang, H. L. Liao, C.-J. Li, and C. Coddet, "Effect of standoff distance on coating deposition characteristics in cold spraying," Mater. Des., vol. 29, no. 2, pp. 297-304, 2008. 
[50] J. Pattison, S. Celotto, A. Khan, and W. O'Neill, "Standoff distance and bow shock phenomena in the Cold Spray process," Surf. Coat. Technol., vol. 202, no. 8, pp. 14431454, Jan. 2008.

[51] K. Taylor, B. Jodoin, and J. Karov, "Particle loading effect in cold spray," J. Therm. Spray Technol., vol. 15, no. 2, pp. 273-279, Jun. 2006.

[52] X.-J. Ning, J.-H. Jang, and H.-J. Kim, "The effects of powder properties on in-flight particle velocity and deposition process during low pressure cold spray process," Appl. Surf. Sci., vol. 253, no. 18, pp. 7449-7455, Jul. 2007.

[53] A. O. Tokarev, "Structure of aluminum powder coatings prepared by cold gasdynamic spraying," Met. Sci. Heat Treat., vol. 38, no. 3, pp. 136-139, Mar. 1996.

[54] H. Y. Lee, S. H. Jung, S. Y. Lee, Y. H. You, and K. H. Ko, "Correlation between Al2O3 particles and interface of Al-Al2O3 coatings by cold spray," Appl. Surf. Sci., vol. 252, no. 5, pp. 1891-1898, Dec. 2005.

[55] Q. Wang, K. Spencer, N. Birbilis, and M.-X. Zhang, "The influence of ceramic particles on bond strength of cold spray composite coatings on AZ91 alloy substrate," Surf. Coat. Technol., vol. 205, no. 1, pp. 50-56, Sep. 2010.

[56] H. Koivuluoto and P. Vuoristo, "Effect of Ceramic Particles on Properties of ColdSprayed Ni-20Cr+Al2O3 Coatings," J. Therm. Spray Technol., vol. 18, no. 4, pp. 555-562, Jun. 2009.

[57] T. Stoltenhoff, H. Kreye, and H. J. Richter, "An Analysis of the Cold Spray Process and Its Coatings," J. Therm. Spray Technol., vol. 11, no. 4, pp. 542-550, Dec. 2002.

[58] J. Xu, J. Tian, T. J. Lu, and H. P. Hodson, "On the thermal performance of wire-screen meshes as heat exchanger material," Int. J. Heat Mass Transf., vol. 50, no. 5-6, pp. 1141-1154, Mar. 2007.

[59] A. G. Evans, J. W. Hutchinson, N. A. Fleck, M. F. Ashby, and H. N. G. Wadley, "The topological design of multifunctional cellular metals," Prog. Mater. Sci., vol. 46, no. 3-4, pp. 309-327, 2001.

[60] J. C. Armour and J. N. Cannon, "Fluid flow through woven screens," AlChE J., vol. 14, no. 3, pp. 415-420, 1968.

[61] W.-Y. Li, H. Liao, G. Douchy, and C. Coddet, “Optimal design of a cold spray nozzle by numerical analysis of particle velocity and experimental validation with $316 \mathrm{~L}$ stainless steel powder," Mater. Des., vol. 28, no. 7, pp. 2129-2137, 2007.

[62] T.-C. Jen, L. Li, W. Cui, Q. Chen, and X. Zhang, "Numerical investigations on cold gas dynamic spray process with nano- and microsize particles," Int. J. Heat Mass Transf., vol. 48, no. 21-22, pp. 4384-4396, Oct. 2005.

[63] A. Sova, S. Grigoriev, A. Kochetkova, and I. Smurov, "Influence of powder injection point position on efficiency of powder preheating in cold spray: Numerical study," Surf. Coat. Technol., vol. 242, pp. 226-231, Mar. 2014.

[64] S. Yin, M. Zhang, Z. Guo, H. Liao, and X. Wang, "Numerical investigations on the effect of total pressure and nozzle divergent length on the flow character and particle impact velocity in cold spraying," Surf. Coat. Technol., vol. 232, pp. 290-297, Oct. 2013.

[65] W.-Y. Li, S. Yin, X. Guo, H. Liao, X.-F. Wang, and C. Coddet, "An Investigation on Temperature Distribution Within the Substrate and Nozzle Wall in Cold Spraying by 
Numerical and Experimental Methods," J. Therm. Spray Technol., vol. 21, no. 1, pp. 4148, Sep. 2011.

[66] N. Sahiti, F. Durst, and A. Dewan, "Strategy for selection of elements for heat transfer enhancement," Int. J. Heat Mass Transf., vol. 49, no. 19-20, pp. 3392-3400, Sep. 2006.

[67] F. Menter, "Zonal Two Equation k-w Turbulence Models For Aerodynamic Flows," in 23rd Fluid Dynamics, Plasmadynamics, and Lasers Conference, 0 vols., American Institute of Aeronautics and Astronautics, 1993.

[68] E. Litovsky, J. I. Kleiman, M. Shagalov, and R. B. Heimann, "Measurement of the thermal conductivity of cold gas dynamically sprayed alumina-reinforced aluminum coatings between $-150{ }^{\circ} \mathrm{C}$ and $+200^{\circ} \mathrm{C}$. New test method and experimental results," Surf. Coat. Technol., vol. 242, pp. 141-145, Mar. 2014.

[69] A. K. Saha and S. Acharya, "Unsteady Simulation of Turbulent Flow and Heat Transfer in a Channel with Periodic Array of Cubic Pin-Fins," Numer. Heat Transf. Part Appl., vol. 46, no. 8, pp. 731-763, 2004.

[70] J. Stasiulevicius, A. Skrinska, and A. Zukauskas, "Heat transfer of finned tube bundles in crossflow," 1988. 


\section{Appendix I: Grid Independency of the Solution}

\begin{tabular}{|c|c|c|c|c|}
\hline \multirow{2}{*}{ Nodes } & $\begin{array}{c}\text { Mass flow rate } \\
(\mathbf{K g} / \mathbf{s})\end{array}$ & $\begin{array}{c}\text { Air temp. }\left({ }^{\circ} \mathbf{C}\right) \\
\text { at outlet }\end{array}$ & $\begin{array}{c}\text { Substrate } \\
\text { temp. }\left({ }^{\circ} \mathbf{C}\right) \text { at } \\
\text { the exit }\end{array}$ & $\begin{array}{c}\text { Flow velocity at } \\
\text { the outlet (m/s) }\end{array}$ \\
\hline \multirow{3}{*}{169914} & $8.3 \mathrm{e}-6$ & 36.2 & 38.4 & 12.1 \\
\cline { 2 - 5 } & $1.6 \mathrm{e}-5$ & 31.8 & 33.3 & 21.3 \\
\cline { 2 - 5 } & $2.9 \mathrm{e}-5$ & 28.4 & 29.9 & 35.8 \\
\hline \multirow{3}{*}{379547} & $8.3 \mathrm{e}-6$ & 36.2 & 38.2 & 21.5 \\
\cline { 2 - 5 } & $1.6 \mathrm{e}-5$ & 31.8 & 33.0 & 35.7 \\
\cline { 2 - 5 } & $2.9 \mathrm{e}-5$ & 28.4 & 29.9 & 12.1 \\
\hline \multirow{3}{*}{577263} & $8.3 \mathrm{e}-6$ & 36.2 & 38.5 & 21.5 \\
\cline { 2 - 5 } & $1.6 \mathrm{e}-5$ & 31.8 & 33.4 & 35.5 \\
\cline { 2 - 5 } & $2.9 \mathrm{e}-5$ & 28.4 & 29.9 & \\
\hline
\end{tabular}

The grid independency results for the $29 \%$ alumina containing sample. 


\section{Appendix II: Convergence History}

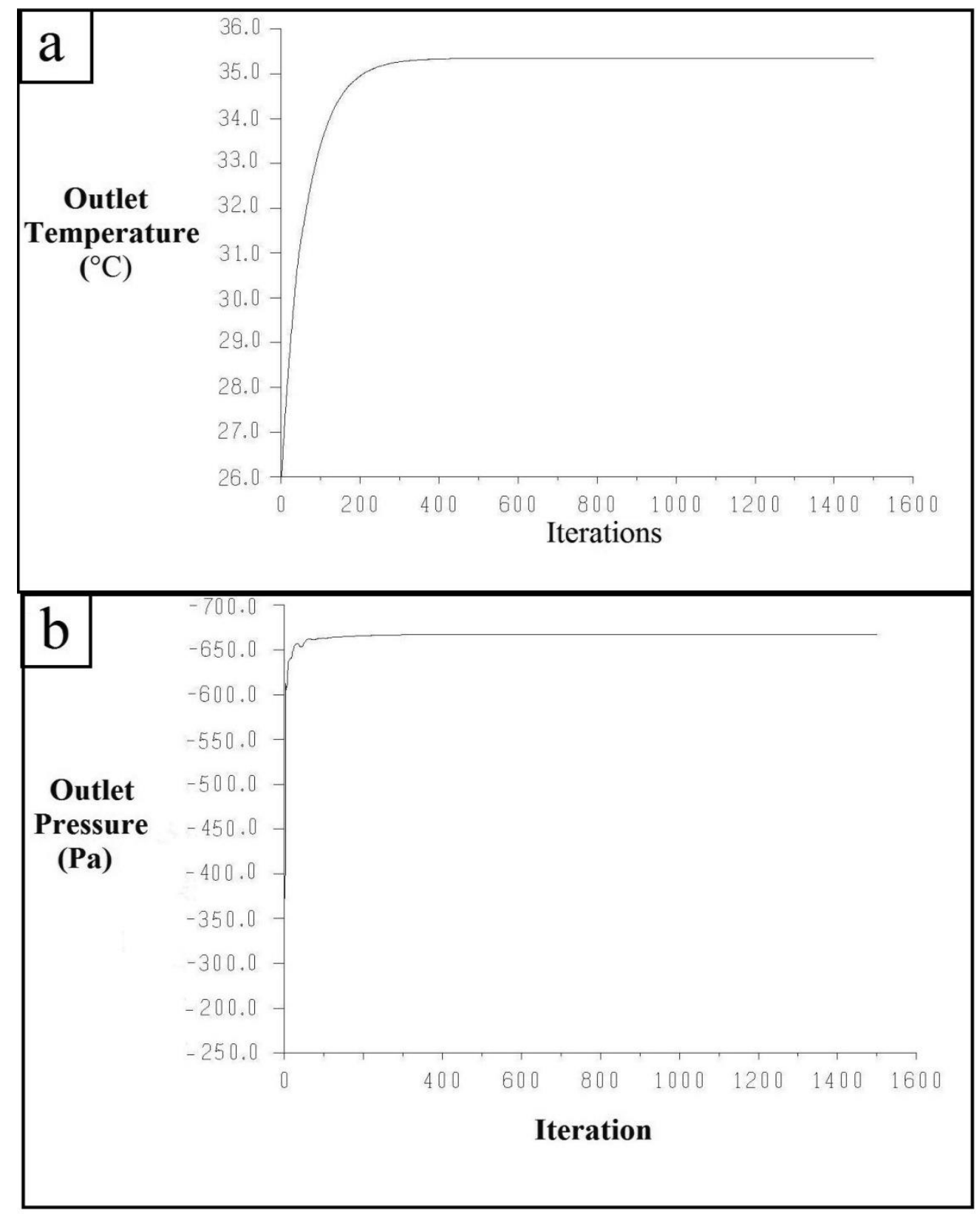

The results of convergence history for $29 \%$ alumina sample at mass flow rate $(\mathrm{kg} / \mathrm{s})$ of $4.0 \times 10^{-4}$ for (a) Temperature outlet and (b) Pressure outlet 


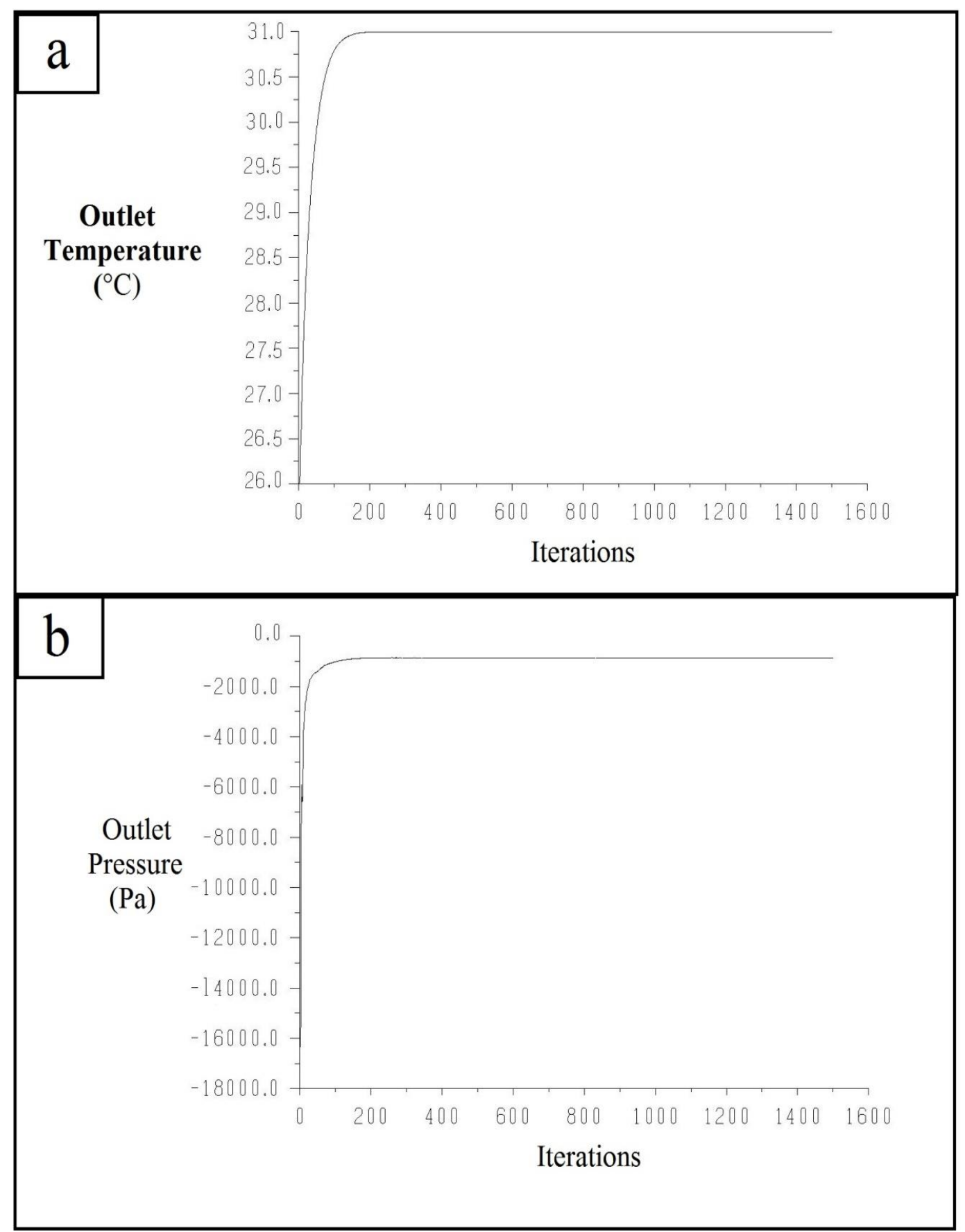

The results of convergence history for $29 \%$ alumina sample at mass flow rate $(\mathrm{kg} / \mathrm{s})$ of $8.0 \times 10^{-4}$ for (a) Temperature outlet and (b) Pressure outlet 


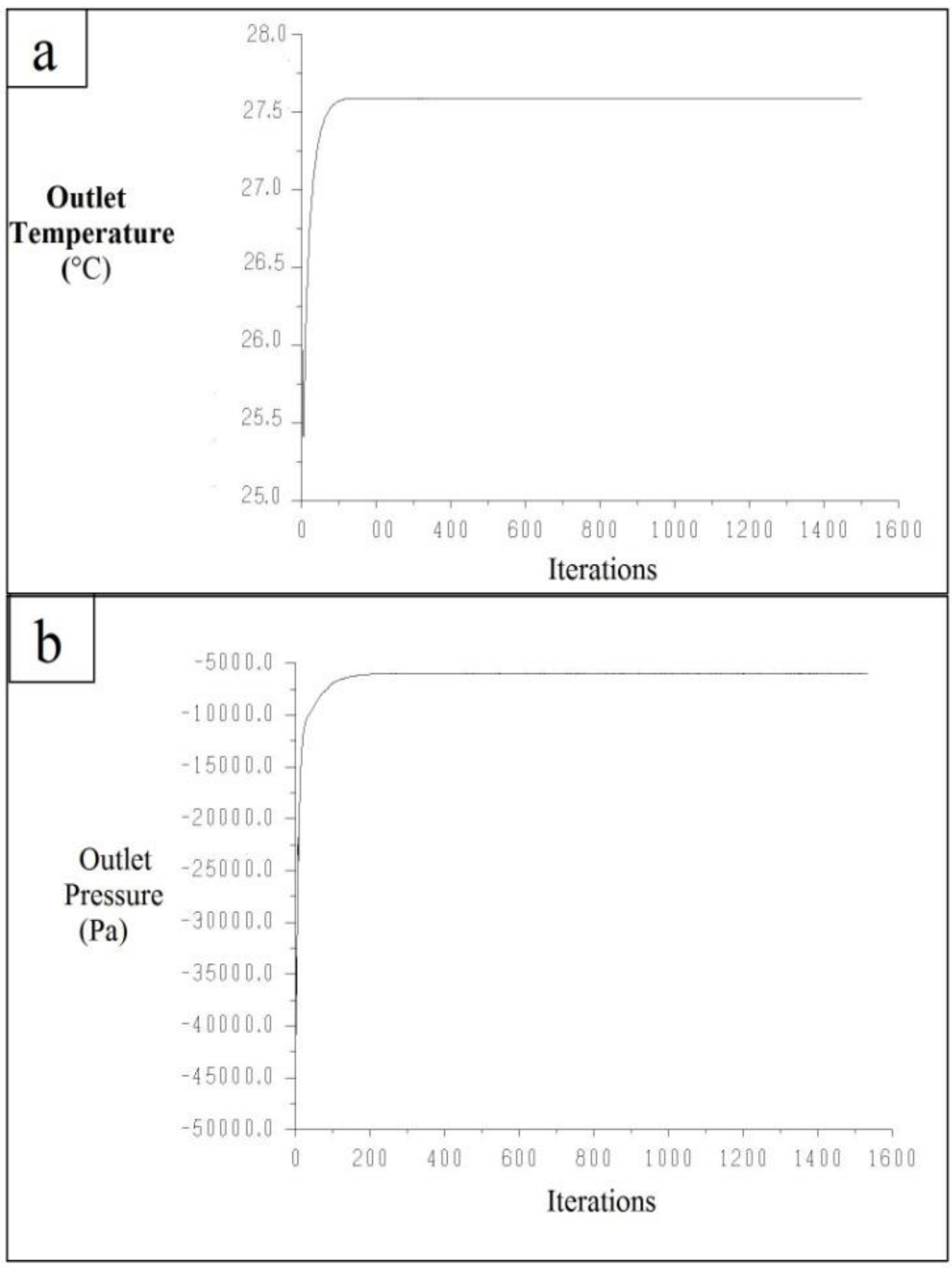

The results of convergence history for $29 \%$ alumina sample at mass flow rate $(\mathrm{kg} / \mathrm{s})$ of $1.4 \times 10^{-3}$ for (a) Temperature outlet and (b) Pressure outlet 


\section{Appendix III: Boundary Condition Used for Different Modelling Cases}

\begin{tabular}{|c|c|c|c|}
\hline Sample & $\begin{array}{c}\text { Mass flow rate } \\
(\mathbf{K g} / \mathbf{s})\end{array}$ & $\begin{array}{c}\text { Inlet air temp. } \\
\left({ }^{\circ} \mathbf{C}\right)\end{array}$ & $\begin{array}{c}\text { Applied heat } \\
\text { flux }\left(\frac{\mathbf{w}}{\mathbf{m}^{\mathbf{2}}}\right)\end{array}$ \\
\hline Pure aluminum & $8.3 \mathrm{e}-6$ & 26.44 & 2440.3 \\
\hline Pure aluminum & $1.6 \mathrm{e}-5$ & 24.75 & 2821.3 \\
\hline Pure aluminum & $2.9 \mathrm{e}-5$ & 23.64 & 2806.84 \\
\hline $19 \%$ alumina & $8.3 \mathrm{e}-6$ & 28.42 & 1370.7 \\
\hline $19 \%$ alumina & $1.6 \mathrm{e}-5$ & 26.17 & 1776.3 \\
\hline $19 \%$ alumina & $2.9 \mathrm{e}-5$ & 24.81 & 2184.02 \\
\hline $29 \%$ alumina & $8.3 \mathrm{e}-6$ & 27.6 & 1385.3 \\
\hline $29 \%$ alumina & $1.6 \mathrm{e}-5$ & 26.0 & 1792.9 \\
\hline $29 \%$ alumina & $2.9 \mathrm{e}-5$ & 24.8 & 2013.5 \\
\hline
\end{tabular}

The values of different boundary conditions used in the numerical model 